\author{
Universidade de São Paulo - USP \\ Escola de Engenharia de São Carlos - EESC \\ Departamento de Engenharia Elétrica
}

\title{
Distribuição de Divisores de Potência em Redes Ópticas Passivas Utilizando Algoritmos Genéticos.
}

\author{
Autor : Tany Villalba Villalba
}

Dissertação de Mestrado apresentada à Escola de Engenharia de São Carlos da Universidade de São Paulo, como parte dos requisitos para a obtenção do título de Mestre em Engenharia Elétrica, área de concentração em Telecomunicações.

Orientadora: Mônica de Lacerda Rocha

São Carlos, SP

Dezembro de 2009 


\begin{abstract}
AUTORIZO A REPRODUÇÃO E DIVULGAÇÃO TOTAL OU PARCIAL DESTE TRABALHO, POR QUALQUER MEIO CONVENCIONAL OU ELETRÔNICO, PARA FINS DE ESTUDO E PESQUISA, DESDE QUE CITADA A FONTE.
\end{abstract}

Ficha catalográfica preparada pela seção de Tratamento da informação do Serviço de Biblioteca - EESC/USP

\begin{tabular}{|c|}
\hline Villalba Villalba, Tany \\
V696d \\
Distribuição de divisores de potência em redes ópticas \\
passivas utilizando algoritmos genéticos; orientador Mônica de \\
Lacerda Rocha. - São Carlos, 2009. \\
Dissertação (Mestrado-Programa de Pós-Graduação em \\
Engenharia Elétrica e Aérea de Concentração em \\
Telecomunicações) - Escola de Engenharia de São Carlos da \\
Universidade de São Paulo, 2009. \\
1. Topologias. 2. Algoritmos Genéticos. 3. Redes ópticas \\
passivas. 4. PON. 5. EPON. 6. GPON. I. Título.
\end{tabular}




\section{FOLHA DE JULGAMENTO}

Candidato(a): Bachiller TANY VILLALBA VILLALBA.

Dissertação defendida e julgada em 05/02/2010 perante a Comissão Julgadora: Apro va da

Aronica de Lacerda Rocho

Aprovada

Prof". Dr" MÔNICA DE LACERDA ROCHA - (Orientadora)

(Escola de Engenharia de São Carlos/USP)

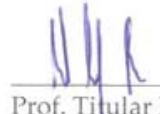

Prof. Tifular MURILO ARAUJO ROMERO

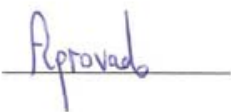

(Escola de Engenharia de São Carlos/USP)

$$
\text { Whinger }
$$

Profa. Dr". MIRIAM REGINA XAVIER DE BARROS

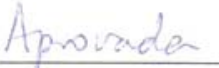

(Instituto Brasileiro de Tecnologia Avançada)

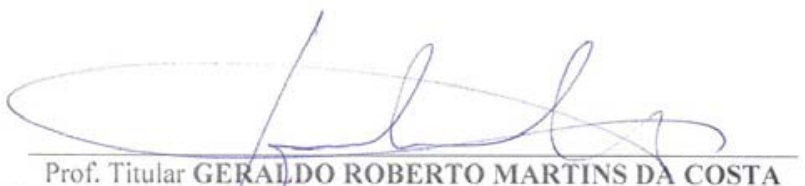

Prof. Titular GERALDO ROBERTO MARTINS DA COSTA

Coordenador do Programa de Pós-Graduação em Engenharia Elétrica e Presiłente da Comissão de Pós-Graduação 
EESC - Escola de Engenharia de São Carlos 


\section{Sumário}

Lista de figuras $\quad \ldots \ldots \ldots \ldots \ldots \ldots \ldots$ iii

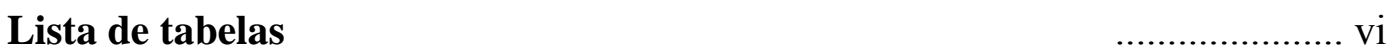

Lista de Acrônimos $\quad$....................... vii

Resumo $\quad \ldots \ldots \ldots \ldots \ldots \ldots \ldots . . . . . . . .1$

Abstract $\quad$...................... xiii

1 Introdução $\quad$ _...................... 1

1.1 Introdução $\quad$ _...................... 1

1.2 Entendendo o problema $\quad$..................... 4

2. Rede de Acesso Óptica

2.1 As redes GPON e Tecnologia PON _................... 9

2.2 Padrões EPON e GPON

2.2.1 EPON _..................... 10

2.2.2 GPON $\quad \ldots \ldots \ldots \ldots \ldots \ldots . . . . .11$

2.3 Componentes ópticos $\quad$ _.................... 12

2.3.1 Terminal de linha $\quad$...................... 12

2.3.2 Unidade de rede óptica

2.3.3 Conectores ópticos $\quad$...................... 14

2.3.4 Acopladores ou Divisores de Pertencia $\quad$....................... 15

2.4 Conceitos de topologias

$2.5 \mathrm{O}$ problema de otimização $\quad$....................... 21

2.6 Orçamentos de Potência $\quad$...................... 21

2.7 Aspectos Econômicos $\quad$ ……............... 22

2.8 Algoritmos genéticos $\quad$...................... 23

3. Estudo de Topologias para Redes Ópticas Passivas

4. Algoritmos Genéticos $\quad$....................... 33 
4.1. Topologia em Barramento 43

4.2. Topologia em Árvore 47

4.3. Topologia em anel 47

5. Simulações 49

5.1. Parâmetros das simulações 49

5.2. Estado Inicial 50

5.3. Utilização do algoritmo genético 54

5.4. Orçamento de potência 60

5.5. Evolução do algoritmo genético 62

5.6. Validação dos resultados 66

5.7. Outras simulações 71

6. Conclusão 83

7. Referências 85 


\section{Lista de figuras}

Figura 1: Topologias com um nível de derivação: (a) barramento, (b) árvore e (c) anel.

Figura 2: Distribuição dos componentes ópticos (OLT, Splitter, ONUs).

Figura 3: Conectores de fibra óptica.

Figura 4: Exemplo de grafo de uma rede.

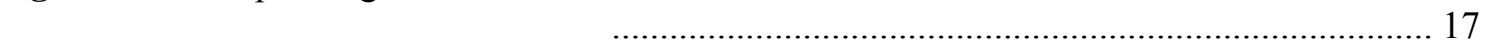

Figura 5: Exemplo de uma rede e do grafo equivalente.

Figura 6: Topologia Física - Topologia Lógica.

.

Figura 7: Grafos correspondentes a diferentes tipos de topologias. a) barramento, b) anel, c)malha.

Figura 8: Grafos correspondentes às topologias em a) estrela e b) árvore.

Figura 9: Colisão entre os sinais gerados por cinco utilizadores numa rede em árvore.

Figura 10: Topologias básicas para redes ópticas.

Figura 10. Topologias básicas para redes opticas.

Figura 11: Distribuição física para o exemplo adotado com apenas um nível de derivação. a)metragem , b)topologia em barramento , c)topologia em árvore, d) topologia em anel.

Figura 12: Distâncias desde a OLT a cada ONU.

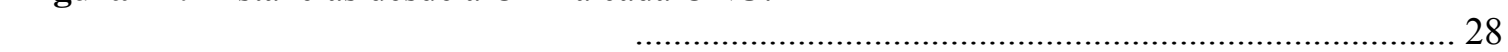

Figura 13: Orçamento de potência para as topologias, usando apenas divisores simétricos.

Figura 14: Orçamento de potência para as topologias, usando também divisores assimétricos.

Figura 15: Fluxograma do algoritmo genético.

Figura 16: Grafo inicial, representação da rede.

Figura 17: Exemplo de um indivíduo da população inicial.

Figura 18: Cromossomo.

Figura 19: Exemplo de dois indivíduos da população.

Figura 20: Topologia hibrida com dois níveis de derivação.

Figura 21: Sistema GPON.

Figura 22: (a) Grupos de 6 ONUs; (b) grupo de 4 ONUs; (c) seleção de grupos. 
Indicador não definido.

Figura 23: (a) formato do indivíduo; (b) indivíduo gerado pelo primeiro percurso; (c) nó cíclico.

Figura 24: Vetor R de um indivíduo para topologia em anel.

Figura 25: Estado inicial do primeiro teste.

Figura 26: Grafo inicial (fixação da OLT e ONUs).

. 53

Figura 27: Topologia gerada em Árvore.

Figura 28: Topologia gerada em Barramento.

$\ldots$

Figura 29: Topologia gerada em Anel.

Figura 30: Comprimento de cabo utilizado entre a OLT e as ONUs.

Figura 31: Orçamento de Potência das topologias geradas pelo AG.

Figura 32: Orçamento de potência utilizando divisores assimétricos.

Figura 33: Evolução do GA para a topologia em árvore.

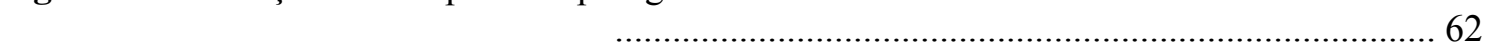

Figura 34: Evolução do GA para a topologia em barramento.

Figura 35: Evolução do algoritmo genético para a topologia em anel.

Figura 36: Distribuição manual para a topologia em árvore.

Figura 37: Distribuição manual para a topologia em barramento.

Figura 38: Distribuição manual para a topologia em anel.

.

Figura 39: Comprimento de cabo utilizado desde a OLT até as ONUs utilizando AG e sem AG.

Figura 40: Topologia em árvore gerada para o segundo teste de 128 ONUs.

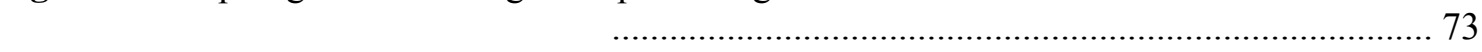

Figura 41: Topologia em anel gerada para o segundo teste de 128 ONUs.

Figura 42: Topologia em barramento gerada para o segundo teste de 128 ONUs.

Figura 43: Comprimento de cabo utilizado desde a OLT até as ONUs, para o segundo teste de 128 ONUs.

Figura 44: Orçamento de potência para o segundo teste de 128 ONUs.

iv 
EESC - Escola de Engenharia de São Carlos

Figura 45: Ordem do vetor da coluna "Divisores" na Tabela 20. 


\section{Lista de tabelas}

Tabela 1: Algumas características das redes EPON e GPON.

Tabela 2: Perdas padrão para dispositivos ópticos passivos.

Tabela 3: Resumo de resultados numéricos para as três topologias, usando divisores simétricos. 28

Tabela 4: Porcentagens de derivação assimétrica, para as topologias em barramento e anel.

Tabela 5: Margens de potência média, mínima e máxima para todas as topologias.

Tabela 6: Pseudocódigo do algoritmo que gera os indivíduos da população inicial.

Tabela 7: Função de otimização para o mínimo de ONUs agrupadas. 30

Tabela 8. Custo de equipamentos. 31

Tabela 9. Função Aptidão - Fitness. 36

Tabela 10. Dados das simulações.

Tabela 11. Simbologia.

Tabela 12. Dados do grafo.

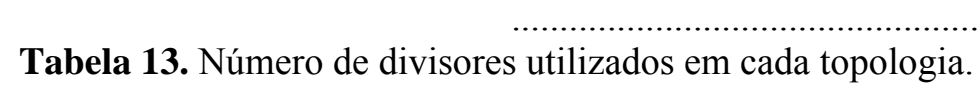

Tabela 14. Porcentagens de derivação.

Tabela 15. Características do algoritmo genético da topologia em árvore.

Tabela 16. Características do algoritmo genético da topologia em barramento.

Tabela 17. Características do algoritmo genético da topologia em anel.

Tabela 18. Valor médio de distâncias.

Tabela 19. Dados do segundo teste........

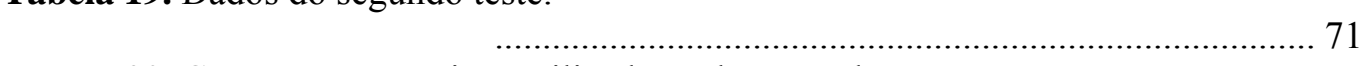

Tabela 20. Componentes ópticos utilizados pelo segundo teste.

Tabela 21. Custo de implementação do teste 2 , considerando portas nos divisores e total fibra óptica 


\section{Lista de acrônimos}

ADSL - Full Rate Asymmetrical Digital Subscriber Line

AG - Algoritmo genético

APON - Asynchronous Transfer Mode Passive Optical Network

ATM - Asynchronous Transfer Mode

BPON - Broadband Passive Optical Network

CDMA -Code Division Multiple Access

CO - Central Office

CPE - Customer Premises Equipment

CSMA/CD - Carrier Sense Multiple Access/Colision Detection

CWDM - Coarse Wavelength Division Multiplexing

DSL - Digital Subscriber Line

DSLAM - Digital Subscriber Line Access Multiplexer

DTH - Direct to Home

DWDM - Dense Wavelength Division Multiplexing

ELAN - Ethernet Local Area Network

EPON- Ethernet based Passive Optical Network

FSAN - Full Service Access Network

FTP - File Transfer Protocol

FTTB - Fiber-To-The-Building

FTTC - Fiber-To-The-Curb

vii 
FTTCab - Fiber-To-The-Cabinet

FTTH - Fiber-To-The-Home

GPON - Gigabit Passive Optical Network

GE-PON - Gigabit Ethernet based Passive Optical Network

IEEE - Institute of Electrical and Electronics Engineers

IP - Internet Protocol

ITU-T - International Telecommunications Union

LASER - Light Amplification by Estimulated Emission of Radiation

LED - Light Emitting Diode

LTM - Line Terminal Multiplexer

OLT - Optical Line Terminal

ONT - Optical Network Terminal

ONU - Optical Network Unit

PON - Passive Optical Network

PTP - Peer-to-peer

QoS - Quality of Service

RDSI - Rede Digital de Serviços Integrados

RPR - Resilient Packet Ring

SDH - Synchronous Digital Hierarchy

SDSL - Symmetric Digital Subscriber Line

SHDSL - Symmetric High-Bitrate Digital Subscriber Line 
EESC - Escola de Engenharia de São Carlos

SONET - Synchronous Optical Network

TCP - Transmission Control Protocol

TDD - Time Division Duplex

TDM - Time Division Multiplexing

TDMA - Time Division Multiple Access

UDP - User Datagram Protocol

VDSL - Very High Bit Rate Digital Subscriber Line

VDSL2 - Very High Bit Rate Digital Subscriber Line Second Generation

VLAN - Virtual Local Area Network

VoIP - Voice over Internet Protocol

WAN - Wide Area Network

WDM - Wavelength Division Multiplexing

WDMA - Wave Division Multiple Access 
EESC - Escola de Engenharia de São Carlos 


\section{Resumo}

Tany V. Villalba., "Distribuição de Divisores de Potência em Redes Ópticas Passivas Utilizando Algoritmos Genéticos", 2009. Tese (mestrado) - Escola de Engenharia de São Carlos, Universidade de São Paulo, 2009.

O objetivo deste trabalho é a otimização da distribuição dos divisores de potência utilizados em redes ópticas passivas, baseados na técnica de algoritmos genéticos, onde cada divisor possui uma única entrada e diversas saídas. O cenário prático de distribuição compreende uma determinada cidade, onde as ruas são as possíveis vias e as casas ou prédios são os possíveis terminais. Partindo de um ponto inicial (OLT- Optical Line Terminator), em geral a central de distribuição, chega-se aos usuários finais (ONUs- Optical Network Units) passando pelos divisores. Observa-se que temos pelo menos um ponto inicial (OLT) e diversos pontos de chegada (as ONUs) - dependendo da quantidade de saídas que o divisor óptico possui, cada uma destas representa um possível usuário ou outro divisor. O posicionamento dos divisores de potência e os caminhos utilizados que usaremos fazem parte de nossa solução. O conjunto destes elementos forma as redes de acesso óptico passivo (PON).

Aspectos importantes considerados na otimização: (i) os comprimentos dos cabos desde a OLT até as ONUs, uma vez que ocorrem maiores degradações do sinal à medida que a distância aumenta, bem como aumentam os custos de implantação em proporção direta ao comprimento utilizado; e (ii) margem de potência no enlace e (iii) custo do enlace.

Durante o processo de otimização, o algoritmo genético desenvolvido propõe um novo procedimento de busca de caminho denominado "nó cíclico".

Os resultados obtidos foram validados por comparações obtidas manualmente em redes de menor escala. Interfaces gráficas para carregamento de mapas urbanos a partir de aplicativos como Google map foram desenvolvidas.

Palavras-chave: Redes Ópticas Passivas, otimização de topologias de rede, algoritmos genéticos, planejamento de rede, Nó Cíclico. 
EESC - Escola de Engenharia de São Carlos 


\section{Abstract}

This study, based on a genetic algorithm, optimizes the distribution of power dividers used, in the access, by passive optical networks, where each splitter has one input and several outputs. The practical scenario of distribution includes a particular city where the streets are the possible ways and the houses or buildings are the possible terminals. Starting from the OLT (Optical Line Terminal), in general the distribution center, the end users (ONUs-Optical Network Units) are connected to the OLT by a path with power divisions. Observe that we have at least one starting point (OLT) and several points of arrival (the ONUs) - depending on the amount of the optical splitter outputs, each of these representing a user. The positioning of the OLT, ONUs and power dividers are part of the solution we are seeking for and all these elements form the access passive optical network (PON).

Important aspects considered: (i) the lengths of the cables from the OLT to the ONUs, once there are more signal degradation as the distance increases, (ii) link power budget and (iii) link cost.

During the optimization process, the developed genetic algorithm proposes a new procedure for finding the optimum path which is called "cyclic node".

The obtainde results have been validated by comparison with manual optimization in a smaller scale network. Graphical interfaces have been developed for uploading city maps from aplicatives Google maps.

Index Terms - Passive Optical Networks, Topology optimization, genetic algorithm, network planning, cyclic node. 
EESC - Escola de Engenharia de São Carlos 


\section{Capítulo 1. Introdução}

\subsection{Introdução}

O aumento crescente da oferta de serviços e aplicações, principalmente aqueles envolvendo transmissão de imagem (por exemplo, vídeo-conferência, vídeo sob demanda e jogos on-line), estimula e justifica a implantação de redes ópticas de acesso. Neste cenário, a utilização de fibras ópticas nas imediações do usuário já permite, a um custo competitivo, que se disponibilize a um número de clientes relativamente pequeno (em geral, até 128) uma capacidade de transmissão elevada (até 2,5 Gb/s por até algumas dezenas de quilômetros [1], tanto na descida quanto na subida dos dados. Além disso, comparadas às redes de fibra óptica ativas, as redes ópticas passivas (Passive Optical Networks, PON), apresentam facilidade de instalação e atualização, baixo custo de operação e manutenção, confiabilidade, imunidade eletromagnética e cabos mais leves e compactos [2] .

A maioria das redes PON sendo instaladas no mundo têm arquitetura do tipo ponto-multiponto com um ou mais níveis de derivação de potência, via divisores ópticos passivos, para distribuição do sinal. $\mathrm{O}$ acesso ao meio na transmissão ascendente é feito através de multiplexação no tempo (TDMA), para evitar colisões no acoplador. Das duas tecnologias PON em implantação (Gigabit PON, GPON, padronizada pelo ITU-T G.984 [1], e Ethernet PON, EPON, padronizada pelo IEEE 802.3ah [3] ), o GPON, adotado no Brasil, oferece vantagens como taxas de tráfego ascendente e descendente mais altas, maior eficiência de banda (na relação cabeçalho/carga útil) e maior variedade de serviços. Pelo lado do EPON, destaca-se positivamente seu custo mais baixo e a maior maturidade tecnológica [4] .

Um dos desafios de planejamento e projeto de uma rede PON diz respeito à distribuição dos divisores de potência, em termos de posicionamento e razão de divisão. Alguns fatores que influenciam na escolha da topologia são: distribuição geográfica dos usuários (determinará o número e o posicionamento dos divisores ópticos) e a quantidade e comprimento de cabos ópticos que farão a ligação entre uma OLT (Optical Line Terminal, localizada na Central) e cada uma das ONUs (Optical Network Units, localizadas nas imediações do usuário).

Uma análise realizada em redes de acesso instaladas mostrou que muitas das fibras utilizadas não são necessárias [5] , isso ocorre porque não houve nenhum estudo e otimização preliminar, ou seja, a 
instalação de fibras ocorreu à medida em que houve demanda dos usuários. Esse fato teve como conseqüência o crescimento desordenado e não planejado da rede, planejamento no qual uma limitação importante a ser levada em conta é o alcance das redes ópticas, que pode ser de ordem física e lógica. No caso da primeira, o alcance depende fortemente da topologia e distribuição dos elementos ópticos que, além das perdas pela divisão de potência, podem sofrer de efeitos como atenuação nos comprimentos de ondas utilizados, elevado número de ONUs ligadas a cada OLT e baixa sensibilidade dos receptores. A limitação lógica está relacionada aos protocolos de comunicação entre OLT e ONUs, que tem como requisito uma janela temporal máxima para recebimento de mensagens [4] .

Em estudo recente, M.R.X. Barros et al. propuseram [5] , o uso de uma distribuição híbrida simétrica e assimétrica da potência óptica na topologia barramento, adequada a uma distribuição linear de ONUs, por exemplo, uma demanda de tráfego ao longo de uma rodovia, visando otimizar o alcance geográfico de uma rede PON (a máxima distância entre a OLT e a ONU mais distante). A topologia proposta naquele trabalho, aplicável a barramentos lineares, tinha dois níveis de derivação, onde o primeiro era assimétrico (acopladores 1:2 usados para derivar uma fração da potência) e o segundo nível simétrico (acopladores 1:N). Avançando esta análise para um caso mais genérico, apresentamos nesta dissertação um estudo semelhante aplicado a três topologias físicas com um nível de derivação: barramento, árvore e anel.

Além do tratamento descrito anteriormente, neste trabalho é proposto um algoritmo para o planejamento de redes ópticas passivas com base na técnica de algoritmos genéticos. Desta forma, considerando mais de um nível de distribuição, são otimizadas as topologias visando minimização do uso de cabos ópticos, atendimento do orçamento de potência dentro dos padrões GPON e custo dos componentes. 


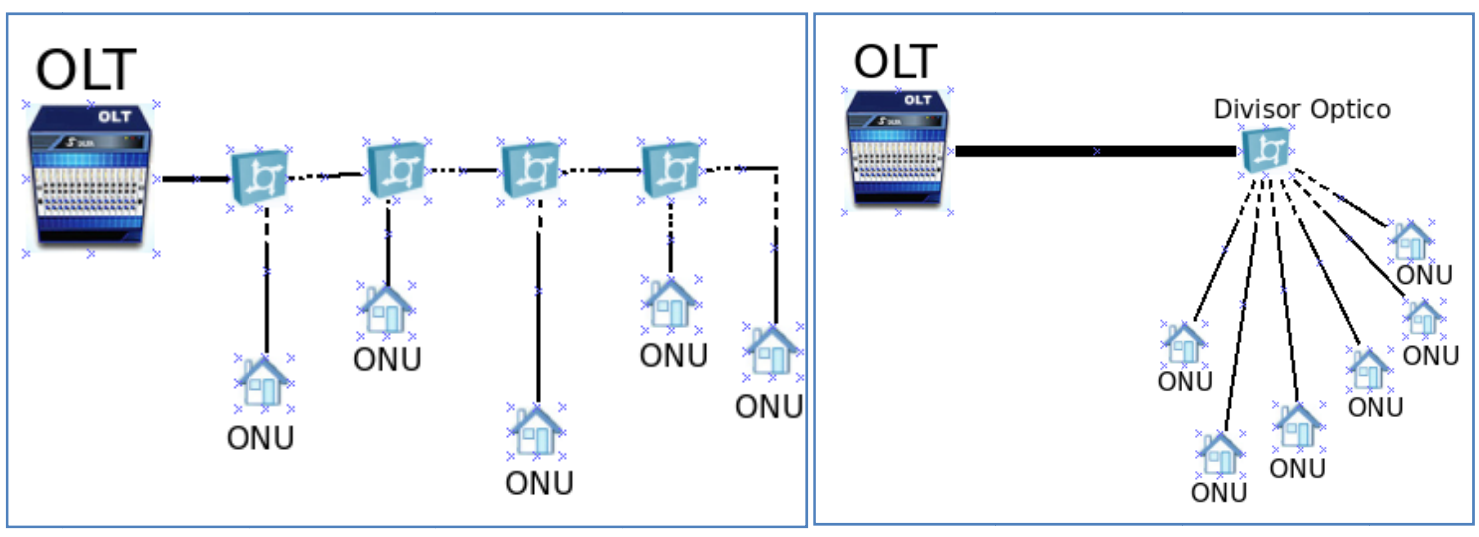

(a)

(b)

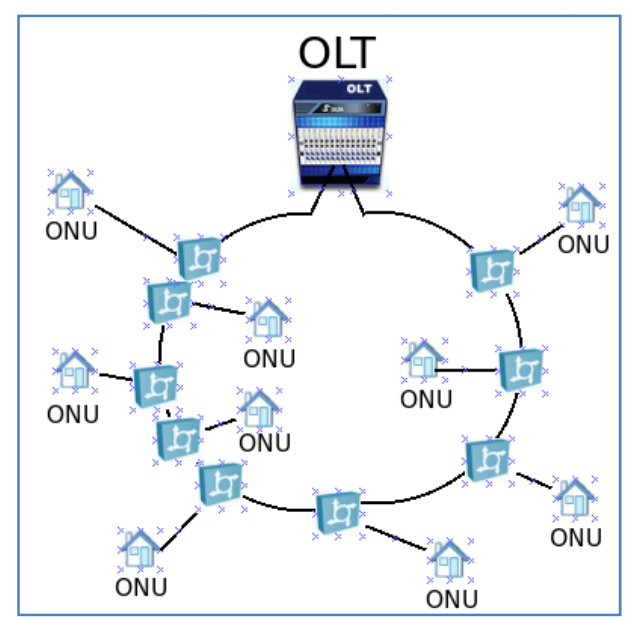

(c)

Figura 1. Topologias com um nível de derivação: (a) barramento, (b) árvore e (c) anel.

A dissertação está assim estruturada: o Capítulo 2 descreve o problema a partir de uma revisão dos conceitos ligados a redes ópticas passivas, às topologias estudadas e os componentes básicos empregados nestas redes. No Capítulo 3 é apresentado um estudo de três topologias de redes ópticas passivas, barramento, árvore e anel, com características de distribuição de potência simétrica e assimétrica. O Capítulo 4 descreve a abordagem utilizando algoritmos genéticos cujos resultados são apresentados no Capítulo 5. O capítulo 6 apresenta as conclusões do trabalho. 


\subsection{Entendendo o Problema}

O mercado atual de telecomunicações, com sua crescente oferta de serviços (tradicionais e de valor agregado) ao usuário final, tem levado as operadoras a migrar suas redes de acesso para tecnologias mais flexíveis e de maior capacidade [6] .

A rede de acesso é a parcela de uma rede pública comutada que conecta o nó de acesso aos usuários individuais. De uma forma mais simples, é a última ligação (ou primeira), em uma rede, entre as imediações do cliente e o primeiro ponto de conexão com a infra-estrutura da rede - a Point Of Presence ( $\mathrm{PoP})$ ou a sede (Central Office - $\mathrm{CO}$ ). A rede de acesso atual é predominantemente constituída de fios de cobre ou par trançado que foi considerado como tendo um dos mais importantes papéis no ato de prover serviços de transmissão de dados [7] .

A rede de acesso óptica apresenta uma largura de banda que chega a gigabits por segundo $(\mathrm{Gb} / \mathrm{s}), \mathrm{o}$ que aumentará ainda mais com o avanço da tecnologia [5] . Esta maior disponibilidade espectral abre a possibilidades de novas arquiteturas para prover serviços de faixa larga. Tomando a rede de acesso como a parte mais importante na entrega dessa largura de banda, é necessário colocar alguns equipamentos, nas imediações do cliente, para gerenciar ou controlar a quantidade de dados transmitidos sobre uma conexão de acesso.

O padrão de redes de computadores, conhecido como Ethernet [3], primeiro emergiu como uma tecnologia de difusão para redes locais (LAN - Local Area Networks). O protocolo envolvido é do tipo "melhor esforço", o que permite tolerância a falhas ocasionais nos quadros, falhas estas causadas por colisões (uma vez que o meio utilizado é compartilhado por todos os dispositivos de rede) ou ruído. Apesar de, nativamente, o Ethernet não prover qualquer tipo de Qualidade de Serviço (QoS Quality of Service), suas características de fácil configuração, alta escalabilidade, custo e suporte a uma larga gama de serviços (incluindo dados, vídeo e voz [1]) garantiram sua adoção global. Com o advento da Internet, o padrão Ethernet tornou-se virtualmente onipresente, dando origem a diversas tecnologias de acesso, inclusive ópticas, como EPON (Ethernet Optical Passive Network).

Os backbones atuais (SDH) da Internet suportam banda larga de transferência na ordem de dezenas de gigabits [8] , o suficiente para transmissão de sinal vídeo em tempo real (Televisão IP). O local onde geralmente são encontradas as menores larguras de banda de transferência na Internet é nas conexões dos usuários finais. Esta conexão entre usuário final e provedor é comumente denominada 
"última milha (last mile)" ou "primeira milha (first mile)" [4] . É esta primeira milha que age como um gargalo de velocidade para os serviços que se quer prestar ao usuário consumidor.

É importante notar que esta conexão de primeira milha não se limita à conexão de um usuário final com um provedor de acesso à Internet. Ela também considera a conexão de um usuário ou assinante de qualquer serviço de redes de comutação de pacotes, como uma rede metropolitana, em um campus de universidade ou empresa corporativa. Nestas redes geralmente há um backbone de banda larga, com as conexões para os usuários finais bem mais lentas. A razão pela qual se abordou o exemplo da Internet deve-se ao fato de que ao se falar em infra-estrutura de redes de grande porte, é prioritário considerar que estas redes tenham conexão com a Internet.

Várias soluções têm sido utilizadas a fim de prover à primeira milha largura de banda crescente [9], o que se conhece pela denominação comercial de "acesso em banda larga" ou "Internet em banda larga". Tecnologias como xDSL, cable modems e rádio são as mais comumente empregadas, oferecendo velocidades de transmissão típicas da ordem de $128 \mathrm{~kb} / \mathrm{s}$ a $2 \mathrm{Mb} / \mathrm{s}$ para o usuário doméstico[10]. Os principais problemas encontrados para o enlace entre o usuário final e o provedor são os gargalos de desempenho, limitações para aumento da largura de banda, complexidade de configuração e custo. As redes de tipo PON (Passive Optical Network) apresentam uma alternativa viável para o atual estado da tecnologia, completando a idéia de "Internet em toda parte (Internet Everywhere)" [11] .

Uma rede óptica passiva (PON) é configurada a partir de uma única fibra óptica que é compartilhada com o uso de splitters ou divisores ópticos [11], tipicamente de custo acessível. Estes splitters dividem o sinal óptico da fibra em feixes separados, que são por sua vez transportados através de fibras individuais, cabos de cobre ou sistemas sem fio, para cada assinante ou usuário final. $\mathrm{O}$ uso do termo passivo explica-se porque, entre a conexão do CO e os usuários finais, não há nenhum equipamento eletrônico ativo dentro da rede (a exemplo de um switch). Somente uma conversão óptica-elétrica é necessária em cada ponto de terminação da fibra, basicamente uma no CO e uma no usuário final. Assim, os usuários finais estão ligados via fibras dedicadas até o splitter, e a partir deste compartilham uma única fibra até o CO [11] [12].

Em sua construção, uma rede GPON (Gigabit PON) ou EPON inclui dois tipos de equipamentos principais, denominadas OLT e ONU [12] . A OLT está no Escritório Central (CO), e trata-se normalmente de um switch. A ONU reside no local do usuário final, localizado em sua residência, no 
edifício ou ainda num armário. No caso específico de EPON, a ONU possui geralmente uma interface WAN tipo 802.3ah [1] e também uma interface tipo 802.3 para ligação com o usuário assinante. A Figura 2 ilustra a rede, com uma OLT à esquerda e diversas ONUs à direita, conectadas à OLT através de um splitter.

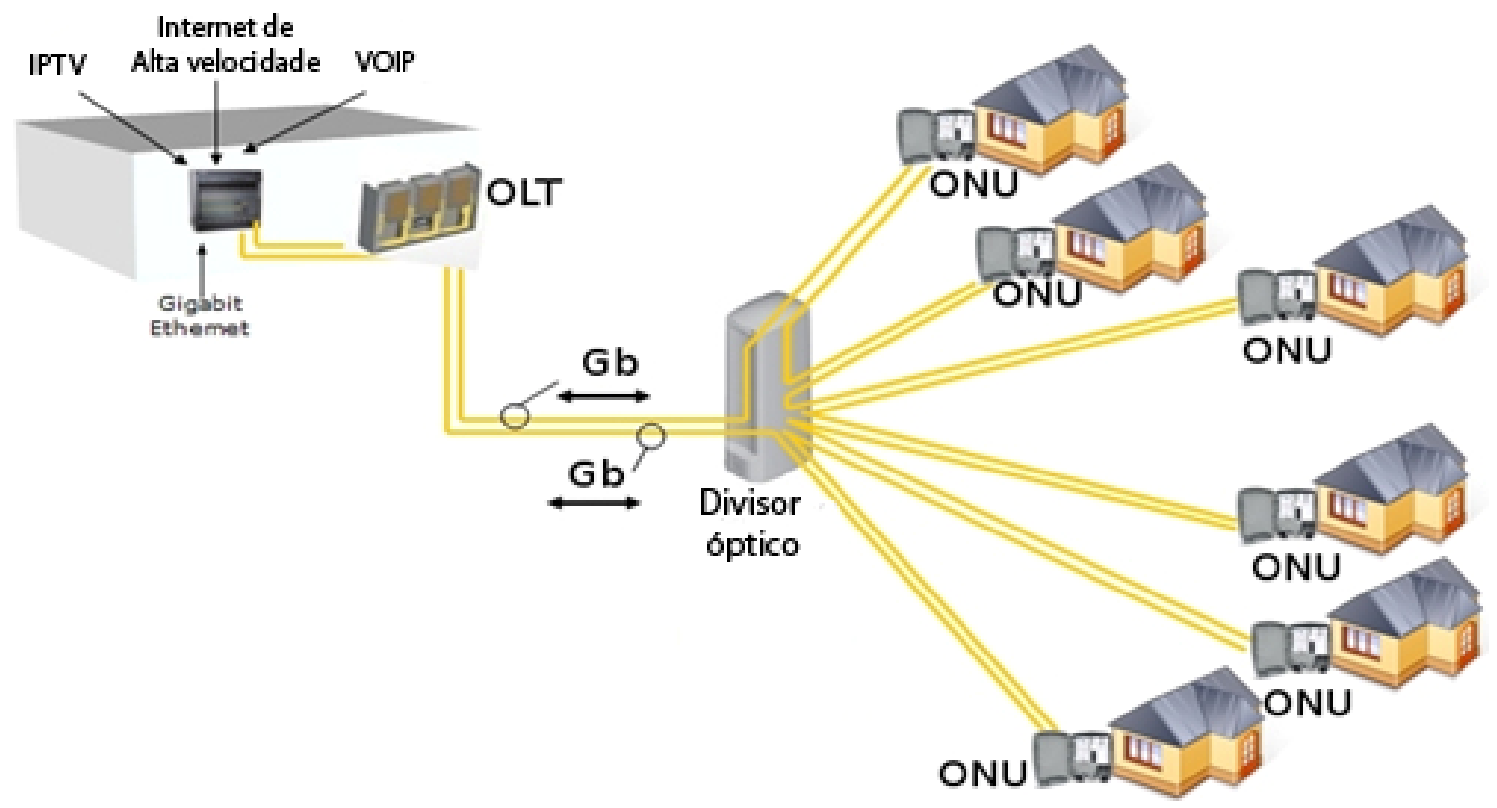

Figura 2. Distribuição dos componentes ópticos (OLT, Splitter, ONUs)[13] .

As ONUs enxergam somente o tráfego vindo do $\mathrm{CO}$ ou OLT, e não podem ver o tráfego transmitido por outras ONUs através da fibra compartilhada (as ONUs filtram o tráfego não direcionado a elas através de protocolo) [4]. Se houver necessidade de conexão ponto-a-ponto entre duas ONUs, isto só pode ser feito por intermédio da OLT. Cada ONU transmite para a OLT em intervalos de tempo (time slots) usando um protocolo de multiplexação de acesso por divisão de tempo (TDMA - Time Division Multiplex Access). Os tempos de transmissão de cada ONU são permitidos e controlados pela OLT através do protocolo ranging [5] .

A infra-estrutura existente não acompanhou o ritmo do crescimento exponencial de tráfego da rede. As novas aplicações de negócio tais como o e-comércio, a videoconferência de alta qualidade, a telemedicina, as transferências de grandes pacotes de dados, os espelhos de dados e o armazenamento de dados estão guiando a necessidade por serviços de banda cada vez mais larga. Novos fornecedores de serviço, tais como ISXs (Internet Service Exchanges), ASPs (Application Service Providers) e SSPs 
(Storage Service Providers) estão emergindo, experimentando um rápido crescimento em seus negócios e formando um mercado à parte [6] .

Nossa motivação é, portanto, implementar ferramentas que auxiliem no planejamento e projeto de redes ópticas passivas visando otimização de recursos. Partiremos de um modelo de estudo prévio[5], testando as topologias mais utilizadas em redes PON (árvore, barramento, anel), utilizando as seguintes variáveis de otimização: número de divisores, comprimento dos cabos de fibra e preço dos equipamentos de conectividade usados para conseguir uma maior qualidade de serviço ao menor custo.

A solução proposta é a utilização de algoritmos genéticos para gerar topologias padrão, e assim limitar o número de soluções possíveis, que podem ser representadas sob forma de vetores compostos de cadeias numéricas [12]. As cadeias resultantes podem então ser tratadas como uma unidade genética que representará os grupos de ONUs do individuo, e que armazenará as características de cada topologia. A proposta consiste em encontrar esta solução melhorando os indivíduos sem sair da sua estrutura de rede, seguindo um processo iterativo. 
EESC - Escola de Engenharia de São Carlos 


\section{Capítulo 2 - Rede de Acesso Óptica}

\subsection{As redes GPON e Tecnologia PON}

As redes GPON (Gigabit Passive Optical Network) são atualmente uma das tecnologias de acesso de alta velocidade que têm atraído grande interesse do mercado de telecomunicações. Este capítulo apresenta o status atual e algumas possibilidades futuras da tecnologia GPON, destacando o estudo das topologias.

Vários analistas têm previsto um crescimento rápido do número de implantações GPON, levando, em poucos anos, ao uso predominante do GPON nos acessos baseados em tecnologias de fibra óptica. Outras tecnologias, tais como Ethernet PON (EPON), também tendem a ser usadas durante os próximos anos [5] [12].

A popularidade do GPON se deve a vários fatores. A tecnologia suporta uma vasta gama de aplicações e serviços, principalmente os serviços de envio unidirecional de vídeo e TV do tipo unicast e broadcast [13]. Ela pode fazer parte de muitas arquiteturas de rede, como por exemplo, na combinação VDSL2 (Very-high speed Digital Subscriber Line 2) e FTTC (Fiber To The Curb, ou fibra óptica até a calçada ou passeio público), ou como o acesso residencial do tipo FTTH (Fiber To The Home).

Uma solução baseada em GPON é parte integrante de uma Arquitetura de Serviços Banda Larga (Full Service Broadband Architecture), projetada para satisfazer as necessidades de convergência fixo-móvel e de redes convergentes NGN (Next Generation Networks) para a oferta de serviços residenciais e corporativos.

A evolução e a padronização do GPON oferecem novas funcionalidades e facilidades que suportarão as futuras redes de acesso de banda larga e de serviços. O próximo passo na evolução nas redes a serem implementadas é o aumento da taxa de bits, dos atuais $2,5 \mathrm{~Gb} / \mathrm{s}$ para $10 \mathrm{~Gb} / \mathrm{s}$, no sentido downstream, e dos atuais $1,25 \mathrm{~Gb} / \mathrm{s}$ para $2,5 \mathrm{~Gb} / \mathrm{s}$, no sentido upstream [1]. A migração para redes do tipo passivas será possível através de um planejamento adequado de uso de comprimentos de ondas que permita a co-existência de múltiplos GPON's na mesma rede óptica. 
Várias operadoras e fornecedores do mercado de telecomunicações consideram o WDM-PON (Wavelength Division Multiplexed PON) como sendo a melhor tecnologia PON de longo prazo[13] . O WDM-PON oferece uma alternativa para o esquema de transmissão GPON do tipo time-shared (tempo compartilhado), onde cada ONU transmite e recebe em um determinado comprimento de onda em lapsos de tempo. Embora atualmente o custo de implementação do WDM-PON seja maior, quando comparado com o do TDM-PON, a pesquisa intensiva em componentes ópticos pode permitir reduções de custos significativas [10].

O padrão GPON, adotado no Brasil, é a base para este trabalho e está normatizado pela ITU-T (International Telecommunication Union - Telecommunication Standardization Sector) [1] na série de normas G.984.x.

O modelo GPON possui as seguintes características [ITU-T]:

- Sentido downstream de dados: comprimento de onda $1490 \mathrm{~nm}$, link budget de $28 \mathrm{~dB}$ e taxa de transferência de $2,488 \mathrm{~Gb} / \mathrm{s}$.

- Sentido downstream de vídeo: comprimento de onda $1550 \mathrm{~nm}$.

- Sentido upstream: comprimento de onda $1310 \mathrm{~nm}$, link budget de $28 \mathrm{~dB}$ e taxa de transferência de $1,244 \mathrm{~Gb} / \mathrm{s}$.

O GPON possui então três fluxos de informação em comprimentos de onda distintos de modo que os dados não disputem banda. Existe uma freqüência reservada para vídeo, o que corresponde às perspectivas mundiais de que a qualidade do vídeo irá aumentar drasticamente, bem como as aplicações que fazem uso intensivo de vídeo, como conseqüência tem-se um aumento da demanda por banda [1].

\subsection{Padrões EPON e GPON}

\subsubsection{EPON}

A rede EPON, ta foi especificada pelo grupo de trabalho IEEE 802.3ah [3] 0. Este grupo, denominado Ethernet na primeira milha (Ethernet in the first mile - EFM), foi projetado para ampliar a aplicação de Ethernet às redes de acesso. O intuito era utilizar as características de baixo custo e simplicidade da arquitetura Ethernet para possibilitar a utilização de tecnologia 
em redes PON. A EPON transporta os dados encapsulados em quadros Ethernet, que facilita o transporte de pacotes IP e a operabilidade entre as LANs Ethernet instaladas. Este padrão foi iniciado o 2000 e concluído em junho de 2004 com a especificação da taxa máxima de transmissão $1 \mathrm{~Gb} / \mathrm{s}$.

Atualmente, o IEEE criou um novo grupo de trabalho chamado P802.3av [15] para definir a camada física que permita operar em taxas de transmissão de $10 \mathrm{~Gb} / \mathrm{s}$. Esta iniciativa foi proposta para atender a futura demanda de tráfego da Internet.

\subsubsection{GPON}

O grupo FSAN iniciou no ano 2001 um projeto para especificar um padrão mais flexível que suportasse diferentes tipos de tráfegos e taxas de transmissão mais elevadas em redes PON. O resultado deste esforço veio com a padronização da série de recomendações G.984.X desenvolvida pelo ITU-T que especifica a rede GPON [1]

O método de encapsulamento de pacotes GPON é o GTC que pode conter pacotes GEM, que tem como base o protocolo genérico de formatação de quadros (generic framing protocol - GFP) [8] e encapsula quadros Ethernet e TDM, e células ATM. Esta rede oferece diferentes taxas de transmissão nas duas direções, downstream e upstream, dispondo das seguintes possibilidades de configuração: na direção downstream a transmissão pode ser 1,25 Gb/s ou 2,5 Gb/s; na upstream $0,155 \mathrm{~Gb} / \mathrm{s}, 0,622 \mathrm{~Gb} / \mathrm{s}, 1,25 \mathrm{~Gb} / \mathrm{s}$ ou 2,5 Gb/s, sendo possíveis quaisquer combinações entre elas, exceto $1,25 \mathrm{~Gb} / \mathrm{s}$ para downstream e 2,5 Gb/s para upstream (a combinação mais utilizada é a 2,5 Gb/s para downstream e 1,25 Gb/s para upstream). O sistema GPON pode suportar tanto o atendimento de tráfego em rajada (variable bit rate - VBR) quanto tráfego em taxa de bit constante (constant bit rate - CBR) e combina as vantagens de QoS do ATM e utiliza a eficiência de cabeçalho do seu padrão. Atualmente, algumas empresas consideram em seu planejamento implementar comercialmente redes GPON com taxa de transmissão de 10 Gbps. As características das redes EPON e GPON são mostradas na Tabela 1 [14]. 
Tabela 1. Algumas características das redes EPON e GPON.

\begin{tabular}{|c|c|c|}
\hline Arquiteturas & EPON & GPON \\
\hline Padrão & IEEE 803.ah & ITU-T G.984 \\
\hline $\begin{array}{l}\text { Tamanho do pacote de } \\
\text { dados }\end{array}$ & $\begin{array}{c}\text { Variável de } 64 \text { bytes até } \\
1518 \text { bytes }\end{array}$ & $\begin{array}{c}\text { Variável de } 53 \text { bytes até } \\
1518 \text { bytes }\end{array}$ \\
\hline Quadro & Ethernet & GFP/ATM \\
\hline $\begin{array}{l}\text { Largura de banda } \\
\text { máxima }\end{array}$ & $1 \mathrm{~Gb} / \mathrm{s}$ & $2,5 \mathrm{~Gb} / \mathrm{s}$ \\
\hline $\begin{array}{l}\text { Comprimento de onda } \\
\text { downstream }\end{array}$ & $1490 \mathrm{~nm}$ ou $1510 \mathrm{~nm}$ & $1480 \mathrm{~nm}$ a $1500 \mathrm{~nm}$ \\
\hline $\begin{array}{l}\text { Comprimento de onda } \\
\text { Upstream }\end{array}$ & $1310 \mathrm{~nm}$ & $1260 \mathrm{~nm}$ a $1360 \mathrm{~nm}$ \\
\hline Tráfego Voz & VoIP ou TDM & TDM \\
\hline Tráfego Vídeo & $1550 \mathrm{~nm}(\mathrm{RF} / \mathrm{IP})$ & $\mathrm{RF} / \mathrm{IP}$ \\
\hline Usuários na PON & $16 / 32$ & 64 \\
\hline $\begin{array}{l}\text { Largura de banda média } \\
\text { por usuário }\end{array}$ & $60 \mathrm{Mbps} / 30 \mathrm{Mb} / \mathrm{s}$ & $40 \mathrm{Mb} / \mathrm{s}$ \\
\hline Eficiência & $49 \%$ & $94 \%$ \\
\hline
\end{tabular}

\subsection{Componentes Ópticos}

\subsubsection{Terminal de linha (OLT)}

A OLT, normalmente localizada nas bordas dos anéis ópticos das redes de transporte SDH, é o ponto de conexão da rede de acesso ao núcleo (core) da rede. A OLT promove a consolidação e concentração do tráfego, o que reduz o número de interfaces interligadas ao núcleo da rede. Viabiliza os serviços para os usuários finais e controla a qualidade do serviço (QoS) e o SLA (Service-level Agreement), que formaliza a disponibilidade dos serviços, os requisitos de desempenho e os 
compromissos com tempos e prazos) [10] . É a OLT que combina as várias interfaces com os seus protocolos em uma única fibra óptica, realizando a multiplexação dos diferentes usuários na fibra.

\subsubsection{Unidade de rede óptica ( $\mathrm{ONU})$}

A ONU ou ONT (Optical Network Terminal) é o equipamento que converte o sinal óptico da OLT em sinal elétrico e demultiplexa o sinal elétrico para divisão da banda base em voz, dados e vídeo [10] . O sinal é então distribuído para as portas padrões dos equipamentos de aplicação de cada usuário final: ATM, Ethernet, IP etc.

O processo de conexão de uma ONU se dá segundo os seguintes passos: depois de ligada, a fica em um estado inicial de alarme; em seguida a ONU começa a receber os dados da OLTe entra em estado de standby até receber a mensagem Upstream-Overhead. A partir de então, a ONU entra num estado chamado Power-Setup no qual ela envia à OLT uma mensagem de Serial-Number-State e aguarda a mensagem de Serial-Number-Request [12] [13] . Depois de recebida esta mensagem, a ONU envia seu Serial-Number - essas duas últimas etapas são repetidas até que a OLT receba duas vezes o Serial-Number da ONU. Depois disso a OLT atribui uma ONU-ID àquela ONU e o transmite a através da mensagem Assign_ONU-ID [8] . Após esse processo de reconhecimento e identificação, entra em cena a fase de medida da distância da OLT para a ONU, chamado de ranging [5] . A OLT atribui a cada ONU um tempo de burst, que é o tempo que a ONU tem para enviar dados; entre o tempo de burst destinado a cada ONU, deve haver um intervalo de guarda para garantir que as informações enviadas por duas ONUs consecutivas não colidam. Tal intervalo de guarda varia de acordo com a diferença entre as distâncias da OLT para cada ONU consecutiva [1].

O mecanismo de medida de distância adotado pelo GPON é o Round Trip Delay (RTD), o qual leva em consideração o tempo de ida e volta do sinal, a velocidade de propagação da luz na fibra, o atraso dos transdutores óptico-elétrico e elétrico-óptico e também o tempo de processamento da ONU [10] . Mais especificamente, o RTD mede a diferença de tempo entre o $1^{\circ}$ bit da mensagem RangingTransmission e a recepção do último bit da mensagem Ranging-Transmission enviada pela ONU. Após todo esse processo a ONU está pronta para transferir dados efetivamente para a OLT [8] .

A OLT se comunica com uma ONU de cada vez, para tanto, cada pacote contém o identificador ONU-ID que é lido pelas ONUs para elas saberem se o pacote é destinado a ela ou não, visto que os 
pacotes enviados pela OLT atingem todas as ONUs, como uma transmissão em broadcast. Dessa maneira apenas aqueles pacotes que contêm o seu identificador são lidos pela ONU [1].

\subsubsection{Conectores Ópticos}

Os conectores ópticos são dispositivos passivos que permitem realizar junções temporárias ponto-aponto entre duas fibras ou, nas extremidades dos sistemas, juntando opticamente a fibra ao dispositivo foto emissor ou foto receptor. A qualidade da conexão é garantida pela precisão com que as peças mecânicas que constituem o conector óptico conseguem posicionar as extremidades das fibras com relação ao corpo exterior do conector.

Os conectores ópticos são utilizados em interface entre dispositivos e redes de área local, conexões com enlaces de dados de pequenas distâncias, ponto onde um sistema de telecomunicações entra em um edifício e conexões entre redes e equipamentos terminais. Oferecem vantagens operacionais em relação às outras técnicas de conexão ponto-a-ponto, como por exemplo, a facilidade de manuseio que não exige nenhum equipamento sofisticado ou conhecimento técnico particular. Por outro lado, apresentam atenuação mais alta que a encontrada nas emendas [16] .

Existe uma grande variedade de conectores para númerosas aplicações distintas com fibras ópticas. Os tipos de conectores ópticos mais comuns atualmente são os conectores com ferrule, os conectores bicônicos moldados e os conectores com lentes (Figura 3) [10] .

O ferrule é um cilindro com buraco de precisão onde é colocada a fibra. Geralmente o ferrule é envolvido por um anel com rosca que o prende a uma luva de conexão. Este tipo de conector óptico está disponível para uma variedade de dimensões de fibras, sendo que existem conectores com ferrules de metal, plástico ou cerâmico, concorrendo entre si nos requisitos custo e qualidade. Dentre os conectores com ferrules, os conectores SMA apresentam perdas de inserção típicas de 0,6 dB. Conectores SC com ferrule de precisão apresentam perdas de inserção inferiores a $0,1 \mathrm{~dB}$. Conectores tipo FC apresentam perdas de no máximo $0,35 \mathrm{~dB}[10]$.

Em conectores bicônicos moldados, o componente central é uma luva bicônica que aceita plugues (cônicos) e alinha os eixos das extremidades das fibras centradas nos plugues. A utilização destes conectores com fibras multímodo alcançam níveis bastante baixos de atenuação do sinal. As perdas típicas desse tipo de conector são da ordem de $0,4 \mathrm{~dB}[13]$. 


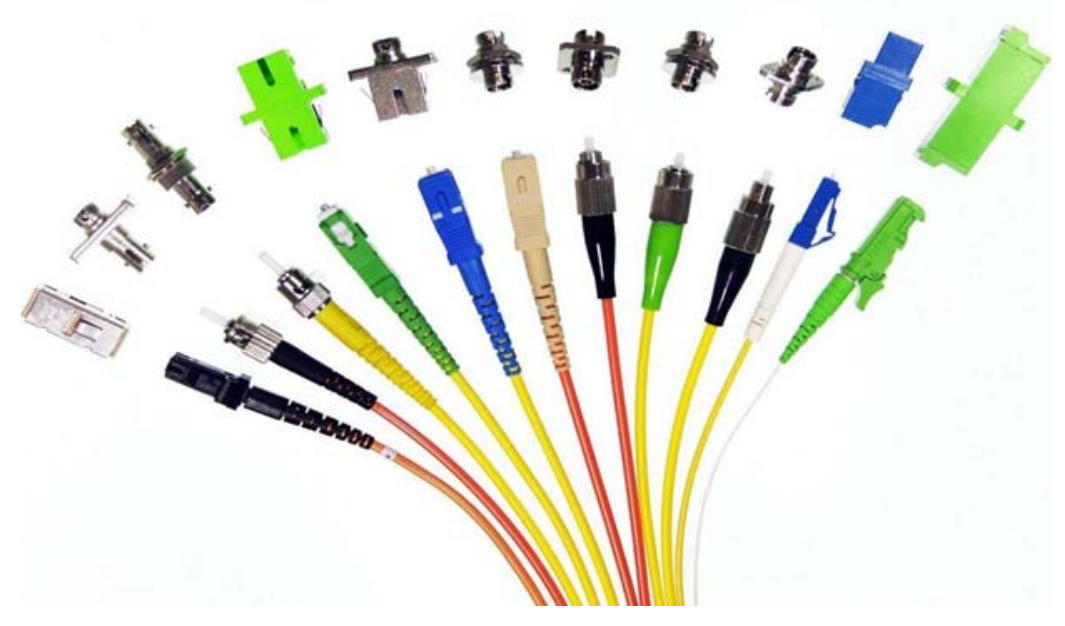

Figura 3. Conectores de fibra óptica [10] .

Conectores com lentes trazem benefícios em termos de redução de perdas de inserção, porém possuem custos maiores do que de outros conectores ópticos, restringindo o número de aplicações para sua utilização.

\subsubsection{Acopladores ou Divisores de Potência}

Os acopladores ópticos podem ser considerados como dispositivos multiportas que permitem combinar ou separar sinais ópticos. São dispositivos puramente ópticos operando como guias de onda óptica e/ou elementos de transmissão, reflexão e refração da luz.

A divisão do sinal entre múltiplas portas de saída resulta em perdas de acoplamento, que são definidas como a razão entre a potência presente em uma determinada porta de saída e a potência de entrada. Além das perdas características de acoplamento (em uma divisão do sinal, por igual, em duas fibras a perda característica é de $3 \mathrm{~dB}$ ), podem existir perdas adicionais dado que são componentes passivos [5] .

Os acopladores são comumente utilizados como elementos básicos de interconexão numa variedade de sistemas e redes locais com fibras ópticas. Por exemplo, no caso de uma rede local em anel, em cada ponto em que um dispositivo é conectado à rede, o sinal precisa ser dividido em uma parte que é entregue ao dispositivo e outra que deve continuar ao longo da rede. Outra aplicação dos acopladores é como separadores ou combinadores em um sistema WDM. Pode-se, através de um acoplador, 
combinar sinais gerados em diferentes comprimentos de onda e transmiti-los em um mesmo canal (fibra). Na maioria das redes, o desempenho dos acopladores ópticos constitui, mais que as características de transmissão da própria fibra, o principal limitante que determina a configuração ótima da rede [13].

Os acopladores dependentes do comprimento de onda são chamados de acopladores WDM, enquanto os acopladores destinados apenas à divisão de potência em um mesmo comprimento de onda recebem o nome de divisores ópticos (splitters).

Em relação à tecnologia são realizáveis os acopladores de fibra e os acopladores por óptica integrada. Acopladores de fibra são construídos a partir da fusão de fibras, em geral com parte da casca removida para unificar os seus núcleos neste trecho de acoplamento, o que produz um acoplador com duas entradas e duas saídas. Geralmente uma destas entradas é isolada ou cortada, gerando um acoplador Y. Já os acopladores por óptica integrada constituem-se de guias de onda fabricados em uma fina camada sobreposta a um substrato.

\subsection{Conceitos de topologias}

As redes de telecomunicações são constituídas por equipamentos baseados numa grande diversidade de tecnologias e em muitos casos concebidos e instalados em épocas muito diferentes. Por exemplo, na rede telefônica pública média de qualquer cidade, há cerca de dez anos atrás ainda era possível encontrar em paralelo com as modernas centrais de comutação digitais, centrais de comutação analógicas com várias dezenas de anos [10] .

Numa rede de telecomunicações podem-se identificar dois tipos básicos de equipamentos: meios de transmissão ou canais de transmissão e elementos (ou dispositivos) de rede designados genericamente por 'nós'. Os meios de transmissão asseguram a transmissão da informação e a interligação entre os diferentes nós. Os meios de transmissão podem ser simples pares de condutores de cobre (pares simétricos) como é o caso da linha telefônica até meios de transmissão mais modernos como é o caso das fibras ópticas. Não se pode igualmente ignorar o cabo coaxial usado nas redes de distribuição de televisão e os canais via rádio usados nas redes celulares ou nas redes de comunicação por satélite.

Nos últimos trinta anos surgiu um grande número de novos tipos de redes de telecomunicações e, certamente, irão surgir mais no futuro. Embora seja importante para um especialista de 
telecomunicações ter um conhecimento detalhado das tecnologias usadas para construir essas diferentes redes, e compreender as suas potencialidades e limitações, também não deixa de ser relevante ser capaz de visualizar essas redes em termos de entidades abstratas, independentes das tecnologias e ausentes em conceitos gerais. Nesse sentido uma rede de telecomunicações pode ser representada por meio de um grafo [17] .

Um grafo é definido geometricamente como um conjunto de pontos designados por vértices interligados por um conjunto de linhas. Um grafo pode ser representado por $G=(V, E)$, onde $V=\{v 1$, $\mathrm{v} 2, \ldots . . \mathrm{v} n\}$ representa o conjunto dos vértices e $\mathrm{E}=\{\mathrm{e} 1, \mathrm{e} 2, \ldots . . \mathrm{em}.\} \mathrm{o}$ conjunto de linhas. A Figura 4 mostra, por exemplo, o grafo $\mathrm{G}=(\{\mathrm{v} 1, \mathrm{v} 2 \ldots . . \mathrm{v} 6\}\{\mathrm{e} 1$, e $2, \ldots . . \mathrm{e} 8\})$. Para representar uma rede de telecomunicações através de um grafo faz-se corresponder um vértice a cada nó e uma linha a cada via de transmissão, como se mostra na Figura 4.

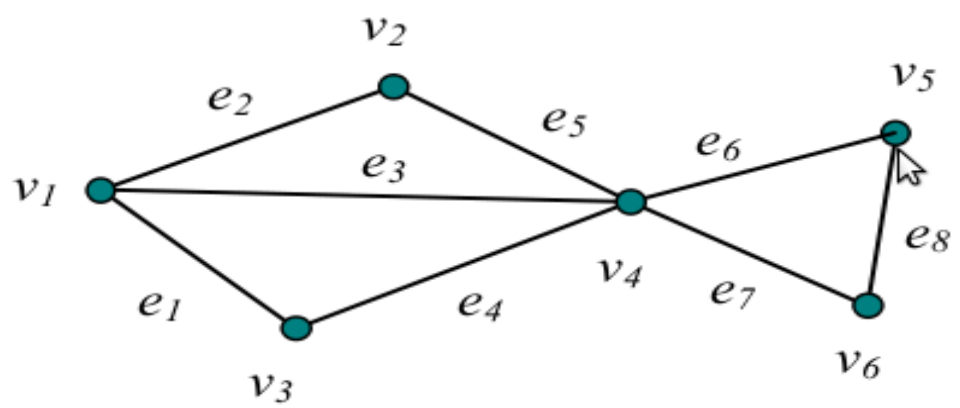

Figura 4. Exemplo de grafo de uma rede.

A estratégia de interligação entre os nós designa-se por topologia da rede, ou de um modo mais preciso, por topologia física. Este refinamento na definição ajuda a distinguir o aspecto físico do modo como a informação é distribuída na rede (topologia lógica). Tendo como exemplo a Figura 5 pode-se admitir que o nó 1 funciona como um nó distribuidor e que toda a comunicação é feita diretamente entre os diferentes nós e o nó 1 . Como conseqüência a topologia física e a topologia lógica são diferentes como se evidência na Figura 6 através da representação dos grafos correspondentes. 

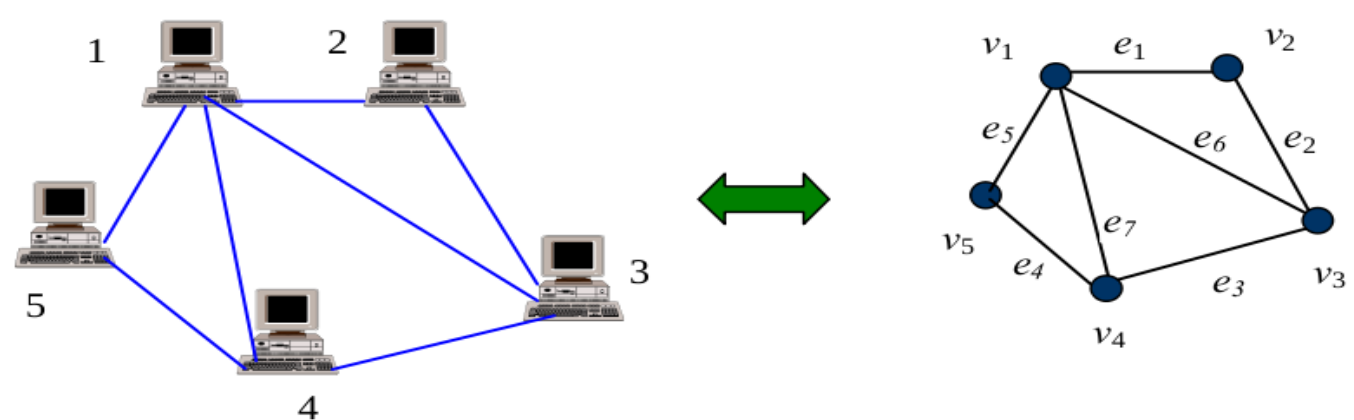

Figura 5. Exemplo de uma rede e do grafo equivalente.
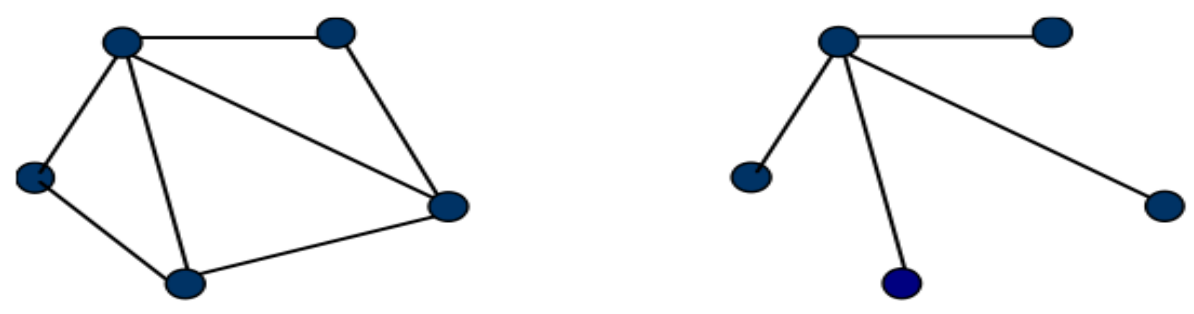

Figura 6. Topologia Lógica - Topologia Física. (em geral usa-se menos conexões físicas, por questão de custo, mas isso não impede a conexão lógica)

Nas redes de telecomunicações encontra-se uma grande variedade de topologias [17] . A escolha dessas topologias influencia a estratégia de otimização e desenvolvimento das redes. Por isso a escolha adequada da topologia constitui uma etapa importante no processo de planejamento da rede. A topologia mais simples é a topologia em barramento. Como se mostra na Figura 7, nessa topologia o meio de transmissão é compartilhado por todos os elementos de rede. O fato do meio ser compartilhado dificulta significativamente o processo de comunicação e impõe a existência de um protocolo de comunicação de modo a evitar colisões entre os sinais enviadas simultaneamente pelos diferentes nós. A topologia em barramento é muito usada nas redes Ethernet nas quais aparece normalmente associada ao protocolo CSMA/CD [10] . 


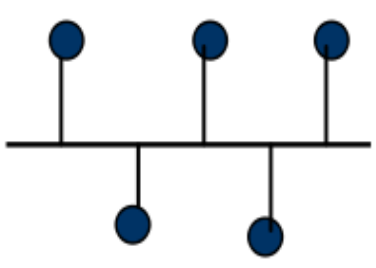

Barramento

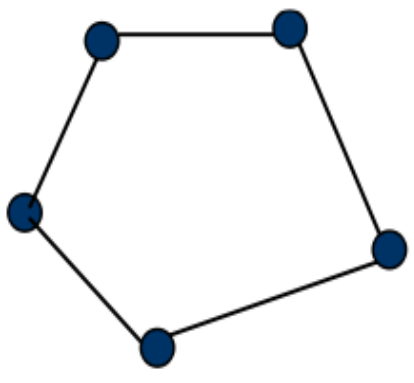

Anel

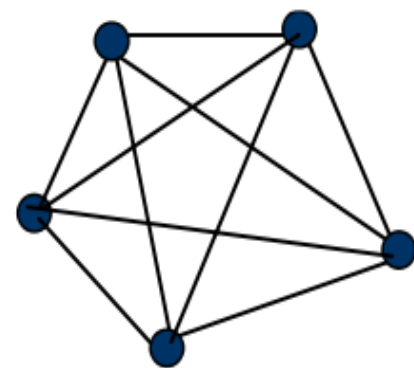

Malha

Figura 7. Grafos correspondentes a diferentes tipos de topologias. a) barramento, b) anel, c)malha.

Na topologia em anel (Figura 7 (b)), cada nó só está interligado aos nós vizinhos. No caso de um nó não se comunicar com outros nós da rede a mensagem terá de ser enviada através dos vizinhos. Uma rede em anel pode ser unidirecional ou bidirecional. Sendo unidirecional toda a informação será transmitida no mesmo sentido e cada nó só pode comunicar diretamente com um nó vizinho, enquanto no caso bidirecional a informação é transmitida nos dois sentidos e cada nó pode se comunicar diretamente com os dois vizinhos. Esta topologia começou por ser usada nas redes de computadores (caso das redes token ring), mas hoje é popular em muitos outros ambientes, como as redes baseadas na hierarquia digital síncrona ou as redes RPR (Resilient Packet Ring). Essa popularidade advém da topologia permitir garantir graus de confiabilidade elevados (resistência a falhas) com um consumo modesto de recursos de transmissão.

A topologia em malha (Figura 7 (c)) não é utilizada em redes de acesso, mas é apresentada neste texto por uma questão de completude. É uma topologia com conexão total caracterizada por apresentar uma ligação direta entre os pares de nós. Numa rede baseada nesta topologia o processo de comunicação estaria muito facilitado, pois qualquer troca de informação entre dois nós não envolveria a intervenção nenhum outro nó. A principal desvantagem desta solução reside na grande quantidade de recursos de transmissão que exige. Por exemplo, uma rede com $N$ nós baseada nesta topologia requer $N \mathrm{x}(N-1) / 2$ vias de transmissão. Quando $N \gg>1$, esse número é aproximadamente proporcional a $N x N$, o que faz com que essa topologia se torne impraticável quando o valor de $N$ ultrapassa algumas dezenas de nós [18]. 


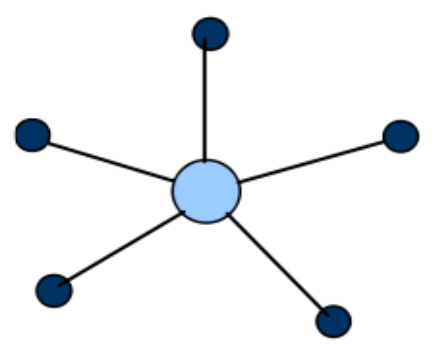

Estrela

a)

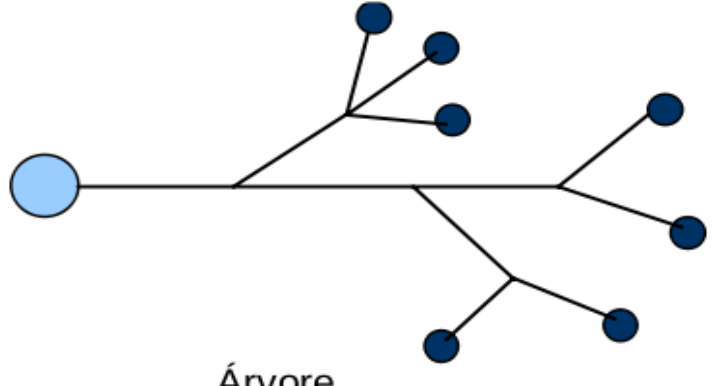

Árvore

b)

Figura 8. Grafos correspondentes às topologias em a) estrela e b) árvore.

A topologia em estrela (Figura 8 (a)) é a solução normalmente usada sempre que é necessário interligar um elevado número de nós. Nesta topologia há uma diferenciação entre as funcionalidades do nó central e as dos restantes nós, já que é este nó que controla as comunicações entre todos os outros. A existência de um nó com responsabilidade acrescida indica que nesta topologia o controle do processo de informação é centralizado [13] . A solução em estrela tem sido muito usada nas redes telefônicas, particularmente na rede de acesso, onde todo o fluxo de informação com o utilizador é controlado pelo comutador local, permitindo concentrar o equipamento sofisticado e caro na rede, e garantir que o equipamento terminal usado pelo utilizador é relativamente simples.

A topologia em árvore (Figura 8 (b)) surgiu associada a serviços distribuídos, onde o objetivo é difundir o mesmo sinal desde o nó onde é gerado (OLT) para todos os outros nós (ONUs). Esta perspectiva distributiva faz com que nos vários pontos de divisão o sinal seja repetido até atingir o equipamento terminal do usuário. Esta solução foi desenvolvida no âmbito das redes de distribuição de televisão por cabo. Com o desenvolvimento tecnológico foi possível introduzir nestas redes um canal ascendente, garantindo, assim, a bidirecionalidade requerida pelos serviços interativos como serviço telefônico e o acesso à Internet. Entretanto, destaca-se que nestas redes o meio de transmissão também é compartilhado por todos os usuários, diferenciando-se assim da simplicidade da rede em anel (Figura 7 (b)). Como conseqüência, também surge o problema da colisão entre os sinais enviados pelos vários usuários (Figura 9) e a necessidade de usar algoritmos de alocação de tempos apropriados para regular o processo de comunicação [10] . 


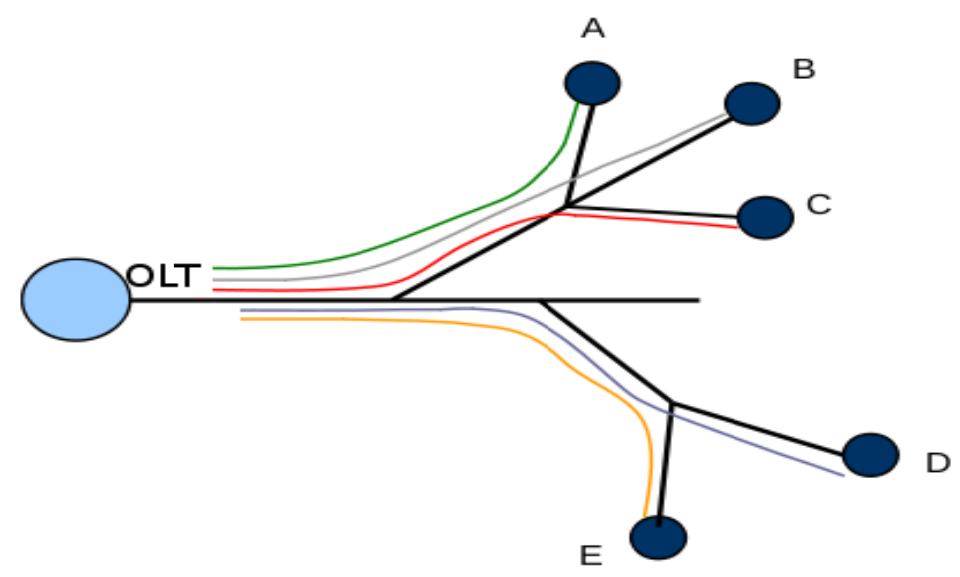

Figura 9. Colisão entre os sinais gerados por cinco utilizadores numa rede em árvore.

\subsection{O problema de Otimização}

A formulação de um problema de otimização qualquer envolve a composição de uma funçãoobjetivo que relacione as diferentes variáveis iniciais ou de contorno. Otimizar um determinado problema consiste em identificar uma das soluções possíveis, ou os respectivos valores para as variáveis consideradas a resposta do problema, que maximize ou minimize o valor da função-objetivo, respeitando as restrições [19] .

Um problema para a otimização é a disponibilidade de rotas onde se deve fazer o cabeamento, pode acontecer que a passagem dos cabos seja realizada por rotas inviáveis, ou que o menor caminho não preveja o crescimento da rede. Muitas vezes, uma rota instalada acaba sendo uma solução não duradora, ou ótima, temporalmente.

Com otimização nas redes existentes, pode-se reduzir os custos associados com perdas no sistema. Alternativamente, podem ser consideradas novas rotas, novos equipamentos ou a instalação de novos nós de distribuição, como forma de aliviar a perda do sinal ou baixo QoS [20] .

\subsection{Orçamento de potência}

O orçamento de potência óptica em um enlace de transmissão por fibra óptica é a diferença entre a potência do sinal transmitido e as perdas produzidas pelos vários mecanismos que introduzem a 
atenuação no enlace, levando-se em conta a mínima potência que pode ser recebida no receptor e uma margem para situações de perda não previstas inicialmente. Este cálculo representa o máximo e o mínimo de perda aceitável para as combinações de componentes aplicados.

A perda para o orçamento de potência óptica é definida em $\mathrm{dB}$, entre os pontos de referência (i.e. entre o transmissor, $\mathrm{Tx}$, e o receptor, $\mathrm{Rx}$ ), na subida e descida do sinal. Isto inclui a perda devido ao comprimento da fibra e aos componentes ópticos passivos (divisores, conectores ópticos, etc.) colocados no caminho. A quantidade de perda não tem o mesmo valor na direção downstream e upstream [1][13] em função das atenuações diferentes para os comprimentos de onda que transportam os sinais descendentes e ascendentes. A perda óptica de um caminho da OLT à ONU é calculada adicionando as perdas de todos os componentes ópticos [9].

Os casos piores e melhores das perdas do caminho óptico são calculados, respectivamente, somando as perdas por atenuação, perdas por conexão e as perdas por derivação em cada divisor. Este cálculo tem por objetivo verificar se o enlace que está sendo projetado apresenta condições de dar suporte ao conjunto transmissor/ receptor. Uma margem adicional pode ser incluída nos cálculos, como previsão para futuras divisões de potência (correspondendo ao aumento do número de usuários da rede), envelhecimento dos componentes, perdas não previstas no projeto, etc.

\subsection{Aspectos econômicos}

O progresso tecnológico na transmissão por fibra óptica tornou tecnicamente possível a disponibilização de uma maior largura de banda em redes de acesso. Desta forma, não há nenhuma razão técnica impedindo que as pessoas tenham conexões gigabit usando os sistemas de acesso óptico que estão no mercado atualmente. Com tecnologias como GPON os obstáculos são essencialmente econômicos. Igualmente em redes metropolitanas, equipamentos DWDM comercialmente disponíveis poderiam tecnicamente entregar uma banda de aproximadamente $1 \mathrm{~Tb} / \mathrm{s}$ para cada CO. Portanto, um foco importante para a pesquisa atual em comunicações por fibra óptica é a redução dos custos [5] .

As operadoras de rede ao redor do mundo estão implantando rapidamente serviços de banda larga na residência dos consumidores. A intenção é que a banda larga trará benefícios à sociedade como um todo, um papel vital para as operadoras de rede, compensando o declínio das receitas da telefonia fixa 
tradicional. Ao implantar redes banda larga, as operadoras estão aumentando significativamente a capacidade de suas redes, e há obviamente um aumento nos custos associados.

O custo unitário da banda tem diminuído com o passar dos anos visto que a tecnologia tem avançado e o volume de produtos fabricados aumentado. O custo de componentes eletrônicos e ópticos (lasers, fibra óptica, etc.) segue uma redução de custos em relação ao volume conhecida como Learning Curve [13] .

Com a diminuição da receita provinda da telefonia fixa, as operadoras têm como opção oferecer novos serviços, fazendo com que o usuário gaste mais com serviços de telecomunicações, e ter estratégias de redução de custo de banda dentro de sua rede.

Para o crescimento da banda permanecer economicamente sustentável, as operadoras de rede de comunicação querem obter seu retorno no capital investido durante o longo período de crescimento. Por tanto, um estudo de otimização de implementação muito importante, para evitar a necessidade de minimização de custo, sem critérios.

\subsection{Algoritmos genéticos}

Embora seja mais detalhado no capítulo 4, a título de síntese, um AG (Algoritmo Genético) inicia gerando um número pré-definido de soluções iniciais, aleatoriamente, formando a população inicial. Computacionalmente, a implementação deste procedimento é muito simples, em função de existirem boas funções geradoras de números aleatórios na maioria das ferramentas de programação. Este procedimento torna-se adequado à codificação dos strings (cromossomo), sendo assim tal forma de codificação será muito útil para a representação da estrutura de rede óptica [17] .

Para o emprego do AG em problemas de otimização com restrições, como o de redes ópticas passivas, após definida a codificação dos strings (cromossomo), compõe-se uma função de avaliação para os indivíduos, a partir da função objetivo original do problema.

Para que esta função de avaliação considere as restrições originais do problema, freqüentemente são empregados fatores de penalização [20]. Ao invés disso, neste trabalho são utilizados nós utilizamos pesos para prioridade de avaliação da função aptidão [20] 
O estudo prévio de topologias antes de efetuar o cabeamento de redes é muito importante, pois permite minimizar os custos, garantir qualidade de serviço e o orçamento de potência. Deve-se dizer que a definição da topologia tem forte influência no planejamento da rede óptica e constitui um dos principais desafios desse trabalho. Alguns fatores que influenciam na escolha da topologia são: a distribuição geográfica da demanda (determinará o número e o posicionamento dos divisores ópticos), custo de cabo a ser utilizado e metros de instalação de fibra óptica. Esses fatores foram identificados como as condições de contorno do problema e incluídos dentro da função aptidão para a análise e avaliação de indivíduos que formaram a solução de nosso problema. 


\section{Capítulo 3 - Estudo de Topologias para Redes Ópticas Passivas.}

Este capitulo descreve o estudo preliminar das topologias mais utilizadas em redes de computadores, realizado como ponto de partida de nosso trabalho. Com base nesses resultados serão planejadas as redes maiores, para tanto, com uso de algoritmos genéticos.

Uma distribuição otimizada de divisores de potência tem início com a escolha da topologia a ser empregada. Essa topologia indicará o comprimento (em quilômetros) e a metragem de cabos que farão a ligação entre a OLT e cada uma das ONUs. Posteriormente, devemos definir as quantidades e os tipos de divisores a serem utilizados.

Uma análise realizada em redes de acesso instaladas mostrou que muitas das fibras implantadas não são necessárias [5] [18] . Isso ocorre porque não houve nenhum estudo e otimização, ou seja, o cabeamento ocorreu apenas em função da necessidade imediata dos usuários. Esse fato teve como conseqüência o crescimento desordenado e não planejado da rede.

Uma limitação muito grande é o alcance físico e lógico das redes ópticas. No caso da primeira, o alcance depende fortemente da topologia e distribuição dos elementos ópticos. Os divisores ópticos podem ainda introduzir uma atenuação adicional nos comprimentos de ondas utilizados, além da redução de potência devida à divisão da mesma por elevado número de ONUs ligadas a cada OLT. Além disso, a baixa sensibilidade dos receptores também limita o comprimento dos enlaces.

Neste trabalho, abordamos as três topologias físicas mais importantes e utilizadas em redes ópticas já instaladas: barramento, árvore e anel. Essas topologias são ilustradas em forma de diagramas de blocos na Figura 10. 


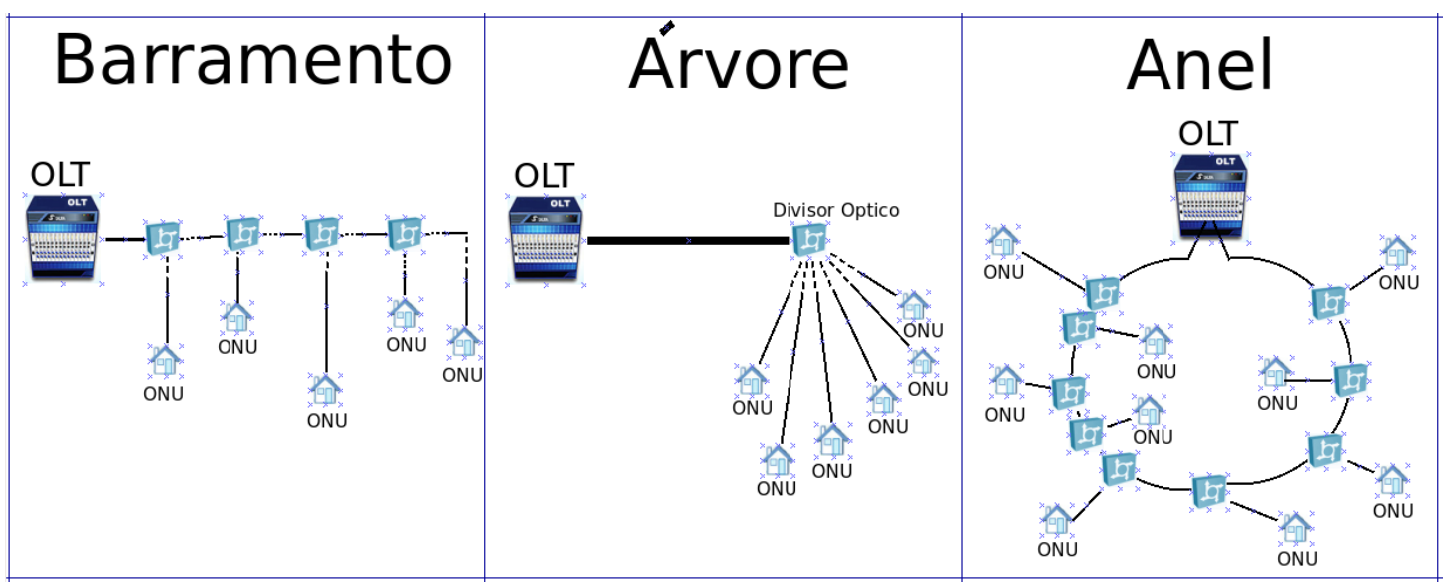

Figura 10. Topologias básicas para redes ópticas.

Para a escolha da topologia que tenha maior margem de potência e menor custo, devemos garantir a acessibilidade e uma mínima margem de potência positiva para cada uma das ONU.

Para analisar as três topologias mencionadas utilizamos inicialmente um cenário físico com apenas um nível de derivação. Posteriormente, para realizar a comparação, fixamos o posicionamento da OLT e das ONUs, encontramos a quantidade de cabos necessária e calculamos orçamento de potência para cada topologia. O exemplo poderia ser aplicável a uma rede ao longo de uma rodovia. A distribuição física das três topologias é ilustrada na Figura 11.

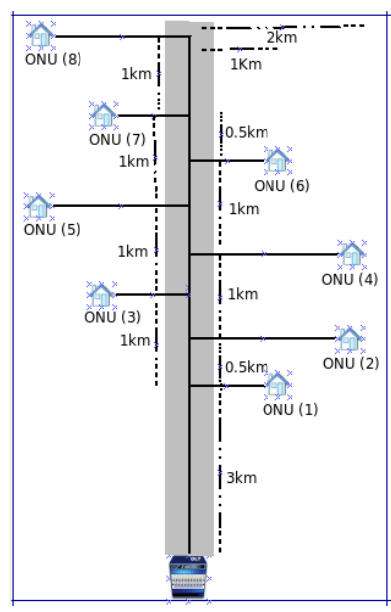

a)

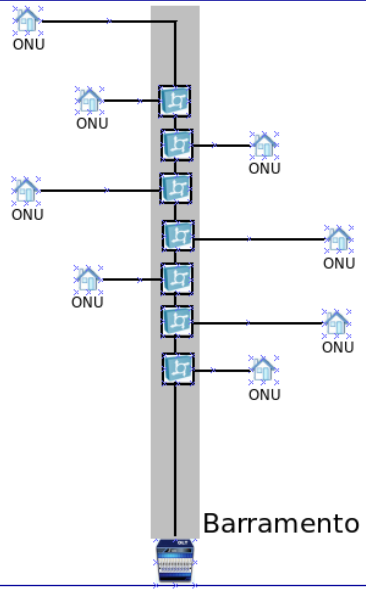

b)

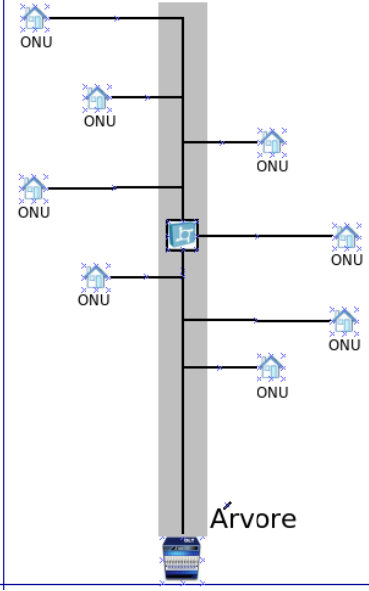

c)

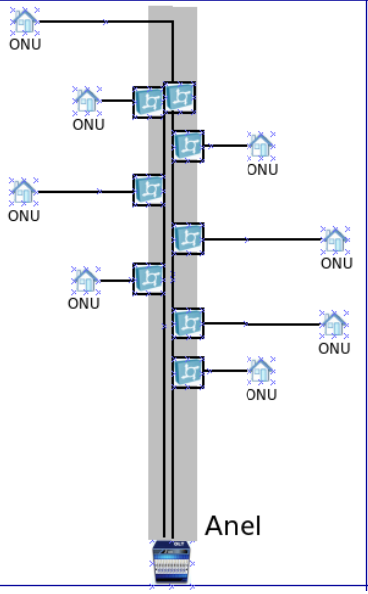

d)

Figura 11. Distribuição física para o exemplo adotado com apenas um nível de derivação.

a) metragem , b)topologia em barramento , c)topologia em árvore , d) topologia em anel. 
Para avaliar as redes em termos de orçamento de potência podemos usar, como figura de mérito, a margem de potência, dada por :

$$
M=P_{T x, O N U}-P_{T}-S_{R x, O L T}
$$

onde $\mathrm{P}_{\mathrm{Tx}, \mathrm{ONU}}$ é a potência óptica transmitida pela $\mathrm{ONU}$, em $\mathrm{dBm}$, e $\mathrm{S}_{\mathrm{Rx}, \mathrm{OLT}}$ é a sensibilidade do receptor da OLT em dBm e o valor de $\mathrm{P}_{\mathrm{T}}$ é a perda total desde o transmissor até o receptor dada por:

$$
P_{T}=2 P_{C}+P_{D, k}+2 k P_{C}+\sum_{i=1}^{k-1}\left(P_{T_{i}}+\alpha_{1310} l_{i}\right)
$$

onde $\mathrm{P}_{\mathrm{C}}$ é a perda por conexão óptica, $\mathrm{P}_{\mathrm{D}, \mathrm{k}}$ é a perda na derivação do k-ésimo divisor, $\mathrm{P}_{\mathrm{Ti}}$ é a perda na transmissão pelo i-ésimo divisor, ${ }_{1310}$ é a atenuação da fibra, em dB/km, e $\mathrm{l}_{\mathrm{i}}$ é a distância entre o i-ésimo divisor e o anterior. As perdas são dadas em dB e os comprimentos em km.

Utilizaremos dados padrões para as simulações de orçamento de potência, como indicado na Tabela 2 .

Tabela 2. Perdas padrão para dispositivos ópticos passivos [5] .

\begin{tabular}{|l|l|}
\hline Medidas & Valor \\
\hline $\begin{array}{l}\text { Coeficiente de atenuação da fibra monomodo para o comprimento de } \\
\text { onda } 1310 \mathrm{~nm} \text { (upstream) }\end{array}$ & $0,4 \mathrm{~dB} / \mathrm{km}$ \\
\hline $\begin{array}{l}\text { Coeficiente de atenuação fibra monomodo para o comprimento de onda } \\
1550 \mathrm{~nm} \text { (downstream) }\end{array}$ & $0,2 \mathrm{~dB} / \mathrm{km}$ \\
\hline Divisor óptico passivo 2 portas & $3,0 \mathrm{~dB}$ \\
\hline Divisor óptico passivo 4 portas & $6,0 \mathrm{~dB}$ \\
\hline Divisor óptico passivo 8 portas & $9,0 \mathrm{~dB}$ \\
\hline Potencia Óptica da ONU & $2 \mathrm{dBm}$ \\
\hline Sensibilidade na OLT & $-29,0 \mathrm{dBm}$ \\
\hline Atenuação máxima por conexão & $0,2 \mathrm{~dB}$ \\
\hline
\end{tabular}


Para obter os resultados utilizamos apenas o comprimento de onda ascendente, pois este sofre maiores perdas. Isso pode ser verificado na curva característica de atenuação para fibras ópticas.

A Figura 12 ilustra a distância entre a OLT e cada uma das ONU, que utilizamos para o cálculo do orçamento de potência e na Figura 13 apresentamos os comprimentos totais de cabeamento. Deve-se perceber que as topologias em anel e barramento têm a mesma distância entre as ONUs e a OLT, apesar da primeira ter maior quantidade de cabeamento que a segunda. Isso é conseqüência do cabo duplo utilizado. Na Tabela 3 apresentamos um resumo das distâncias e número de divisores obtidos para os comprimentos e número de divisores usados.

Tabela 3. Resumo de resultados numéricos para as três topologias, usando divisores simétricos.

\begin{tabular}{|l|l|l|}
\hline \multicolumn{1}{|c|}{ Qualificação física } & $\begin{array}{l}\text { Quantidade de Cabo de } \\
\text { Fibra Óptica }\end{array}$ & Número de Divisores \\
\hline Anepologia & 56,5 & 8 divisores (2 portas) \\
\hline Árvore & 56,5 & 1 divisor (8 portas) \\
\hline Barramento & 50.5 & 7 divisores (2 portas) \\
\hline
\end{tabular}

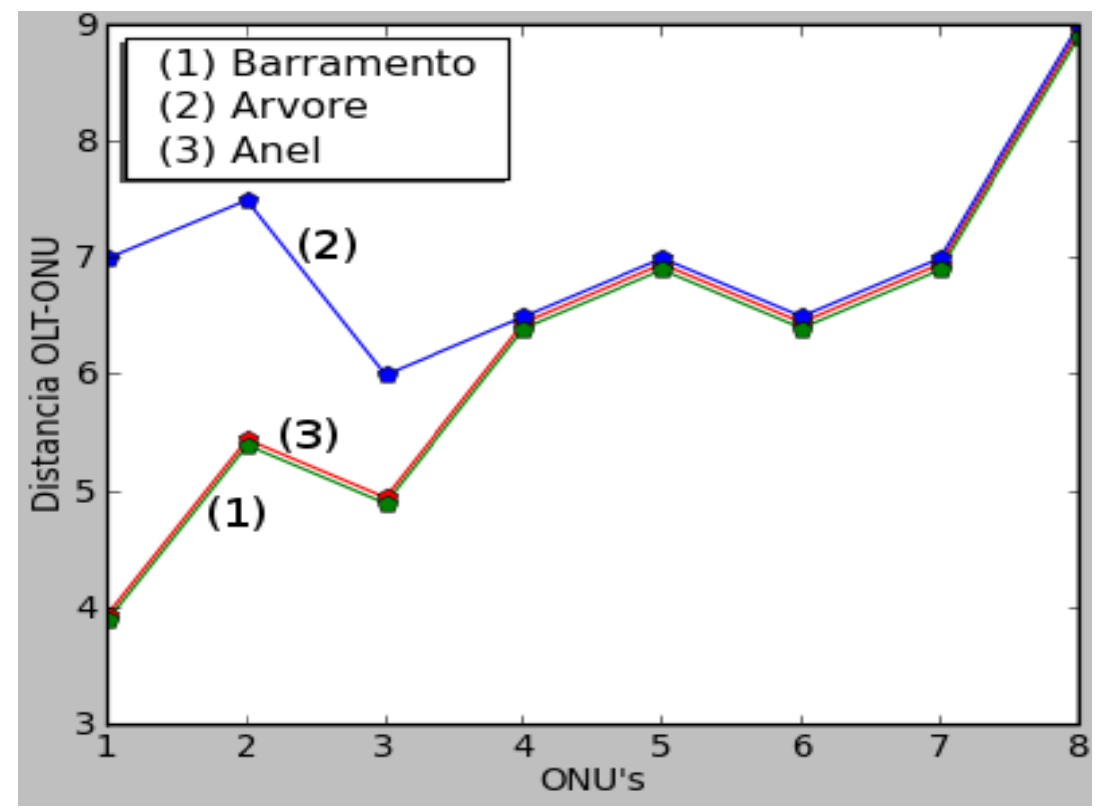

Figura 12. Comprimento de cabo desde a OLT a cada ONU. 
Apresentamos na Figura 13 os valores de margem de potência para cada ONU, simulados para todas as topologias escolhidas, utilizando apenas divisores simétricos.

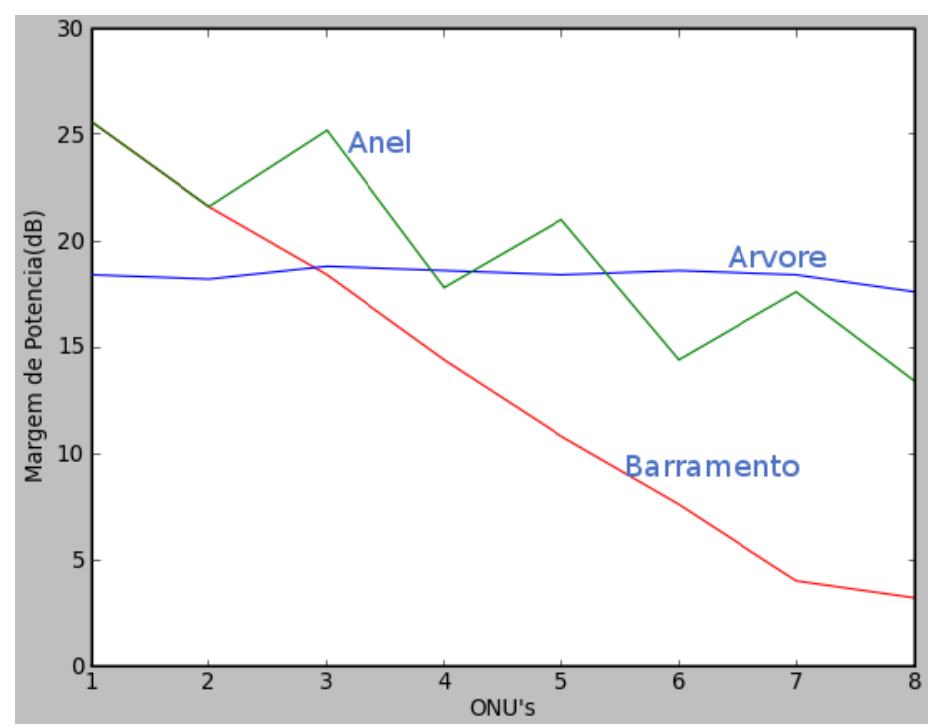

Figura 13. Orçamento de potência para as topologias, usando apenas divisores simétricos.

Pode-se verificar que a curva para a topologia em árvore apresenta a melhor e mais homogênea margem de potência para o cenário escolhido enquanto a topologia em barramento apresentou um decréscimo significativo à medida que mais ONUs são percorridas.

Os divisores com fração de derivação têm sido bastante utilizados em topologias em anel e barramento para balancear a potência e melhorar o desempenho, facilitando a instalação e o controle pela operadora.

Para comparação utilizaremos divisores assimétricos nas topologias anel e barramento. Os valores das porcentagens, estimados para ótimo desempenho manualmente, são indicados na Tabela 4. 
Tabela 4. Porcentagens de derivação assimétrica, para as topologias em barramento e anel.

\begin{tabular}{|l|l|l|}
\hline & Barramento \% Derivação & Anel \% Derivação \\
\hline DIV. ONU 1 & $7 \%$ & $18 \%$ \\
\hline DIV. ONU 2 & $10 \%$ & $27 \%$ \\
\hline DIV. ONU 3 & $11 \%$ & $17 \%$ \\
\hline DIV. ONU 4 & $16 \%$ & $45 \%$ \\
\hline DIV. ONU 5 & $21 \%$ & $30 \%$ \\
\hline DIV. ONU 6 & $29 \%$ & $100 \%$ \\
\hline DIV. ONU 7 & $47 \%$ & $43 \%$ \\
\hline DIV. ONU 8 & & $100 \%$ \\
\hline
\end{tabular}

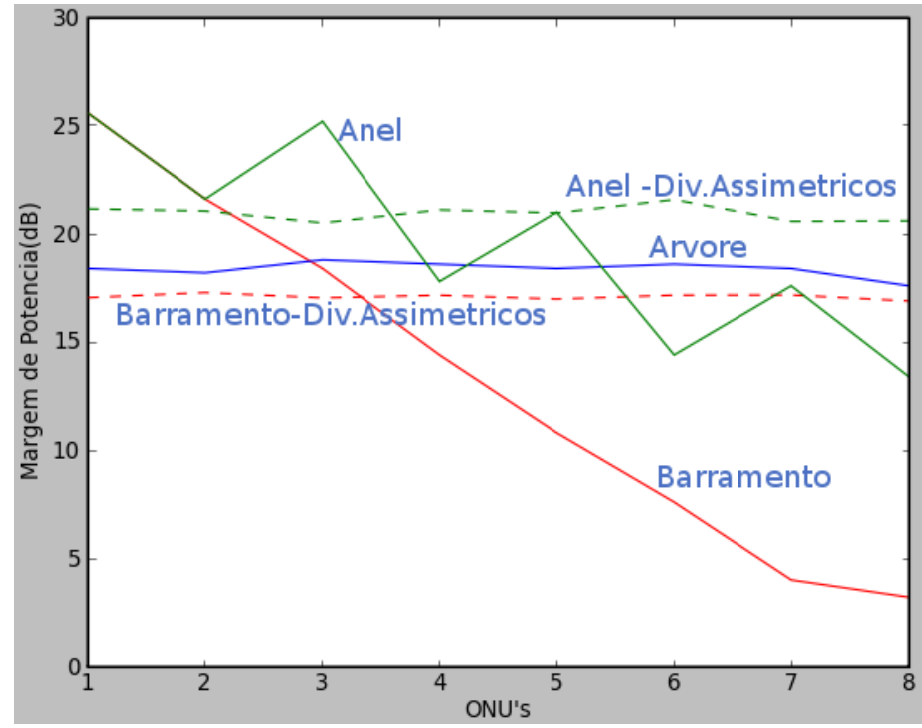

Figura 14. Orçamento de potência para as topologias, usando também divisores assimétricos.

Neste caso, a topologia em anel com divisores assimétrico apresenta a melhor resposta, seguida da topologia em árvore e barramento com divisores assimétricos. Apesar desta primeira utilizar a maior quantidade de divisores e cabeamento. Além disso, o custo da rede será influenciado. A Tabela 5 
mostra os resultados do orçamento de potência, os valores de média, mínima e máxima da margem de potência são exibidos

Tabela 5. Margens de potência média, mínima e máxima para todas as topologias.

\begin{tabular}{|l|l|l|l|l|}
\hline $\begin{array}{l}\text { Topologia } \\
\text { Orçamento } \\
\text { Potencia }\end{array}$ & $\begin{array}{l}\text { Média de de } \\
\text { Margem de } \\
\text { Potencia } \\
(\mathrm{dB})\end{array}$ & $\begin{array}{l}\text { Margem } \\
\text { Mínima de } \\
\text { Potência } \\
(\mathrm{dB})\end{array}$ & $\begin{array}{l}\text { Margem Máxima de } \\
\text { Potência (dB) }\end{array}$ & $\begin{array}{l}\text { Variação (Máx- } \\
\text { Mín) (dB) }\end{array}$ \\
\hline Anel & 19,5 & 13,4 & 25,6 & 12,2 \\
\hline Árvore & 18,3 & 17,6 & 18,8 & 1,2 \\
\hline Barramento & 13.2 & 3,2 & 25,6 & 22,4 \\
\hline Anel Div. Assimétrico & 21,5 & 20,5 & 20,9 & 0,4 \\
\hline $\begin{array}{l}\text { Barramento Div. } \\
\text { Assimétrico }\end{array}$ & 17,0 & 16,8 & 17,3 & \\
\hline
\end{tabular}

Cada topologia apresenta vantagens e desvantagens. Pode-se dizer que cada topologia tem utilizações distintas, dependendo do tipo da prioridade de otimização, custo, melhores margens de potência, menor cabeamento ou maior facilidade de controle que estamos buscando.

Antes de fazer uma abordagem geral, resumiremos as vantagens e desvantagens encontradas com os vários testes realizados para cada topologia. No caso das topologias em anel e barramento também utilizamos divisores assimétricos.

- Topologia em anel: A principal motivação para o uso desta topologia é a segurança oferecida em cenários onde a continuidade da comunicação é muito importante. No caso do exemplo anterior, o número de divisores e a quantidade de cabos foi maior, resultando no encarecimento da implantação. Outro inconveniente é que esta topologia normalmente usa um cabo duplo no anel, o que aumenta ainda mais o custo da rede, embora adicione proteção à mesma [20] .

Apesar destas desvantagens, as simulações mostraram que a utilização em conjunto com divisores assimétricos apresenta melhores margens de potência quando se tem um baixo 
número de ONUs na rede. No entanto, é mais sensível ao aumento da quantidade de ONUs do que a configuração em árvore.

- Topologia em Barramento: A vantagem desta topologia é a economia de potência, em casos onde os grupos de clientes estão muito distantes entre eles e da OLT. Essa foi a segunda melhor opção, perdendo apenas para a topologia em anel utilizando divisores assimétricos.

Permite também um melhor controle da rede [5] e o crescimento futuro. Além disso, foi a topologia que utilizou a menor quantidade de cabos, porém, o número de divisores foi maior que a topologia em árvore.

- Topologia em Árvore: Minimiza o número de divisores, devido ao fato deles serem simétricos, mas a quantidade de cabos é maior que na topologia em barramento e igual ou menor que a topologia em anel. 


\section{Capítulo 4 - Algoritmos Genéticos}

Os Algoritmos Genéticos (AG), desde os conceitos básicos apresentados por Holland , vêm sendo utilizados em várias áreas de pesquisa e em situações do mundo real com bons resultados, e como é apresentado na literatura tem sido muito utilizado em redes de computadores [17] .

As utilizações dos AGs são relacionadas de uma forma ou de outra a uma análise multidimensional, onde se busca conseguir uma solução global otimizada. Geralmente o material genético é utilizado para codificar os valores dos vários parâmetros que definem o espaço de resultados admissíveis, e procura-se encontrar o valor destes parâmetros (valor dos indivíduos) que soluciona um certo problema de otimização.

Para solucionar o problema de otimização na distribuição de divisores de potência em redes ópticas passivas foi escolhida a teoria de grafos em conjunto com algoritmos genéticos (Figuras 16). Em nosso problema tentamos otimizar a quantidade de cabeamento, número de divisores, orçamento de potência e custo de implementação.

O uso de grafos pode ser levado em consideração também em problemas de roteamento de tráfego em redes de comutação, tais como custo de conversão e tempo de latência. Todos os parâmetros podem ser analisados e a melhor rota para o tráfego de dados entre nós poder ser obtida através de algoritmos apropriados. Mas não serão tratados neste trabalho.

Algoritmos Genéticos são inspirados na teoria da evolução de Darwin e utilizam um processo evolutivo. O algoritmo começa com um conjunto de soluções (representadas por indivíduos) o conjunto de estes é chamado população. Soluções de uma população são utilizadas para formar uma nova população. Isto é motivado pela expectativa de que a nova população seja melhor que a primeira. De acordo com sua adequação, quanto melhores, mais chances de reprodução terão. Esse processo é repetido até que alguma condição seja satisfeita (por exemplo o aperfeiçoamento da melhor solução ou limite de iterações). O fluxograma da figura 15 ilustra o processo AG aplicado ao problema aqui apresentado. 


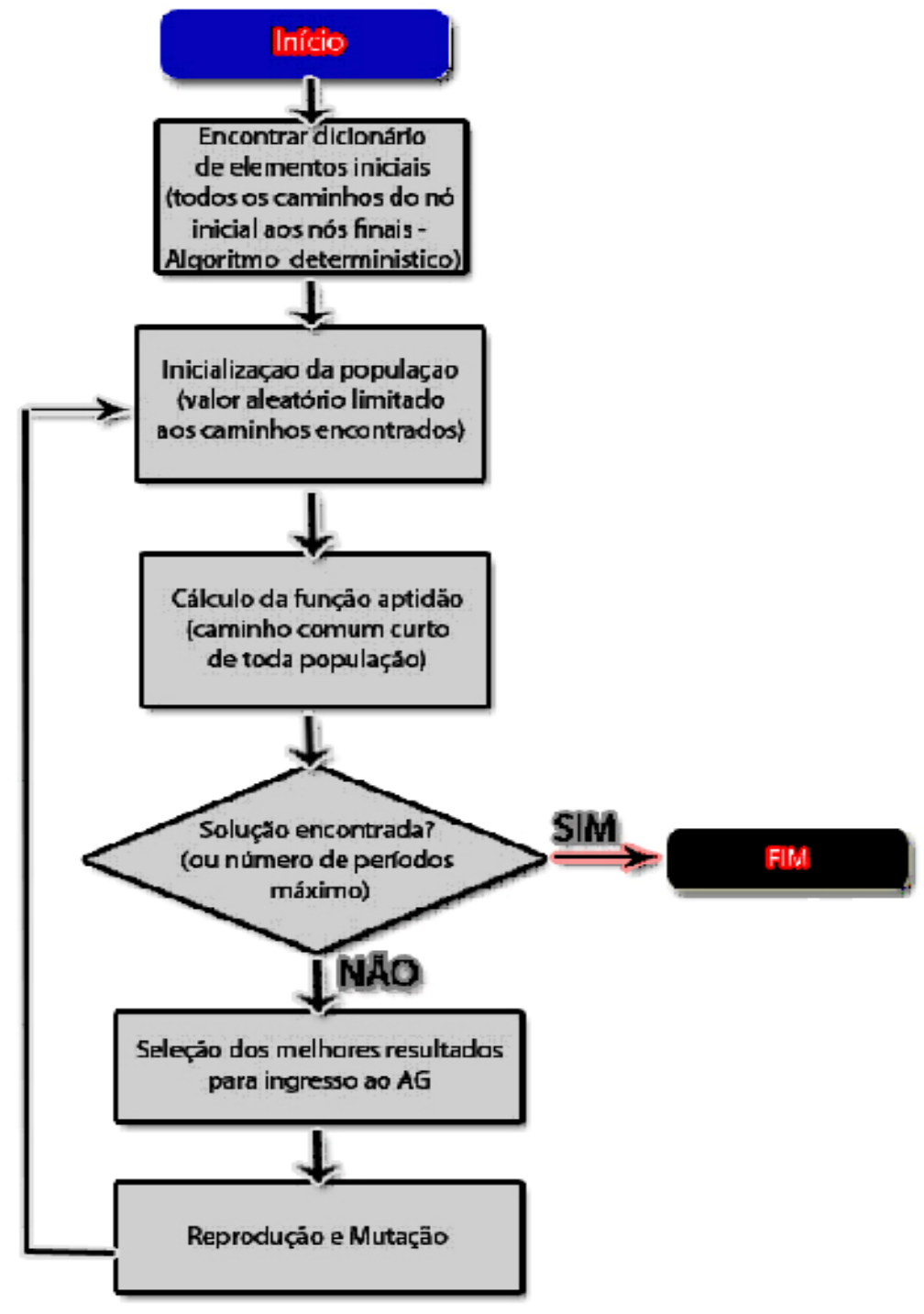

Figura 15. Fluxograma do algoritmo genético.

No fluxograma da Figura 15, observa-se que cada iteração do algoritmo genético corresponde à aplicação de um conjunto de quatro operações básicas: cálculo de aptidão (fitness), seleção, cruzamento e mutação. Ao fim destas operações cria-se uma nova população, chamada de geração que, espera-se, represente uma melhor aproximação da solução (posicionamento dos divisores e geração da topologia) do problema de otimização que a população anterior. A população inicial é gerada de forma quase totalmente aleatória (seguindo uma ordem direita, uma ordem esquerda e 28 gerações aleatórias). A função aptidão bruta de um indivíduo da população é medida por uma função de erro, também chamada de função objetivo do problema de otimização que se mostra no losango no 
fluxograma, a função também tem critérios de parada do algoritmo em geral (gerações que não apresentam otimização), esta é usada para limitar o número de gerações.

Diante das opções de otimização de rede buscada, sua modelagem requer limites e restrições impostas às variáveis de entradas. A Norma ITU-T para redes GPON limita em $20 \mathrm{~km}$ a diferença entre as distâncias físicas das ONUs e projetos de hardware e software permitem até 128 ONUs ligadas por OLT. A OLT está localizada na central da operadora e é gerenciada diretamente, enquanto as ONUs são fixadas nas casas dos usuários (FTTH) e são monitoradas pela OLT.

Para unificar os termos faremos notações usando grafos não dirigidos, onde cada esquina representa um nó do grafo e cada arco um caminho possível entre os nós (Figura 16). No caso real, um arco seria uma rua que possui informações como espaçamento entre os nós, nome da via e existência de instalações anteriores por onde se poderia passar o cabeamento.

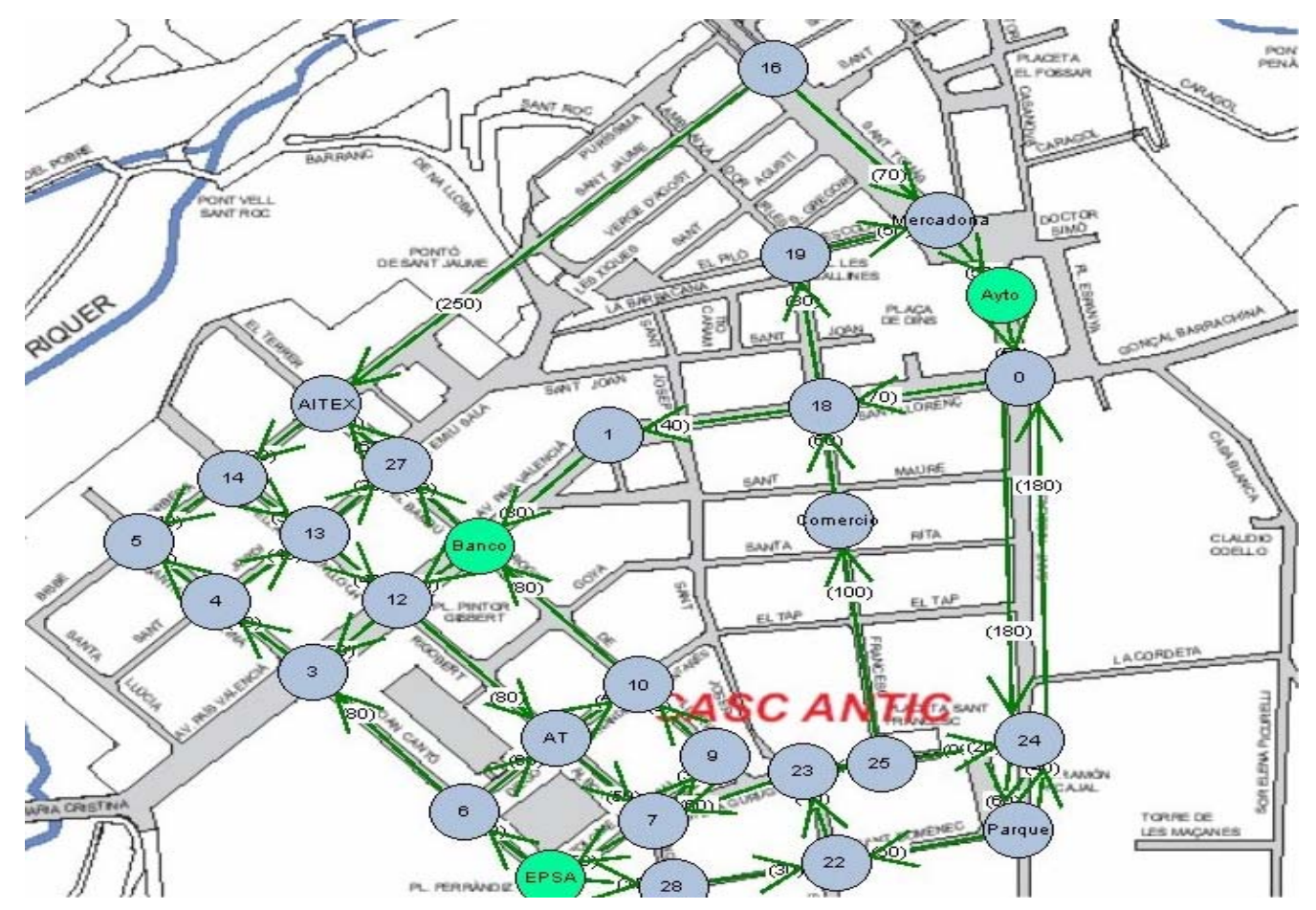

Figura 16. Grafo inicial, representação da rede.

O uso de algoritmos genéticos tem certas vantagens, como por exemplo, o menor tempo necessário para encontrar a solução em relação os algoritmos de tipo polinomial e serem opções para problemas que não têm solução convencional. No entanto, possuem também desvantagens como convergir para uma solução de máximo local, dando uma falsa resposta ótima e necessitar de uma população inicial, 
que deve ser uma solução possível ao problema (não necessariamente a melhor). O inconveniente da falsa resposta ótima pode ser evitado com um maior número de mutações na população, mas a necessidade de geração da população inicial constituirá um problema facilmente solucionável. Para tanto, precisaremos de algoritmos adicionais para geração de cromossomos por tanto indivíduos. Como se mostra no procedimento na Tabela 6.

A população inicial que utilizamos é um conjunto indivíduos formados por um grupo de caminhos entre OLT e as ONUs (cromossomo é apenas um caminho para uma ONU) e para isso, utilizaremos o algoritmo recursivo polinomial [17]. No entanto, como descrito anteriormente, esta não é uma boa opção pelo tempo que precisa para convergir, mas pode ser implementado marcando os nós percorridos e procurando todos os nós em uma única execução. Dessa forma cada nó é analisado apenas uma vez e o número de processos é reduzido para $\mathrm{M} \leq \mathrm{N}$, onde $\mathrm{N}$ é o número de nós que tem o grafo, para gerar cada individuo.

Tabela 6. Pseudocódigo do algoritmo que gera os indivíduos da população inicial.

Arranjo de caminhos $=[]$

Filhos Ordem Esquerda (OLT)

Para todos os filhos da OLT

Percorrer esquerda (filho[enésimo])

//Definição da função "percorrer"

Função Percorrer esquerda (Nó)

Se filho é ONU

Marcar Caminho (Arranjo de caminhos)

Se Arranjo de caminhos esta completo (Arranjo de caminhos)

Parar Percorrer esquerda

Caso Contrario

Filhos= Filhos Ordem Esquerda de (Nó)

Para Todos os Filhos

Percorrer esquerda(filho[enésimo])

O algoritmo anterior é recursivo e deve usar vários tipos de percurso: esquerdo, direito e aleatório.

Em nosso caso, foram realizadas simulações com 30 iterações para criar a primeira população no 
intuito de obter uma melhor estimativa da população inicial. O número de processo para cada iteração é:

30xM onde $\mathrm{M} \leq \mathrm{N}$ e $\mathrm{N}$ é o número de nós do grafo.

A estrutura utilizada é: um único caminho entre a OLT e cada ONU é denominado cromossomo, o conjunto de caminhos, um para cada ONU, é o indivíduo, e o conjunto de indivíduos forma a população. Nossa primeira população contará aproximadamente com 30 indivíduos, cada um deles formado por " $n$ " cromossomos, que corresponde ao número de ONUs.

Um exemplo de um indivíduo (conjunto de cromossomos) da primeira população obtida é ilustrado na Figura 17.

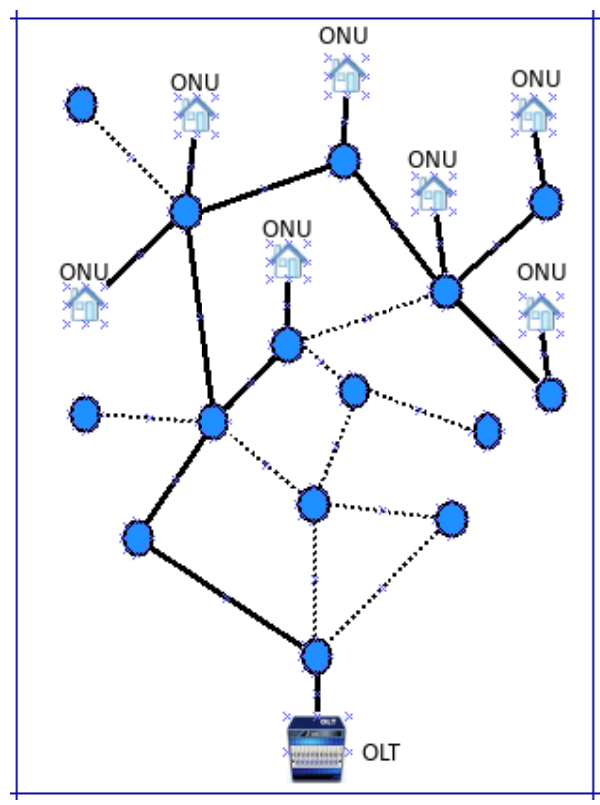

Figura 17. Exemplo de um indivíduo da população inicial.

O tipo de representação dos cromossomos que usaremos é inteiro, por ser o mais conveniente para uso em grafos [19]. Assim, seja o exemplo de cromossomo [N1,N2,N3,N4,N11,...., Nx], onde N1 é a posição da ONU e $N x$ é a posição da OLT. Os valores dos nós intermediários $(\mathrm{N} 2, \mathrm{~N} 3, \mathrm{~N} 4$...) representam a rota entre a OLT e a ONU dentro do grafo, como se ilustra graficamente na figura 18. 


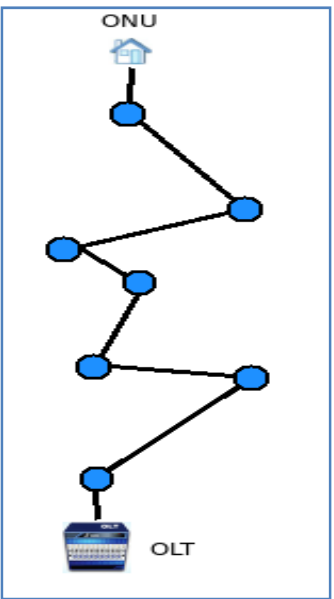

Figura 18. Cromossomo de uma rede óptica passiva no AG proposto.

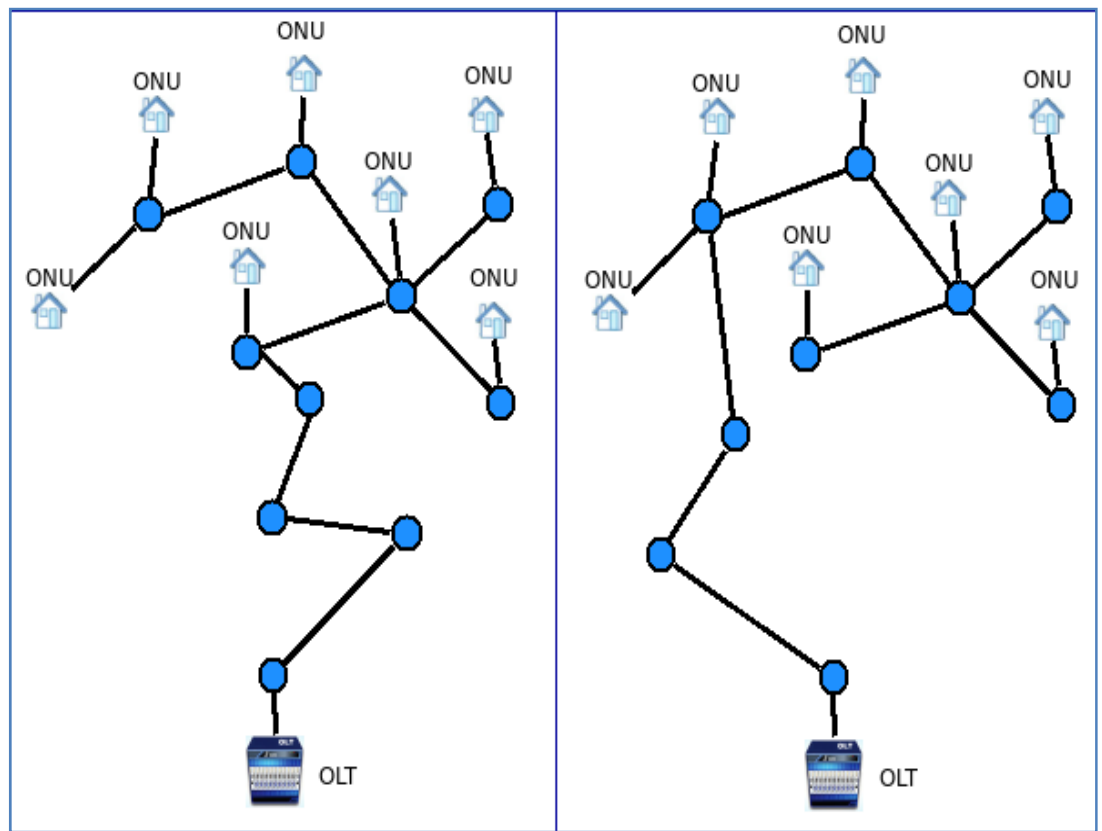

Figura 19. Exemplo de dois indivíduos da população de uma rede óptica passiva no AG proposto.

As distâncias entre a OLT e as ONU ainda não foram avaliadas até o presente momento, pois estas possivelmente possuem rotas mais longas dentro do grafo. Posteriormente, cada caminho será otimizado usando algoritmos genéticos para cada topologia. 
Para alcançar o número máximo de 128 ONUs ligadas a cada OLT devemos utilizar divisores ópticos simétricos de "n" portas no segundo nível, em todas as topologias, para se ter pelo menos dois níveis de derivação, como é ilustrado na Figura 20.

O objetivo do algoritmo genético é gerar uma topologia, calcular o número de divisores, suas posições, os tipos ou classes e a quantidade em quilômetros de cabos utilizados para, posteriormente,

realizar cálculo do potência.

Figura 20. Topologias hibridas com dois níveis de derivação.

Outro parâmetro de entrada para o algoritmo genético é o número máximo e mínimo de ONUs que podem ser ligadas a cada divisor do segundo nível, pois isto influencia na escolha dos divisores simétricos padrões.

A definição do número de portas dos divisores simétricos do segundo nível é muito importante, podendo ser utilizadas para o planejamento de crescimento da rede. Para exemplificar, vamos utilizar o número máximo de 28 ONUs para um divisor de 32 portas. Desta forma, 4 portas ficam disponíveis para o futuro crescimento da rede, o que implica em $87.5 \%$ de uso e $12.5 \%$ de projeção. Outro ponto importante é o número mínimo de ONUs que podem ser agrupadas, como ilustramos na Figura 22 (a) e (b) .

O número mínimo de ONUs que podem ser ligados a um divisor do segundo nível é muito importante para se saber a quantidade de divisores que serão utilizados. A Figura 21 (a) ilustra um exemplo extremo da escolha do número mínimo de ONUs ligadas por divisor, cujo máximo é fixado em 7 e o mínimo em 5. O algoritmo irá agrupar minimamente 5 ONUs por divisor simétrico e incluirá também as 2 ONUs mais afastadas para completar este limite. Se o valor mínimo fosse alterado para 
4, aconteceria como apresentamos na Figura 21 (c), nota-se apenas as ONUs que estão próximas são agrupadas, deixando para outro grupo as duas mais afastadas. Então, quanto maior for o intervalo entre o número máximo e mínimo de ONUs ligadas por divisor, o resultado obtido tende a minimizar a quantidade de cabos, porém, ocorre um aumento no número de divisores necessários. Entretanto, quanto menor for este intervalo, o algoritmo tende a otimizar o número de divisores aumentando a quantidade de cabo.

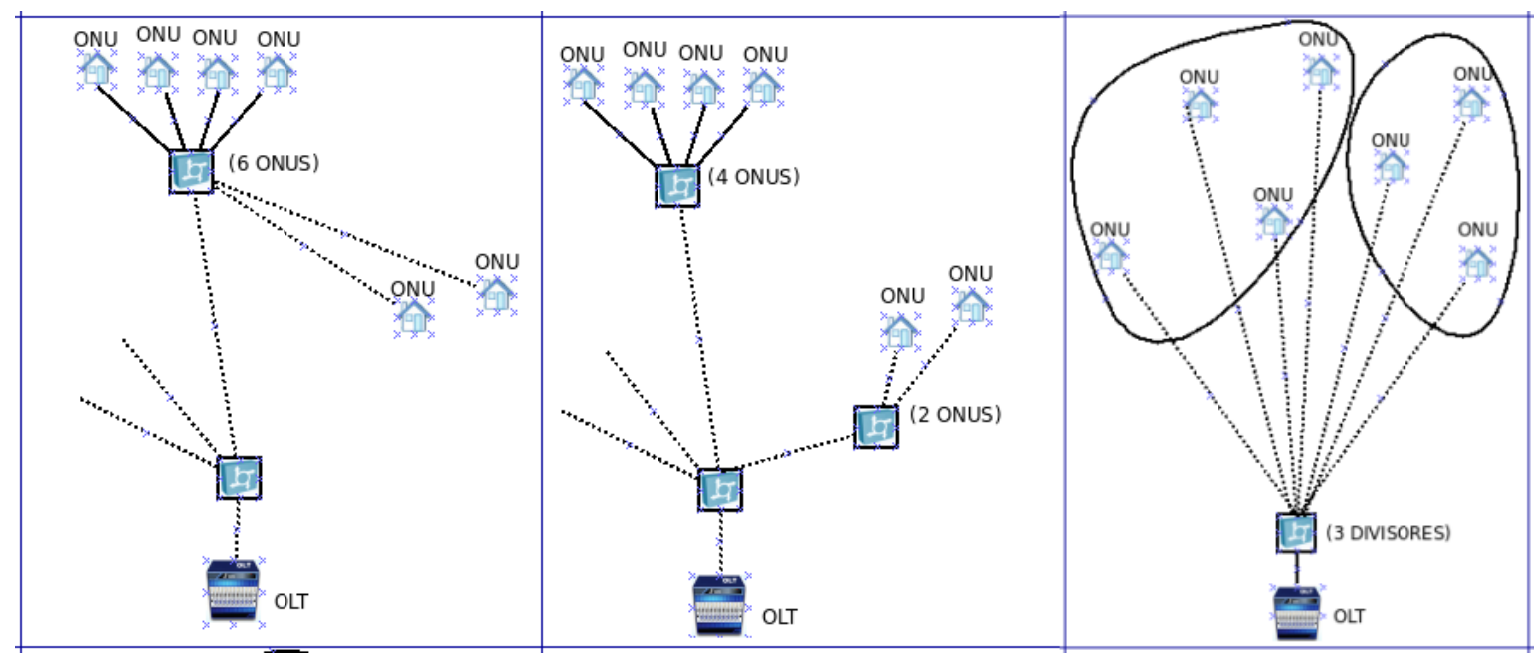

Figura 21 . (a) Grupos de 6 ONUs; (b) grupo de 4 ONUs; (c) seleção de grupos.

Os parâmetros máximos e mínimos, como supracitados, são os números de ONUs que podem ser ligadas a cada divisor do segundo nível. O primeiro é conhecido e fixado pelo usuário, no entanto, o segundo é o mais importante, pois influencia na escolha dos divisores simétricos padronizados. Este valor mínimo será gerado pelo algoritmo de mínimo custo, que será avaliado em cada iteração dentro do algoritmo genético, como se ilustra na Tabela 8. 
EESC - Escola de Engenharia de São Carlos

Tabela 7. Função de otimização para o mínimo de ONUs agrupadas.

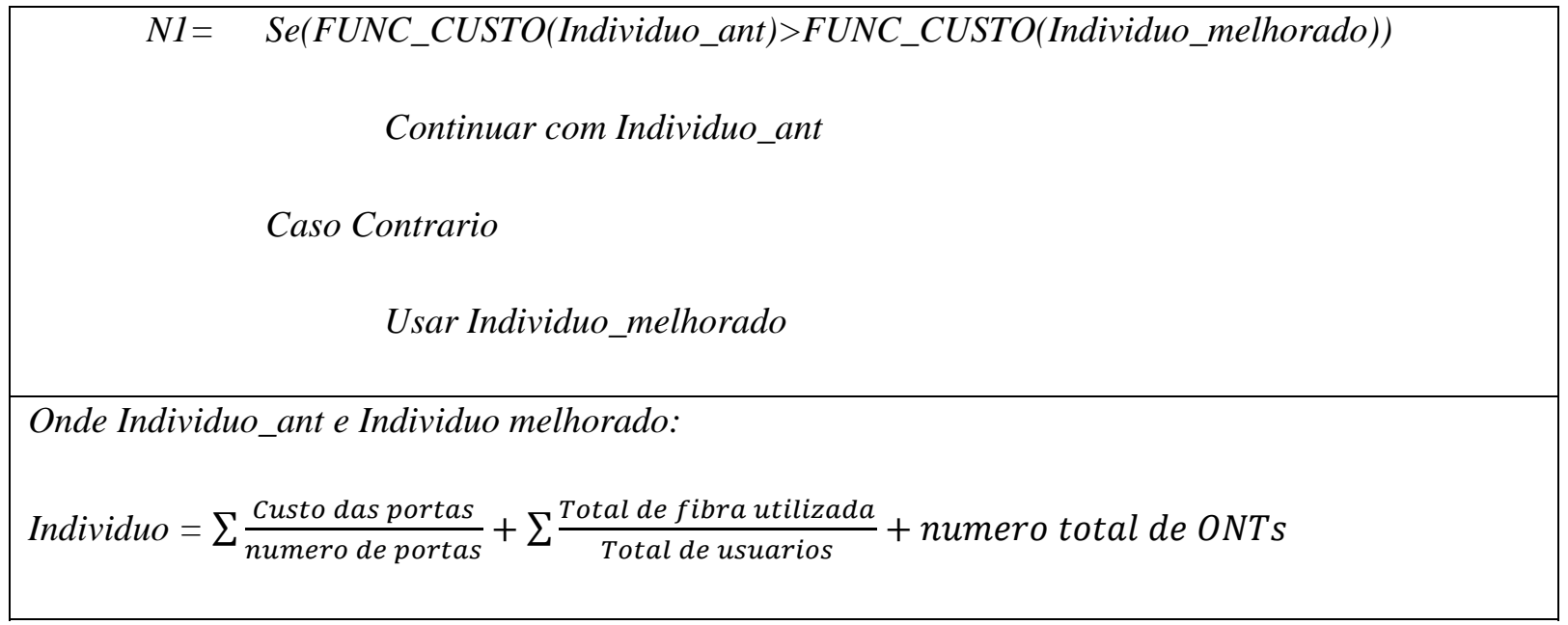

Os custos apresentados neste trabalho foram obtidos de uma empresa de telecomunicações com anos no mercado de venda de equipamentos (FUJITSU). Apresentamos na Tabela 9 os custos de cabos e equipamentos para cada nó da rede, segundo o modelo da Figura 22, que ilustra uma rede passiva padrão.

Tabela 8. Custo de equipamentos - FUJITSU [22] .

\begin{tabular}{|l|l|}
\hline Equipamentos & Custo \\
\hline ONU & 100 dólares \\
\hline Fibra óptica cabeada & 15,63 dólares (metro) \\
\hline Placa com uma oorta da OLT & 46,88 dólares \\
\hline Porta do Divisor (um conector) & 31,25 dólares \\
\hline
\end{tabular}




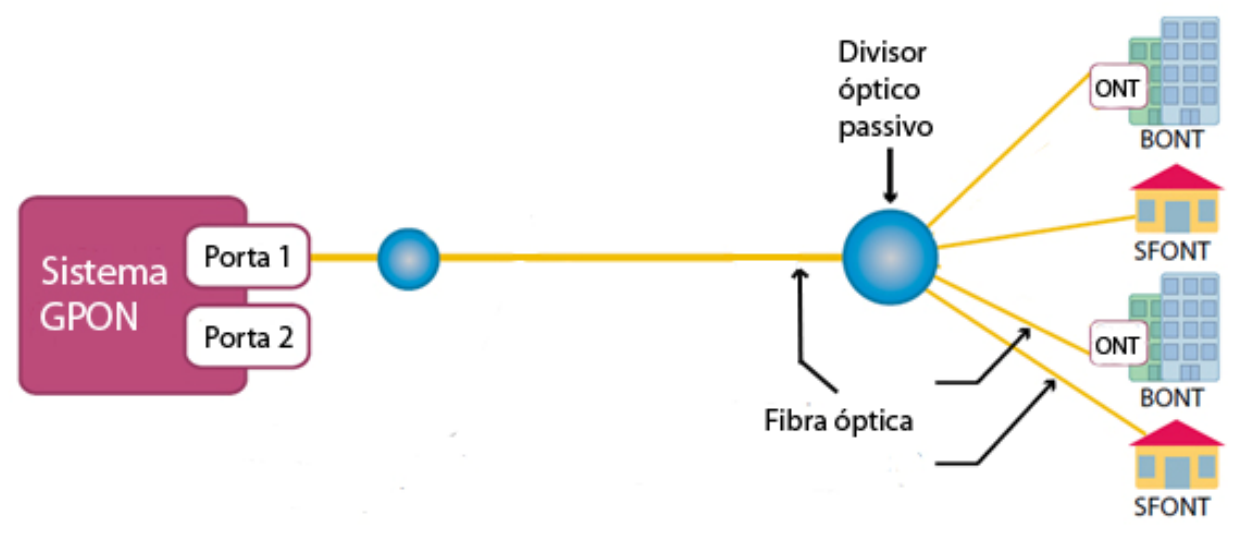

Figura 22. Sistema GPON - FUJITSU [22] .

O algoritmo genético irá agrupar as ONUs em grupos de " $n$ " elementos (n menor ou igual ao valor máximo de ONUs ligadas a um divisor) para gerar um estado inicial. Isto pode ser realizado de forma aleatória ou por proximidade. Posteriormente, o algoritmo tenta trocar algumas ONUs de grupo no intuito de otimizar a posição dos divisores em cada geração.

A posição dos divisores dos dois níveis de derivação será fixada inicialmente no nó mais próximo da OLT e posteriormente serão afastados para gerar a topologia desejada, como podemos observar na Figura $21(\mathrm{c})$.

A função objetivo, ou aptidão, é o objeto de nossa otimização. Esta será um conjunto de testes para identificar os indivíduos mais aptos, ou mesmo uma "caixa preta" onde sabemos apenas o formato dos dados de entradas e nos retorna o valor a ser otimizado. Uma vantagem dos algoritmos genéticos está no fato de não ser necessário que se conheça o funcionamento da função objetivo, mas apenas tê-la disponível para ser aplicada aos indivíduos e compará-los. A equação aptidão para a avaliação de cada indivíduo é dada na Tabela 9. 
Tabela 9. Função Aptidão - Fitness.

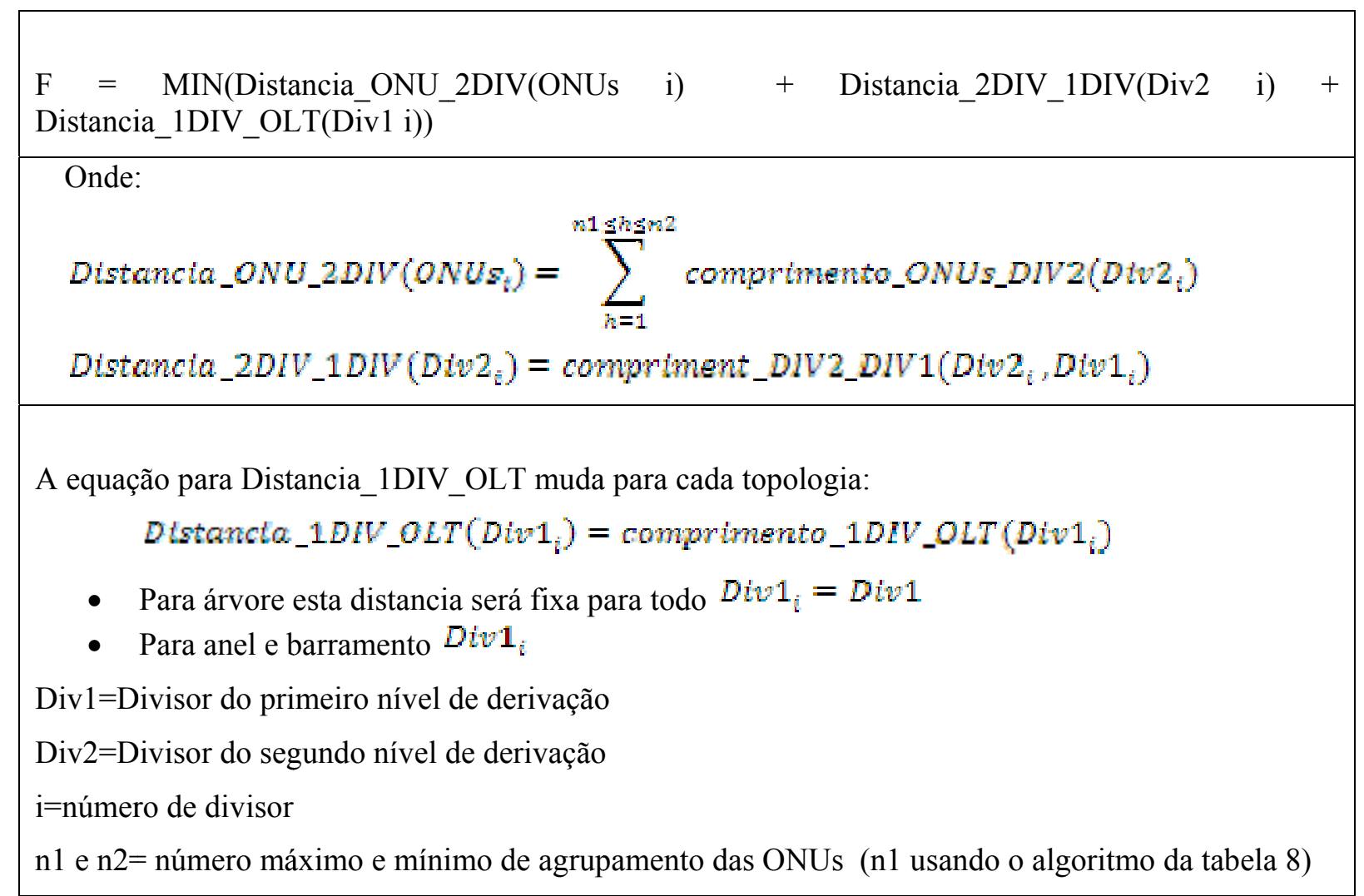

Outro processo dos algoritmos genéticos é a mutação, esta vai acontecer dentro de cada individuo entre os cromossomos. O tipo de reprodução é assexuado, porque acontece dentro de cada individuo e apenas entre cromossomos que pertencem a ele. Para o caso do problema apresentado, não podemos fazer uma mutação qualquer mas temos que agir sem quebrar o grafo de ligações entre nós. A seguir apresentamos o formato dos individuo da população e a mutação ocorrida neles.

\subsection{Topologia em Barramento}

Para a topologia em barramento, adotamos o critério:

Pai [[O1],[O2],[O3],[O4], ....] [P1 , P2 , A1,A2,A3,A4,.... , R1 , R2 , R3]

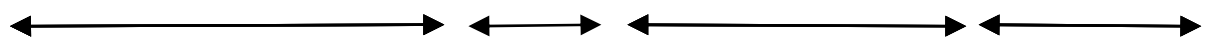


EESC - Escola de Engenharia de São Carlos
$\mathrm{O}$
$\mathrm{P}$
A
$\mathrm{R}$

Onde:

$\mathrm{O}=\mathrm{O}$ vetor que representa cada grupo de ONUs ligadas ao seu divisor de nível dois.

P2 = Posição nova do divisor do segundo nível.

P1 = Posição anterior do divisor do segundo nível.

A = Arranjo que contém o caminho do divisor de segundo para o primeiro nível.

$\mathrm{R}=\mathrm{O}$ caminho entre a OLT e cada divisor do nível 1.

Esta situação está ilustrada na Figura 23. 


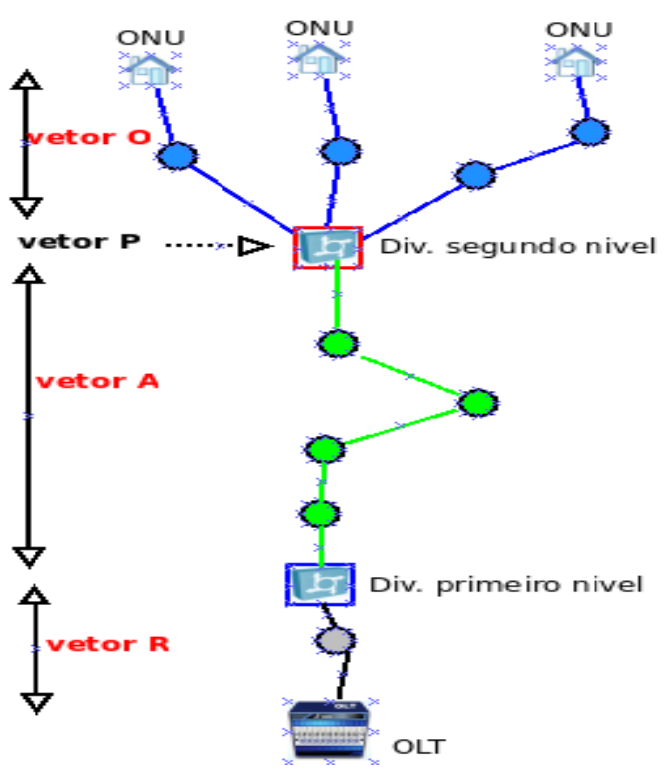

(a)

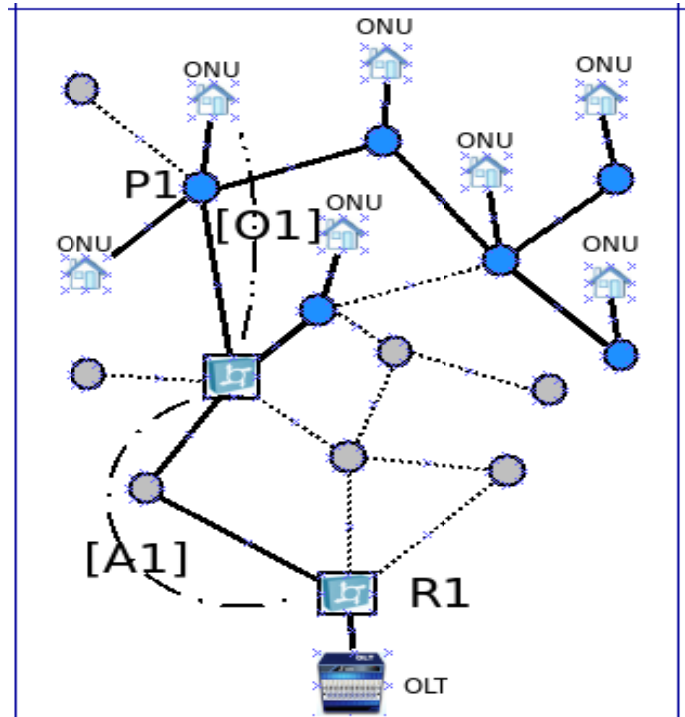

(b)

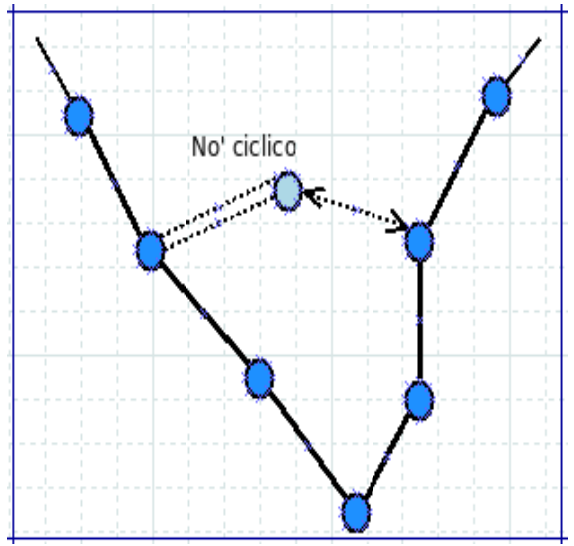

(c)

Figura 23. (a) formato do indivíduo; (b) indivíduo gerado pelo primeiro percurso; (c) nó cíclico.

Como indicado, após o deslocamento da posição $P 1$ para $P 2$, cada elemento de arranjo $O$ terá que ser alterado para incluir $P 1$, ou subtrair, para o caso de $P 2$ estar incluído dentro do arranjo $O_{i}$.

Para realizar as mutações, utilizamos três tipos de alterações, dentro de cada individuo,entre os cromossomos que o formam. A primeira tenta mudar de grupo uma ONU ligada a outro divisor, aquela que tenha o maior comprimento no vetor $\mathrm{O}_{\mathrm{i}}$ (distância entre $\mathrm{ONU}$ e divisor de segundo nível). Desta forma, traçamos um novo caminho desta ONU até o novo divisor de grupo. Este caminho será 
realizado pelo algoritmo apresentado na Tabela6. Para isto, partimos da ONU e percorremos os caminhos, em ordem de menor distância, desde o nó atual ao divisor de segundo nível ao que se pretende unir (apenas fazemos uma alteração na ultima linha Percorrer esquerda(filho[enésimo]) por Percorrer Nó mais perto(filho[enésimo]) ), como ilustrado na Figura 23(b). A segunda mutação é realizada no individuo com elementos do arranjo R. Este contém os nós que formam a topologia tentando seguir aquele caminho do divisor de segundo nível que tem a ONU mais distante e que por tanto apresenta a menor margem de potência. A terceira mutação é realizada no arranjo A. Este representa o(s) caminho(s) do divisor de nível 1 até o divisor de nível 2. Desta forma, a mutação agrega um nó cíclico que contém um novo nó em qualquer posição aleatória, como podemos observar na Figura 23 (c). Este arco cíclico será criado para encontrar um caminho entre este novo nó agregado com outro já existente dentro do arranjo A. O nó cíclico é adicionado em uma posição aleatória do vetor utilizando qualquer novo nó ligado dentro do grafo. Sabemos que o vetor é um caminho (conjunto de nós) dento do grafo e adicionar um novo nó é incluir sua posição dentro do vetor.

Para reprodução utilizamos também um tipo de reprodução assexuada (ao interior do individuo) porque não se pode garantir que todas as combinações mantenham uma ligação entre os nós. Para gerar um novo individuo, descartando o anterior, comparamos a somatória dos vetores $O$ e aquele que for menor passará para o novo individuo criado. Posteriormente, comparamos os vetores $[A]+[R]$ retirando os elementos de $\mathrm{R}$ que não gerem uma ligação com o vetor A no processo anterior. Essa soma será inserida no novo individuo e se este tiver sua função aptidão maior que um dos seus pais, será trocado pelo melhor cromossomo pai.

Para ilustrar o processo, segue-se um exemplo de indivíduo:

Indivíduo 1 [[O1],[O2],[O3],[O4],...] [P1,P2,A1,A11,A1,A2,A3,A20,A3,A4,... R1,R2,R3]

Indivíduo 2 [[O1],[O2],[O7],[O4],...] [P3,P2,A1,A2,A13,A2,A3,A4,A17,A4,.., R1,R2,R3]

Indivíduo 3 [[O1],[O2],[O9],[O4],...] [P3,P2,A1,A25,A1,A2,A30,A2,A3,A4,..,R1,R2,R3]

O vetor $O$ inicialmente terá apenas um elemento, como mencionado anteriormente o único elemento será o nó da posição padrão (posição mais próxima da OLT). 


\subsection{Topologia em Árvore}

Para gerar essa topologia utilizamos o algoritmo explicado no tópico anterior, com apenas uma

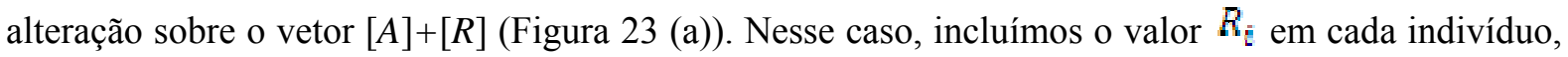
preferencialmente o último elemento do arranjo $R$. O deslocamento do $R_{i \grave{i}}$ sempre tenta usar o maior caminho marcado da ONU até a OLT. Isto é importante porque também permitirá garantir que o arranjo seja válido dentro do grafo e a margem de potência na ONU seja a maior possível.

Pode-se perceber que o deslocamento do divisor do primeiro nível é similar ao algoritmo utilizado para o segundo nível de divisores. Isso ocorre pela utilização de divisores simétricos.

Para o divisor do primeiro nível se deslocar é necessário agregar $R_{1}$ ao final do arranjo $A$ para todos os cromossomos do indivíduo, fazendo com que o novo $R_{1}$ seja qualquer outro caminho, de preferência o já marcado pela ONU mais distante da OLT, como ilustrado a seguir.

$$
\begin{aligned}
& \text { Pai }[[\mathrm{O} 1],[\mathrm{O} 2],[\mathrm{O} 3],[\mathrm{O} 4], \ldots . .][\mathrm{P} 1, \mathrm{P} 2, \mathrm{~A} 1, \mathrm{~A} 2, \mathrm{~A} 3, \mathrm{~A} 4, \ldots . ., \mathrm{R} 1] \\
& \text { Indivíduo } 1[[\mathrm{O} 1],[\mathrm{O} 2],[\mathrm{O} 3],[\mathrm{O} 4], \ldots . .][\mathrm{P} 1, \mathrm{P} 2, \mathrm{~A} 1, \mathrm{~A} 11, \mathrm{~A} 1, \mathrm{~A} 2, \mathrm{~A} 3, \mathrm{~A} 20, \mathrm{~A} 3, \mathrm{~A} 4, \ldots, \mathrm{R} 1] \\
& \text { Indivíduo } 2[[\mathrm{O} 1],[\mathrm{O} 2],[\mathrm{O} 7],[\mathrm{O} 4], \ldots . .][\mathrm{P} 3, \mathrm{P} 2, \mathrm{~A} 1, \mathrm{~A} 2, \mathrm{~A} 13, \mathrm{~A} 2, \mathrm{~A} 3, \mathrm{~A} 4, \mathrm{~A} 17, \ldots, \mathrm{R} 1, \mathrm{R} 2] \\
& \text { Indivíduo } 3[[\mathrm{O} 1],[\mathrm{O} 2],[\mathrm{O} 7],[\mathrm{O} 4], \ldots . .][\mathrm{P} 3, \mathrm{P} 2, \mathrm{~A} 1, \mathrm{~A} 25, \mathrm{~A} 1, \mathrm{~A} 2, \mathrm{~A} 30, \mathrm{~A} 2, \mathrm{~A} 3, \mathrm{~A} 4, \ldots, \mathrm{R} 1]
\end{aligned}
$$

\subsection{Topologia em anel}

Nas análises abordadas na primeira parte deste trabalho mostramos que o anel poderia ter qualquer tamanho e ainda utilizar o cabeamento parecido com a topologia em barramento, entretanto, apenas cabos duplos seriam utilizados para a transmissão de ida e volta. A lógica do algoritmo é a mesma para a topologia em barramento, alterando unicamente o vetor $R$, que forma a topologia em anel $([R 1, \ldots, R 2, \ldots, R 3, \ldots, R 5, \ldots R 3, \ldots R 2, \ldots R 1])$. Para alterar os valores do vetor $R$ são necessários que vários arcos cíclicos sejam agregados, tentando seguir todos os caminhos desde o divisor do nível 1 para $o$ divisor do nível 2 da topologia em barramento, como é ilustrado na Figura 24. 
Em suma, quando esta topologia é otimizada, tentando minimizar o cabeamento e número de divisores, a resposta coincide com a obtida na topologia em barramento.

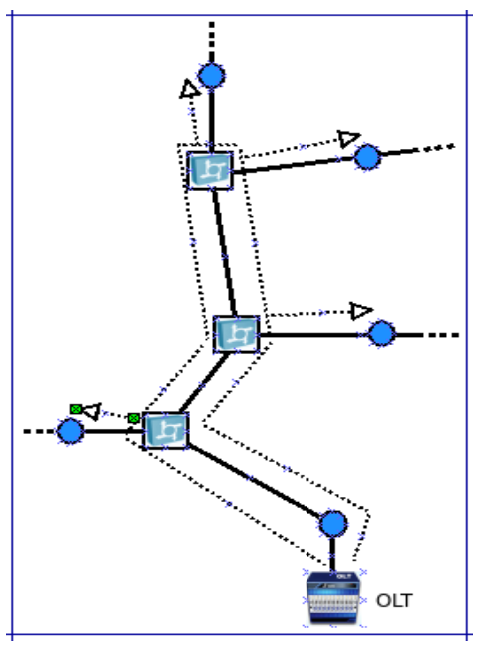

Figura 24. Vetor R de um indivíduo para topologia em anel. 


\section{Capítulo 5 - Simulações}

\subsection{Parâmetros das simulações}

Neste capítulo são apresentados os resultados computacionais obtidos pelo algoritmo genético para a distribuição de divisores de potência utilizando topologias físicas de redes, bem como as comparações com distribuições realizadas sem ajuda do computador (para validação do algoritmo). São analisadas as curvas de comprimento de cabos, as curvas de orçamento de potência e a evolução do algoritmo genético durante o processo de otimização até chegar a um máximo global que será nossa resposta final. Um máximo global é uma solução a nosso problema de otimização, é o valor obtido pelo AG, onde a solução é considerada aceitável.

Como dito anteriormente, o estado inicial do problema é o grafo e a posição da OLT e ONUs dentro do grafo. $\mathrm{O}$ posicionamento dos divisores e o número de portas que serão necessárias para ligar as ONUs serão encontrados pelo algoritmo genético.

O tamanho do grafo que utilizaremos é considerado menor, em comparação com os testes posteriores para poder compará-lo facilmente com nossa distribuição desenhada manualmente. $\mathrm{O}$ tamanho e simplicidade do grafo nós permite realizar as somatórias de distâncias utilizando apenas uma calculadora ou uma planilha eletrônica.

Por fim, apresentamos o número de indivíduos e gerações utilizadas pelo algoritmo para conseguir a solução do problema.

Mostramos na Tabela 10 os dados e tipos de divisores padrões (número de portas do divisor) que foram utilizados para gerar as curvas de orçamento de potência.

Para a perda por derivação nos divisores se utiliza uma equação não linear (logarítmica) que significa que a potência é dividida equitativamente para todas as portas. O número de portas dos divisores é sempre par, como listados na Tabela 10, isto significa que se o algoritmo precisar ligar 3 ONUs, então, terá que utilizar um divisor de 4 portas. Esta consideração é muito importante na hora de encontrar o orçamento de potência da topologia resultante, pois influi nas perdas. 
Tabela 10. Dados das simulações.

\begin{tabular}{|l|l|}
\hline Medidas & Valor \\
\hline $\begin{array}{l}\text { Coeficiente de atenuação da fibra monomodo para o } \\
\text { comprimento de onda } 1310 \mathrm{~nm} \text { (upstream) }\end{array}$ & $0,4 \mathrm{~dB} / \mathrm{km}$ \\
\hline $\begin{array}{l}\text { Perda por derivação máxima no divisor óptico } \\
\text { passivo para cada 2 portas }\end{array}$ & $3 \mathrm{~dB} *$ logaritmo(num_portas, base2) \\
Exemplo: para 2 portas $=3,0 \mathrm{~dB}$
\end{tabular}

Primeiramente, apresentaremos o grafo inicial que representa a entrada de nosso algoritmo genético, em seguida mostraremos as soluções geradas e as comparações com as distribuições desenhadas para cada topologia.

\section{2.- Estado Inicial}

Um dos principais dados para a implementação dos algoritmos genéticos é o estado inicial e as condições iniciais do problema. Para projetar corretamente uma rede de telecomunicações definimos uma área real (mapa) e todas as ligações possíveis que serão consideradas pelo algoritmo na busca das soluções. As posições e números de OLT e ONUs são fixados como no caso real, onde a demanda é exata e, por segurança, a posição da OLT fica próxima da operadora.

Este estado inicial é utilizado pelo algoritmo genético, para a distribuição manual e na realização das comparações e validação dos resultados obtidos. No estado inicial não existe divisores de potência e a posição destes ainda é desconhecida no início.

A solução do grafo e do problema é uma topologia híbrida com divisores com dois níveis de derivação, no segundo nível sempre haverá uma topologia em árvore, para conseguir abranger um número grande de ONUs. 


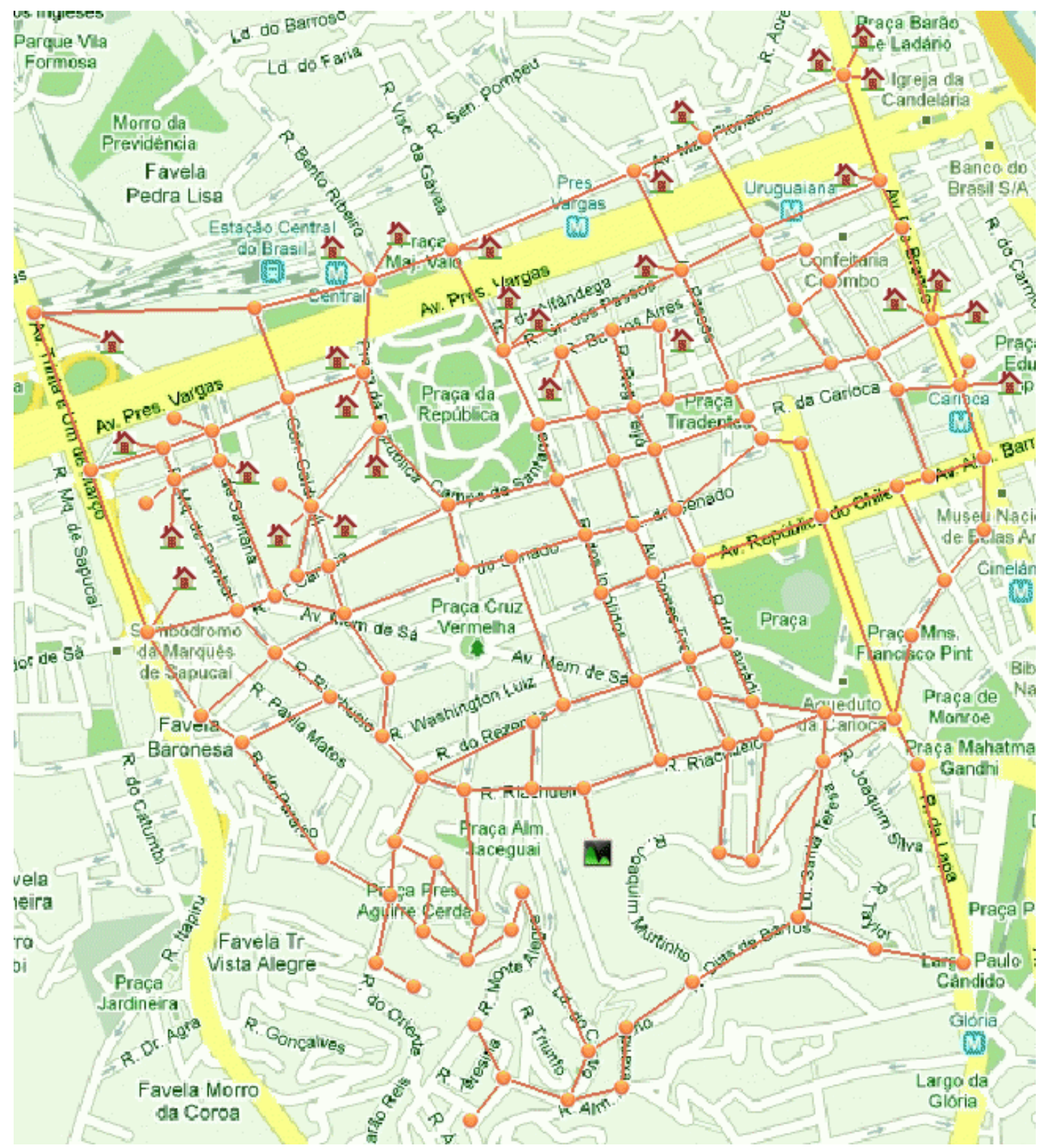

Figura 25. Estado inicial do primeiro teste.

Assim, conforme apresentado segue o significado dos símbolos utilizados na Tabela 11 . 
Tabela 11. Simbologia.

\begin{tabular}{|c|c|}
\hline Figura & Significado \\
\hline O & Nó \\
\hline W & OLT \\
\hline 点 & ONU \\
\hline (4) & Divisores (Divisor primeiro nível de derivação, divisor segundo nível de derivação) \\
\hline
\end{tabular}

Os procedimentos para fixação das posições das ONUs e da OLT no grafo são: só pode ser uma ONU o nó que tiver uma única conexão com outro nó, e similarmente para a OLT. No entanto, a posição escolhida pelo algoritmo genético para um divisor não pode ser a mesma que a das ONUs ou OLT, embora o algoritmo genético possa dar uma mesma posição para dois divisores (lembrando que, na prática, é a operadora que determina o posicionamento dos divisores).

Neste caso os dados do grafo estão listados na Tabela 12.

Tabela 12. Dados do grafo.

\begin{tabular}{|l|l|}
\hline \multicolumn{1}{|c|}{ Elementos } & \multicolumn{1}{c|}{ Valor } \\
\hline Número de Nós (incluído as ONUs e OLT) & 147 \\
\hline Número de ONUs & 28 \\
\hline Número de OLTs & 1 \\
\hline Área máxima (limitada pelo mapa) & $1,8 \mathrm{~km}$ por $2 \mathrm{~km}$ \\
\hline
\end{tabular}

Como mostrado anteriormente (Norma ITU-T G.984.1) o limite de ONUs ligadas a uma OLT é 128, porém é o número máximo de portas dos divisores e a máxima divisão de potencia. 
Para melhor entendimento, retiramos o mapa referencial deixando apenas o grafo e as distâncias entre nós extraídas do mapa, como indicado na Figura 26. A importância real da utilização do mapa de referência é para o caso de exemplos maiores (em termos de número de ONUs e de nós).

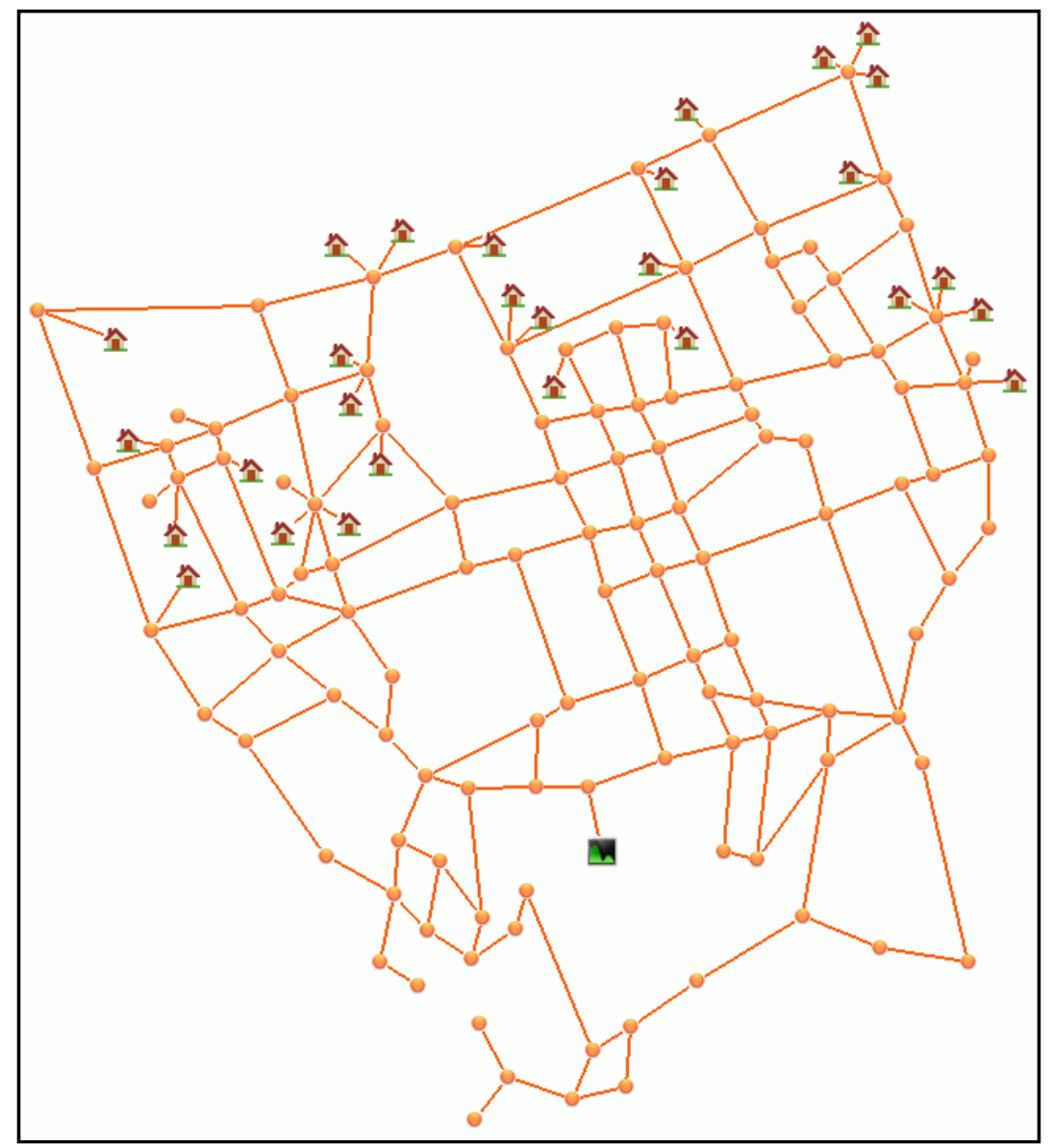

Figura 26. Grafo inicial (fixação da OLT e ONUs).

$\mathrm{O}$ algoritmo genético encontra um conjunto de caminhos entre a OLT e as ONUs, agrupadas com topologia árvore no segundo nível de derivação e gera a topologia pedida no primeiro nível. O que denominamos topologia final é um arranjo híbrido das duas. 


\subsection{Utilização de algoritmo genético.}

Para esta simulação usaremos no máximo 12 ONUs em cada grupo, para poder utilizar divisores de borda de 16 portas, deixando 4 portas para o crescimento da rede, como se mostra na Figura 27 (a).

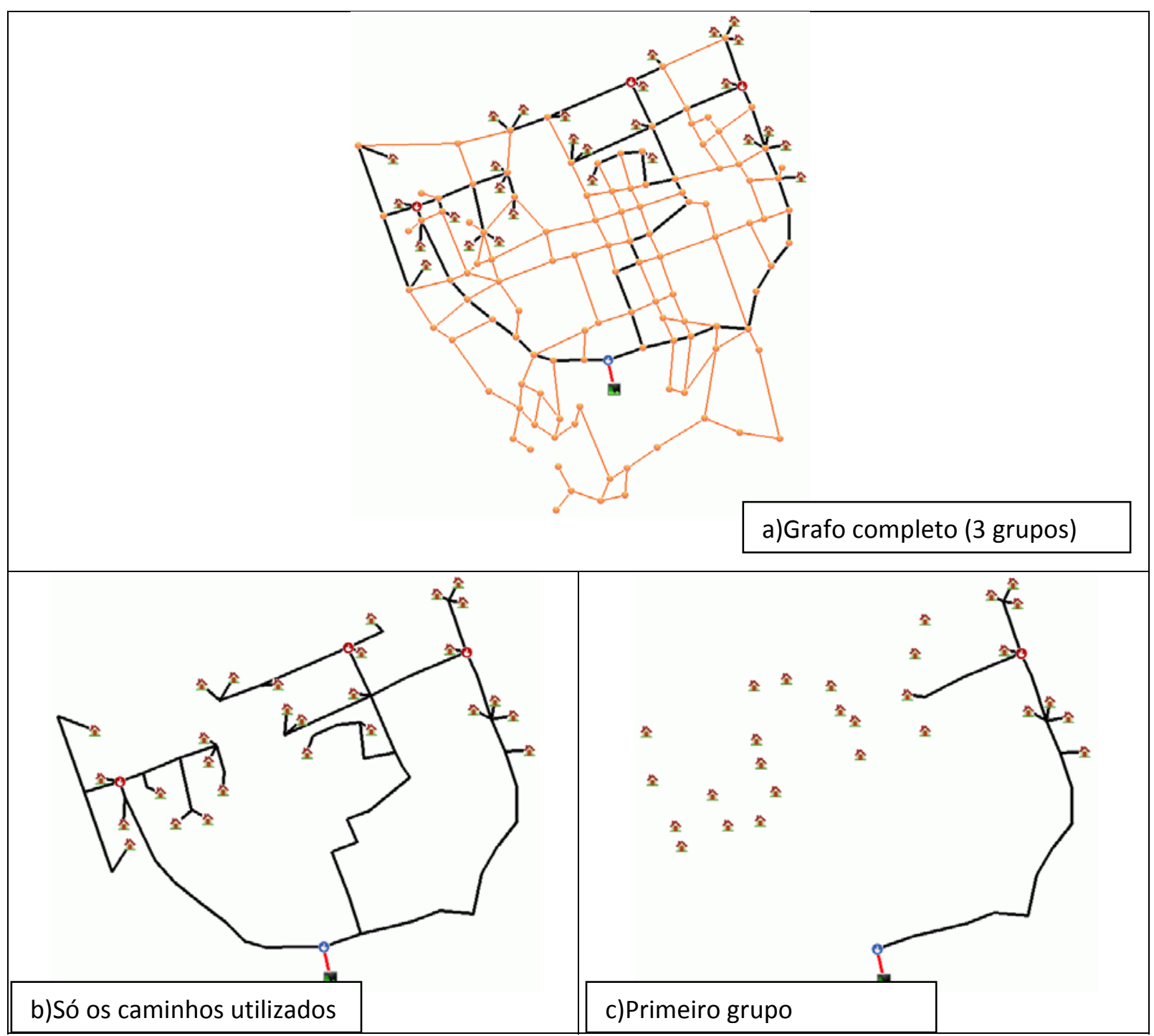




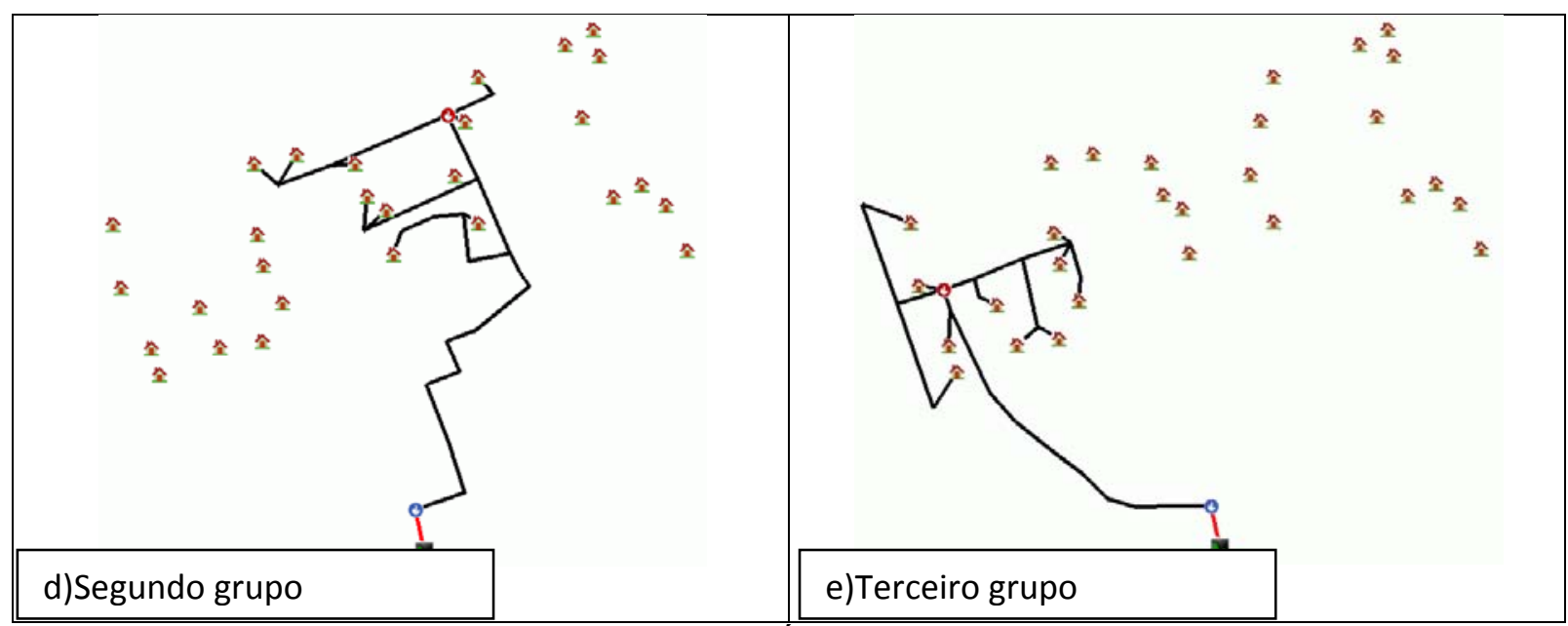

Figura 27. Topologia gerada em Árvore para uma rede de 28 ONUs.

Na Figura 27 (a) e (b) apresentamos a topologia híbrida em árvore encontrada pelo algoritmo genético. Como apresentado nesta figura, foram encontrados 3 grupos de ONUs, nas Figuras 27 (c) (d) e (e) são mostrados cada grupo isoladamente. A linha de cor vermelha indica o tronco da árvore, na parte superior do tronco será colocado o único divisor de primeiro nível (4 portas, deixando uma livre). Cada um dos grupos tem um divisor com o número máximo de 12 ONUs ligadas. O algoritmo genético determina o agrupamento e o número de ONUs utilizando o critério de custo.

$\mathrm{Na}$ Tabela 13 ilustramos as descrições sugeridas pelo algoritmo genético para cada topologia. Na coluna de "Divisores" é mostrada a lista de divisores indicando o número de portas e a coluna "Total de portas" é utilizado para analisar os custos. Como já abordamos anteriormente, o custo do divisor é calculado pelo número de portas. O "Total de fibra" utilizado é determinado somando os caminhos existentes em cada topologia e a quantidade resultante será aproveitada para a equação de perdas (atenuação na fibra) e custo de implantação. 
EESC - Escola de Engenharia de São Carlos

Tabela 13. Número de divisores utilizados em cada topologia.

\begin{tabular}{|l|l|l|l|l|}
\hline Topologia & Divisores & $\begin{array}{l}\text { Total } \\
\text { Divisores }\end{array}$ & Total portas & $\begin{array}{l}\text { Total Fibra } \\
\text { utilizada }\end{array}$ \\
\hline Árvore & {$[4,16,16,16]$} & 4 & 52 & $18,5 \mathrm{~km}$ \\
\hline Barramento & {$[2,16,2,16,16]$} & 5 & 52 & $17,3 \mathrm{~km}$ \\
\hline Anel & {$[2,16,2,16,2,8]$} & 6 & 46 & $22 \mathrm{~km}$ \\
\hline
\end{tabular}

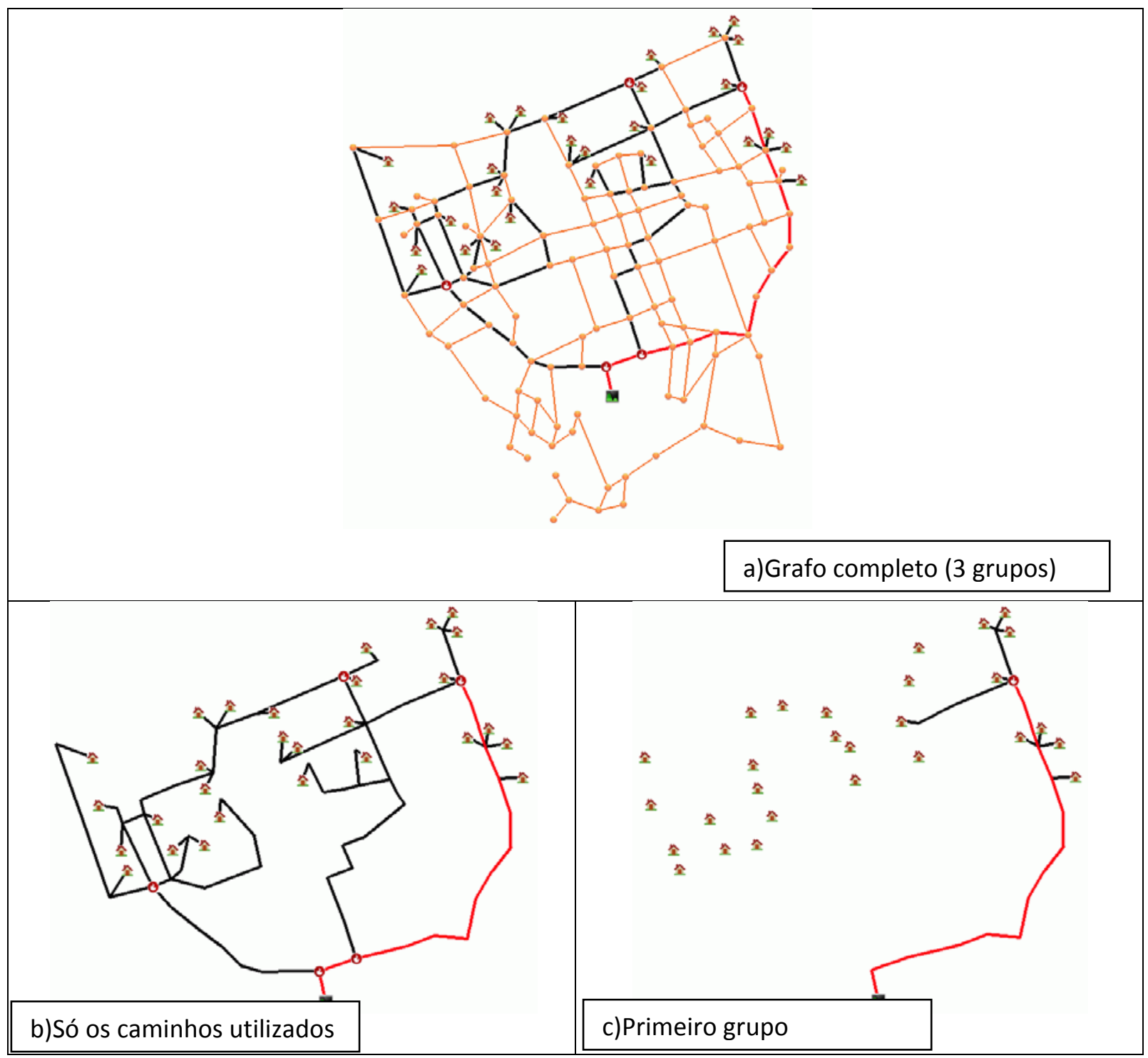




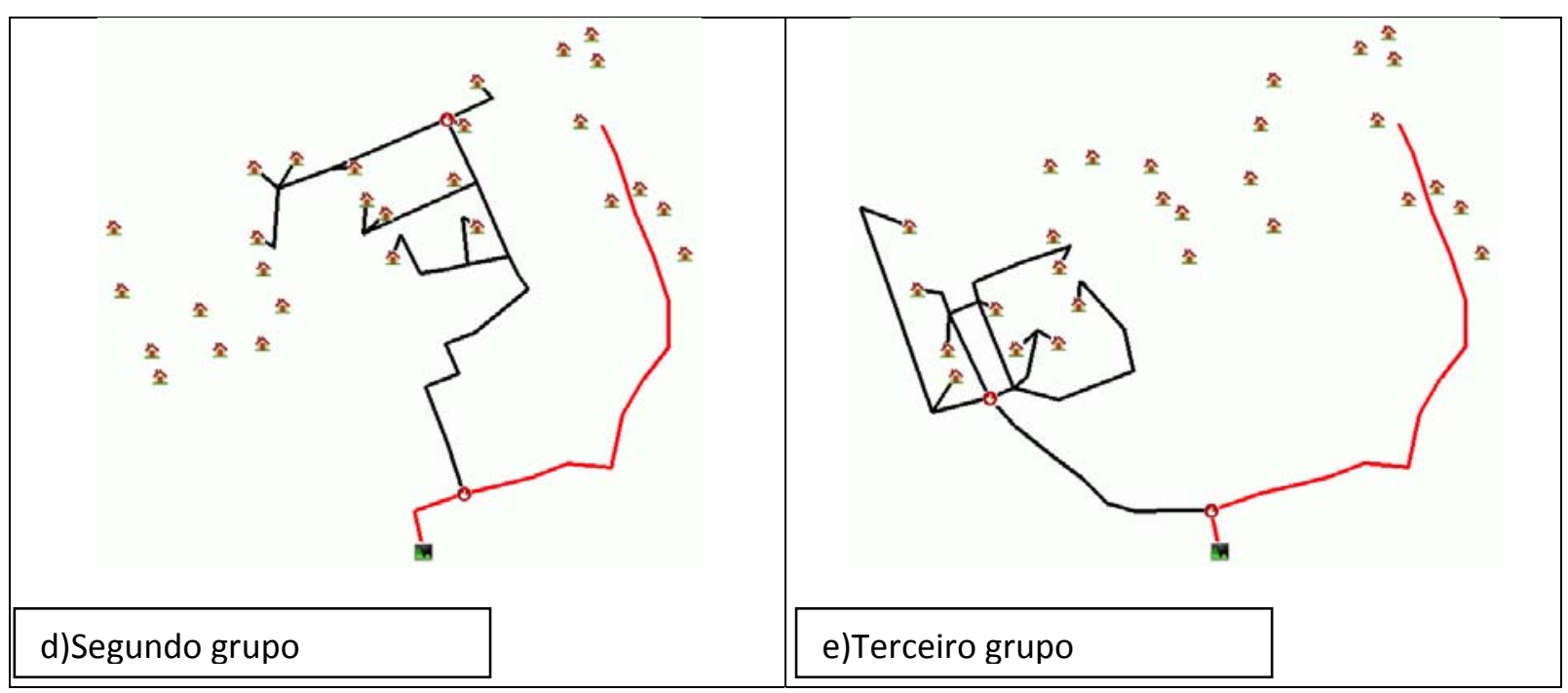

Figura 28. Topologia gerada em Barramento para uma rede de 28 ONUs.

A seguir apresentamos na Figura 28 (a) e (b) o resultado da topologia em barramento . Similarmente, como ilustrado na topologia em árvore, na Figura 28 (a), incluímos todos os nós do grafo e na Figura 28 (b) apenas os caminhos utilizados para melhorar a visualização e entendimento. Como apresentamos na topologia em árvore, o número de grupos encontrados foram 3, desta forma cada grupo é descrito nas Figuras 28 (c), (d) e (e).

A linha vermelha nas Figuras 28 (a) representa o barramento principal. No final da linha de barramento é colocado o último divisor que é compartilhado. Este ligará os dois últimos ramos da árvore do segundo nível. 


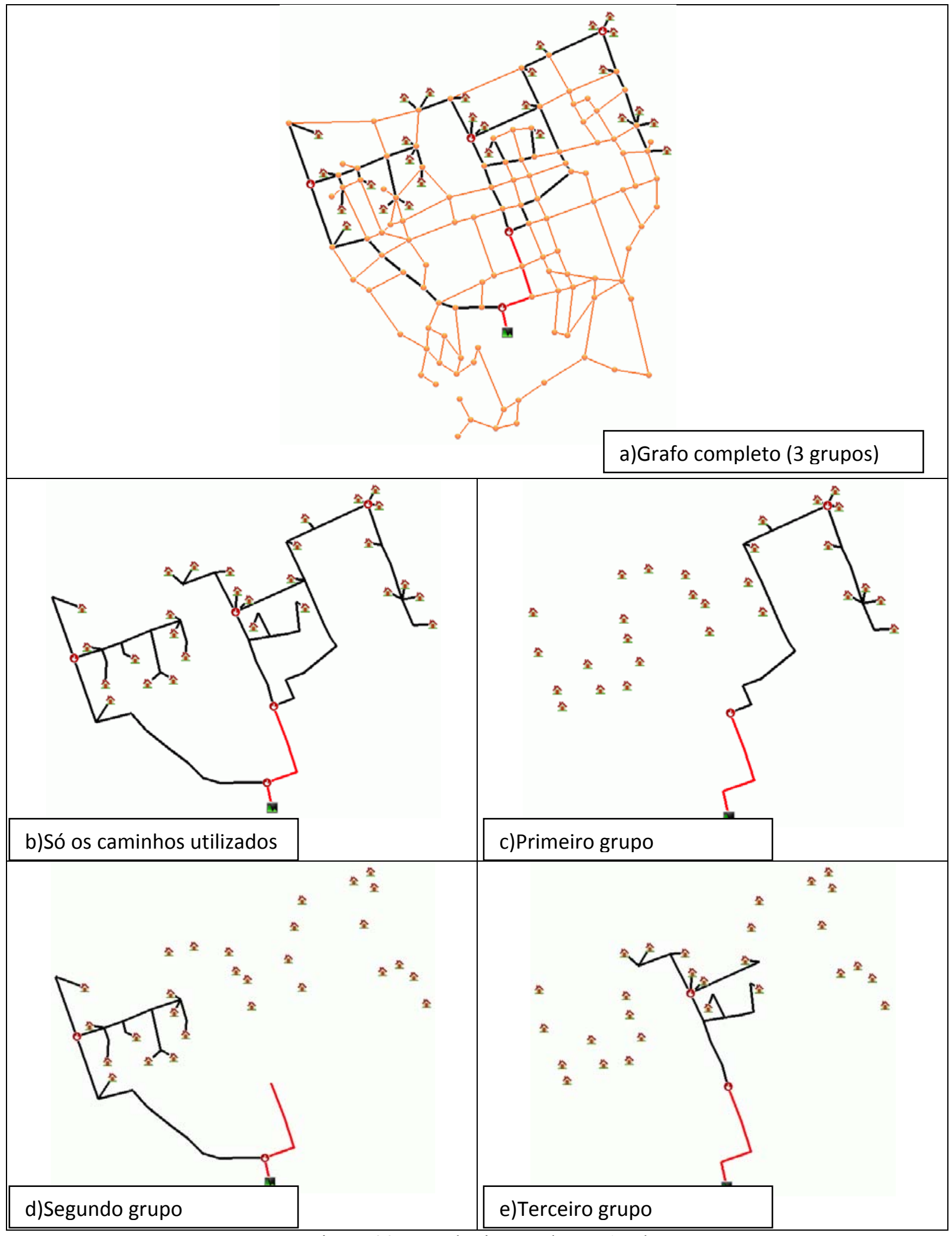

Figura 29. Topologia gerada em Anel. 
A topologia em anel é formada por um barramento fechado nas extremidades, a Figura 29 (a) e (b) mostra uma topologia similar a barramento. No entanto, é um anel fechado que inicia e termina na OLT. A utilizaçao de uma topologia em anel é unicamente para fins de prover mecanismos de proteção. Se uma rede em anel é otimizada com critérios de menor caminho, orçamento de potência e custo, ela possui dimensões muito parecidas com a topologia em baramento.

Nas Figuras 29 (c), (d) e (e) são ilustradas os grupos de árvores ligados ao anel principal representado pela linha de cor vermelho.

O primeiro resultado obtido é a curva de distâncias para todas as topologias ilustradas na Figura 30. As curvas mostram as distâncias desde a OLT até as ONUs. Esta distância é considerada pelo caminho ótimo gerado pelo algoritmo genético para as três topologias. No entanto, nem sempre a distância entre uma ONU e a OLT é a menor em termos absolutos, mas é a menor correspondente ao seu grupo de ONUs a que pertence.

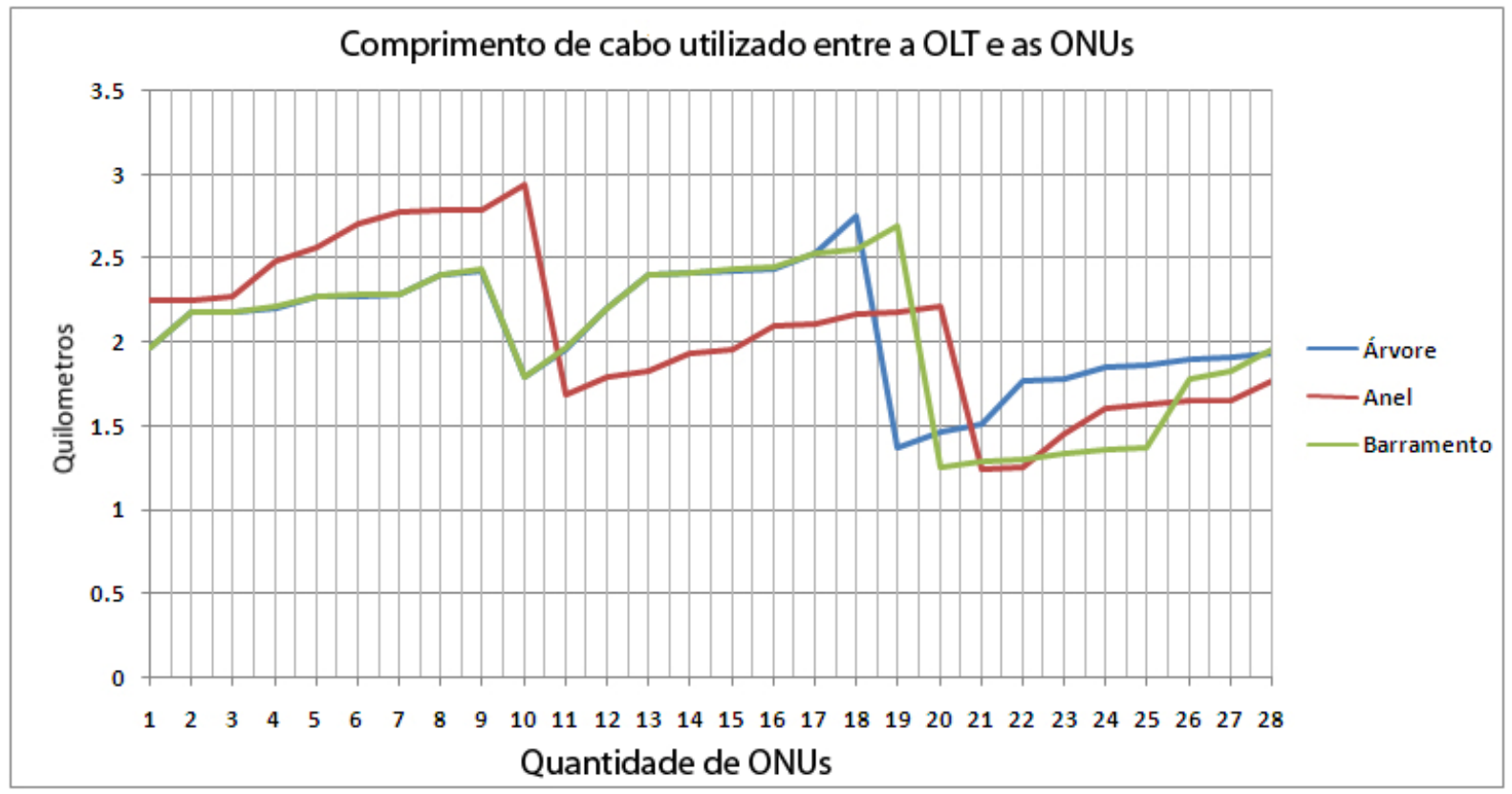

Figura 30. Comprimento de cabo utilizado entre a OLT e as ONUs.

As distâncias de cada indivíduo são utilizadas dentro do algoritmo genético para calcular o custo de implementação de cada geração e o orçamento de potência, obtendo um número corresponde ao indivíduo e sua subsistência no sistema (escolha do melhor pai para reprodução e mutação). 
A área do mapa deste exemplo é $2 \times 1,8 \mathrm{~km}^{2}$, como foi mostrado na Tabela 12 (estado inicial), porém as distâncias são menores ou próximas, com se observa na Figura 30.

As distâncias, o número de divisores e o número de conexões irão determinar o valor da potência dadas a cada ONU.

A configuração dos divisores e a quantidade total de fibras utilizadas nesta topologia são listadas na Tabela 13. Esses dados igualmente foram utilizados para o cálculo de custos e orçamento de potência no processo de otimização do algoritmo genético.

\subsection{Orçamento de Potência.}

O orçamento de potência na Figura 31 corresponde às três topologias utilizando divisores simétricos. O número de portas dos divisores é determinado pelo algoritmo utilizando o limite máximo fixado.

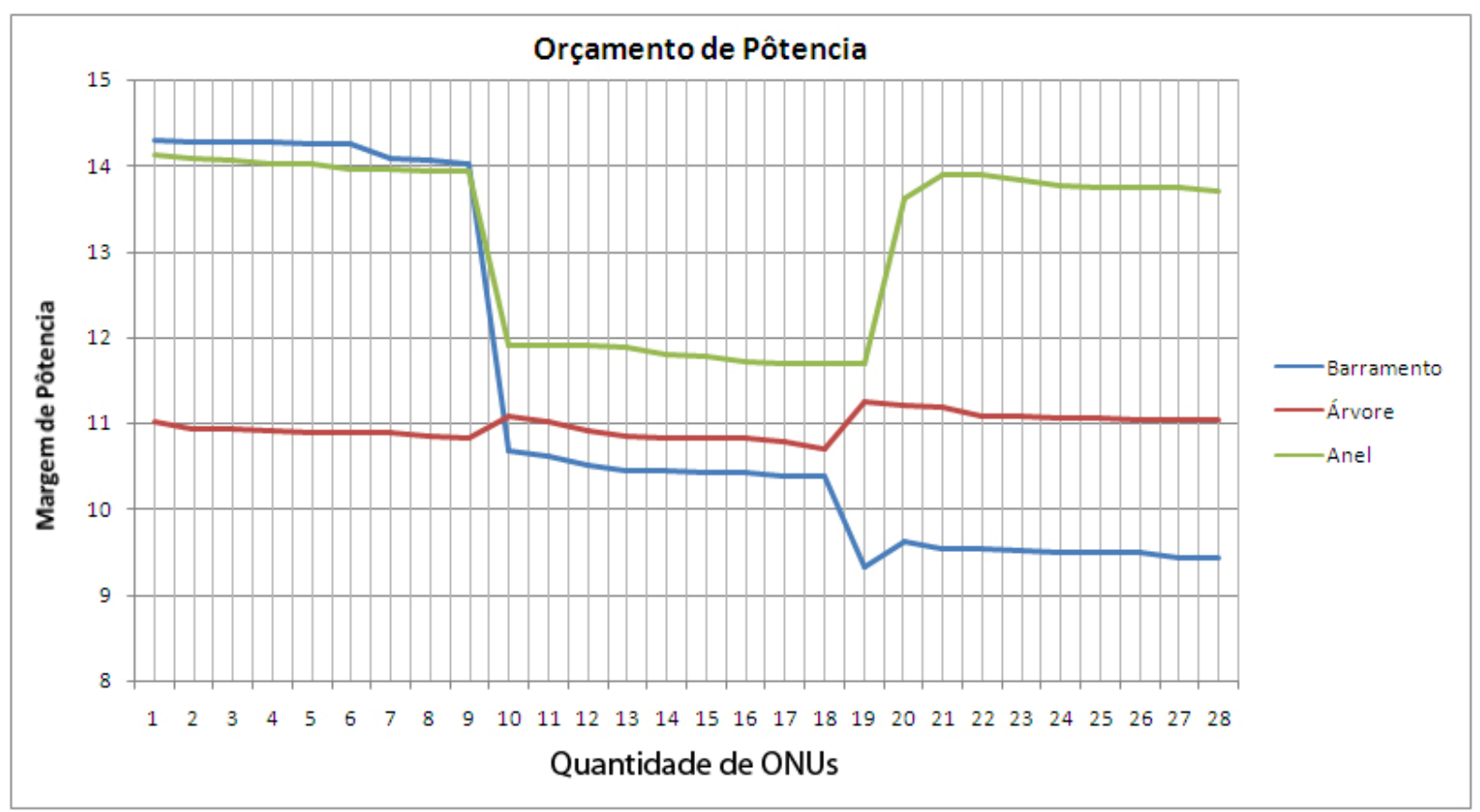

Figura 31. Orcamento de Potência das topologias geradas pelo AG. 
Existe a posibilidade da utilização de divisores assimétricos, para as topologias de barramento e anel, sendo apenas considerado para o cálculo de orçamento de potência (divisão assimétrica de potência nos divisores do primeiro nivel). A utilizacao de divisores assimétricos em redes híbridas tem sido empregada para balancear a potência e melhorar o QoS. Assim, a potência é dividida equitativamente paras todos os grupos e para todas as ONUs.

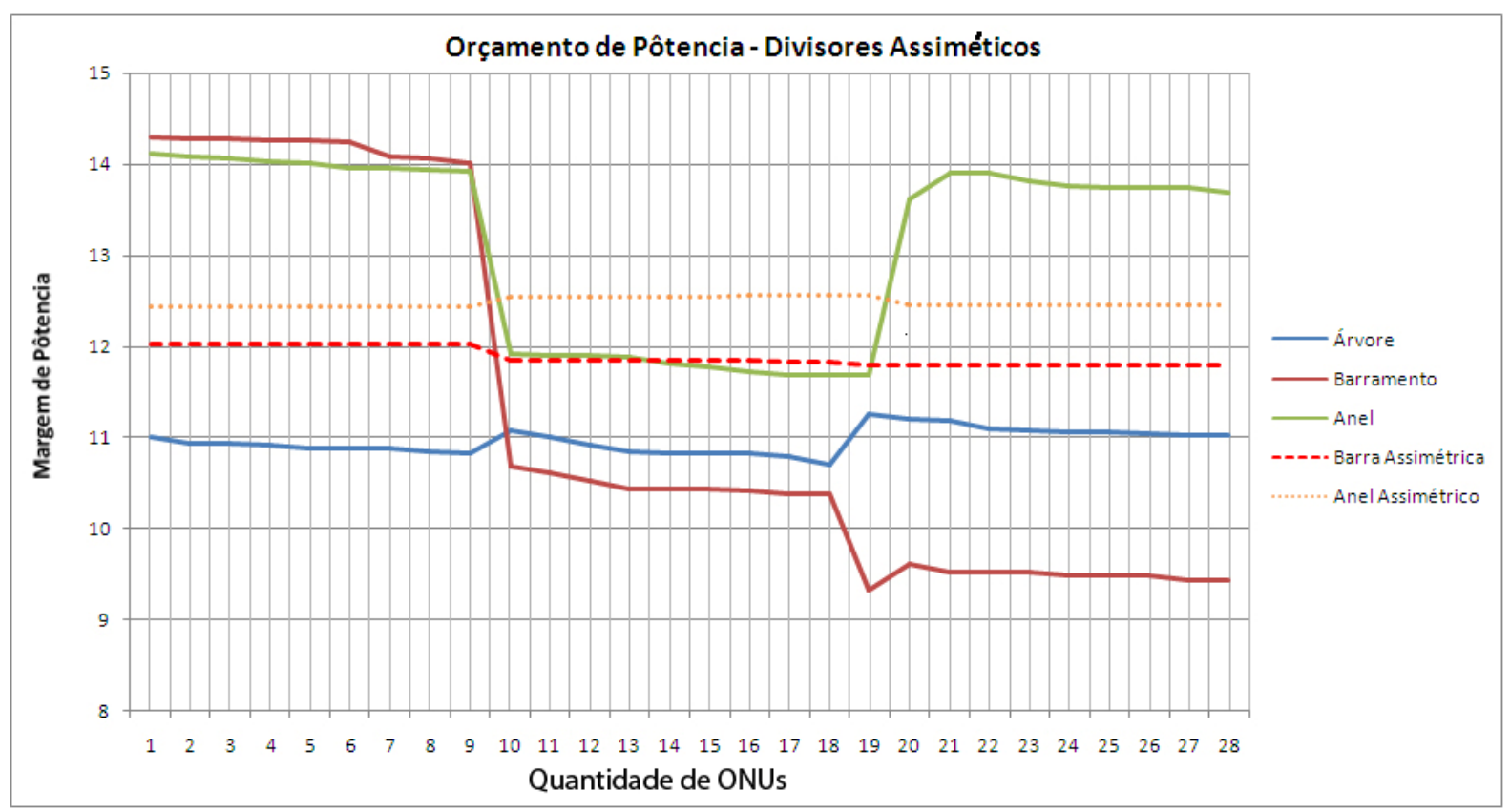

Figura 32. Orçamento de potência utilizando divisores assimétricos.

Na Figura 32 foi avaliada a divisão assimétrica de potência com as porcentagens da Tabela 14. Como se ilustra na Figura 32, as curvas pontilhadas pertencem à margem de potência dos divisores assimétricos. A melhoria obtida está na estabilidade das curvas, para esta configuração.

A estabilidade da curva de potência garante o crescimento da rede e menor dependência do aumento de ONUs em qualquer dos grupos. Por exemplo, na curva da topologia em barramento simétrico, o terceiro grupo é fortemente dependente do crescimento da rede, devido à baixa potência do trecho. 
Tabela 14. Porcentagens de derivação.

\begin{tabular}{|l|l|l|}
\hline & Barramento \% Derivação & Anel \% Derivação \\
\hline DIV. ONU 1 & $30 \%$ & $37 \%$ \\
\hline DIV. ONU 2 & $52 \%$ & $54 \%$ \\
\hline DIV. ONU 3 & & $100 \%$ \\
\hline
\end{tabular}

As porcentagens de derivação foram encontradas pelo algoritmo genético, tentando distribuir a mesma quantidade de potencia para cada ONU.

\subsection{Evolução do algoritmo genético}

O algoritmo genéticosé um processo de otimização. Na Figura 33 mostramos a evolução do melhor individuo de 7 gerações utilizadas para gerar a topologia em árvore. A evolução é mostrada em termos de otimização de distâncias entre a OLT e as ONUs do individuo.

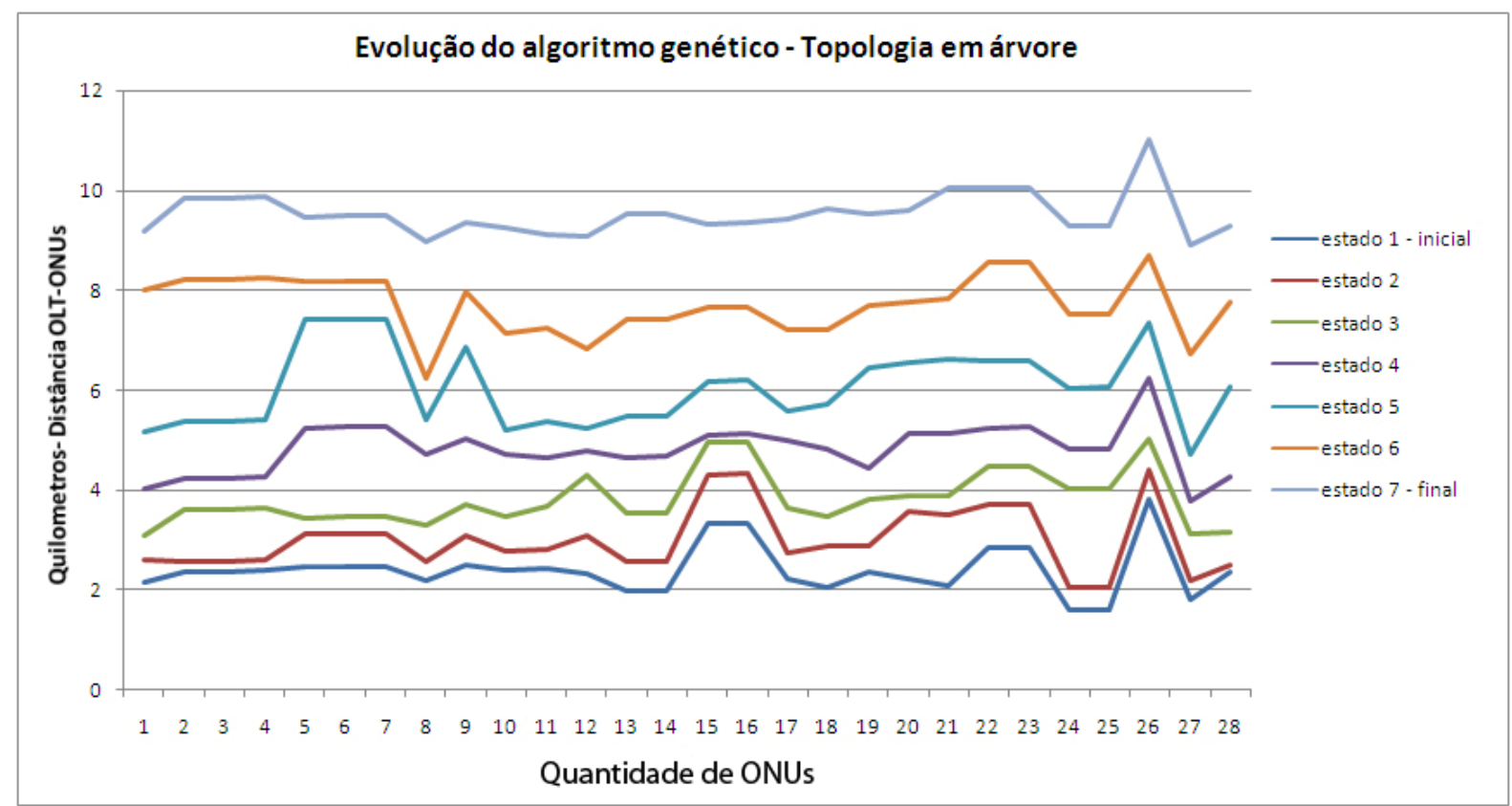

Figura 33. Evolução do GA para a topologia em árvore. 
Como foi descrito anteriormente, utilizamos um número fixo de indivíduos em cada geração (Tabela 15). A mutação foi realizada em aproximadamente 7\% dos indivíduos em cada iteração e o cruzamento foi de $75 \%$. Esta é uma taxa alta para garantir a otimização em grupo.

O "estado 1" na Figura 33 representa o estado inicial do indivíduo considerado o melhor da sua geração, o valor médio dele é 10 quilômetros e podemos comparar com o estado final (estado 7) cuja media é 2.1 quilômetros, o que nos mostra uma otimização do estado 1 para o estado 7, e assim para cada geração como é observado na figura.

Tabela 15. Características do algoritmo genético da topologia em árvore.

\begin{tabular}{|l|l|}
\hline Descrição & Quantidade \\
\hline Indivíduos utilizados em cada geração & 30 \\
\hline Mutação & $7 \%$ \\
\hline Cruzamento & $75 \%$ \\
\hline Gerações & 582 \\
\hline
\end{tabular}

Similarmente na Figura 34 mostramos as curvas de evolução da topologia em barramento para o melhor individuo de cada geração, desde o início das iterações no algoritmo genético. A média da distância do estado 7 é igual à topologia em árvore, aproximadamente 2 quilômetros. 


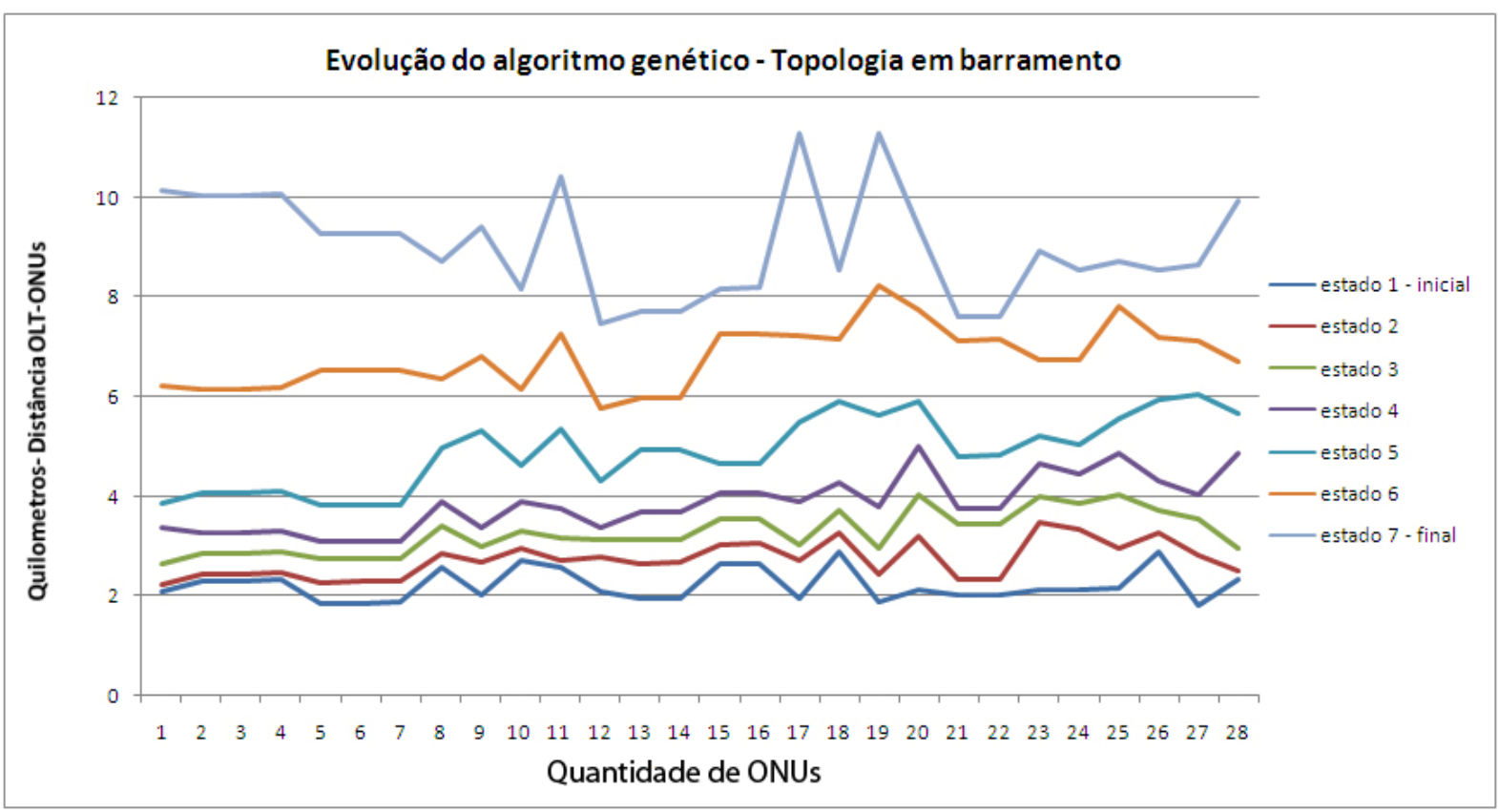

Figura 34. Evolução do GA para a topologia em barramento.

A Tabela 16 ilustra a quantidade fixa de indivíduos utilizados em cada geração, a mutação e cruzamento são variáveis e dependem do estado inicial e da evolução dos indivíduos que farão que a porcentagem suba ou desça.

O limite de iterações é 1500 gerações, no caso do exemplo para as três topologias nunca atingiu este valor, sempre foi abaixo do limite, como se mostra na Tabela 16 e na topologia anterior.

Tabela 16. Características do algoritmo genético da topologia em barramento.

\begin{tabular}{|l|l|}
\hline \multicolumn{1}{|c|}{ Descrição } & \multicolumn{1}{|c|}{ Quantidade } \\
\hline Indivíduos & 30 \\
\hline Mutação & $8 \%$ \\
\hline Cruzamento & $77 \%$ \\
\hline Gerações & 480 \\
\hline
\end{tabular}


O numero condições para gerar uma topologia em anel é maior que das outras (gerar o anel central da topologia), porém a velocidade da otimização é mais lenta e a média da distância do estado final é maior. No entanto, as ONUs ficam mais distantes da OLT (uma diferença de 0.2 quilômetros a mais que as outras topologias).

Cada estado posterior sempre é melhor que o anterior, porque os indivíduos são selecionados pela função avaliação e mantendo apenas os 30 melhores indivíduos para a próxima geração. A condição de "não ter mudanças nos indivíduos ao longo de varias iterações" gera a solução, porém as curvas sempre apresentaram otimização.

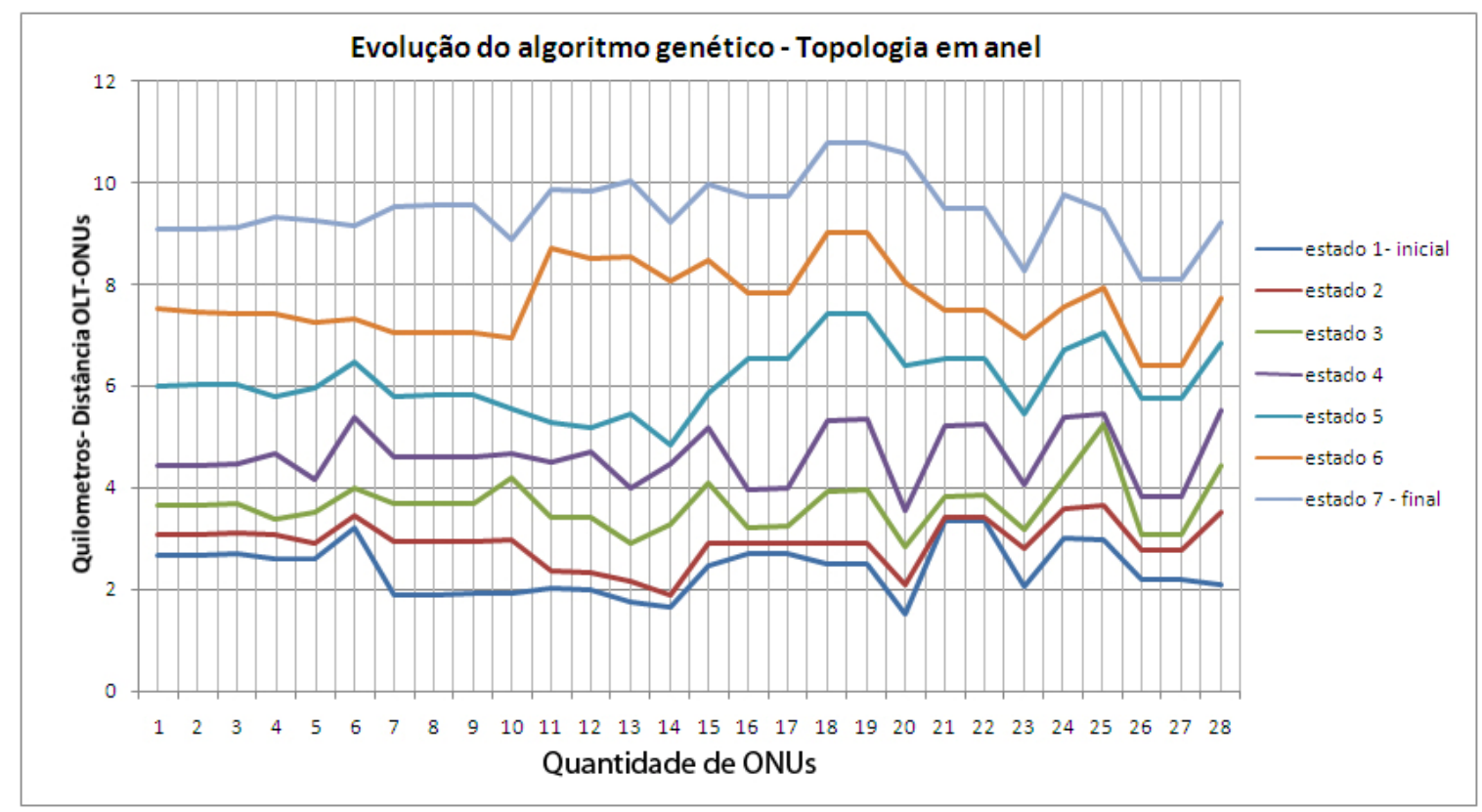

Figura 35. Evolução do algoritmo genético para a topologia em anel.

Tabela 17. Características do algoritmo genético da topologia em anel.

\begin{tabular}{|l|l|}
\hline \multicolumn{1}{|c|}{ Descrição } & \multicolumn{1}{c|}{ Quantidade } \\
\hline Indivíduos & 30 \\
\hline Mutação & $6 \%$ \\
\hline Cruzamento & $72 \%$ \\
\hline Gerações & 613 \\
\hline
\end{tabular}


A Tabela 17 lista as porcentagens de mutações, cruzamentos e número de gerações da topologia anel. Como foi dito esses valores modificam dependendo fortemente da geração do estado inicial (a faixa de porcentagens é limitada, para não ter uma taxa de mutação ou cruzamento muito baixa).

\subsection{Validações dos resultados}

A razão de se ter selecionado um tamanho pequeno para o grafo da simulação foi para permitir realizar uma comparação das soluções geradas pelo algoritmo genético e uma distribuição com otimização obtida manualmente.

Como ilustrado na Figura 36 , para desenhar uma topologia em árvore foram agrupadas as ONUs em 3 grupos de menos de 12 ONUs interligados. Este limite também foi usado na condição inicial do algoritmo genético. Os polígonos de cor azul claro representam as ONUS selecionadas para cada grupo, a linha azul representa o tronco da topologia em árvore; o ponto azul, a posição do divisor do primeiro nível; e as linhas vermelhas determinam o caminho de interligação entre o tronco principal e os galhos da árvore. Os pontos vermelhos são a posição dos divisores de segundo nível que conectam as ONUs e a OLT. 


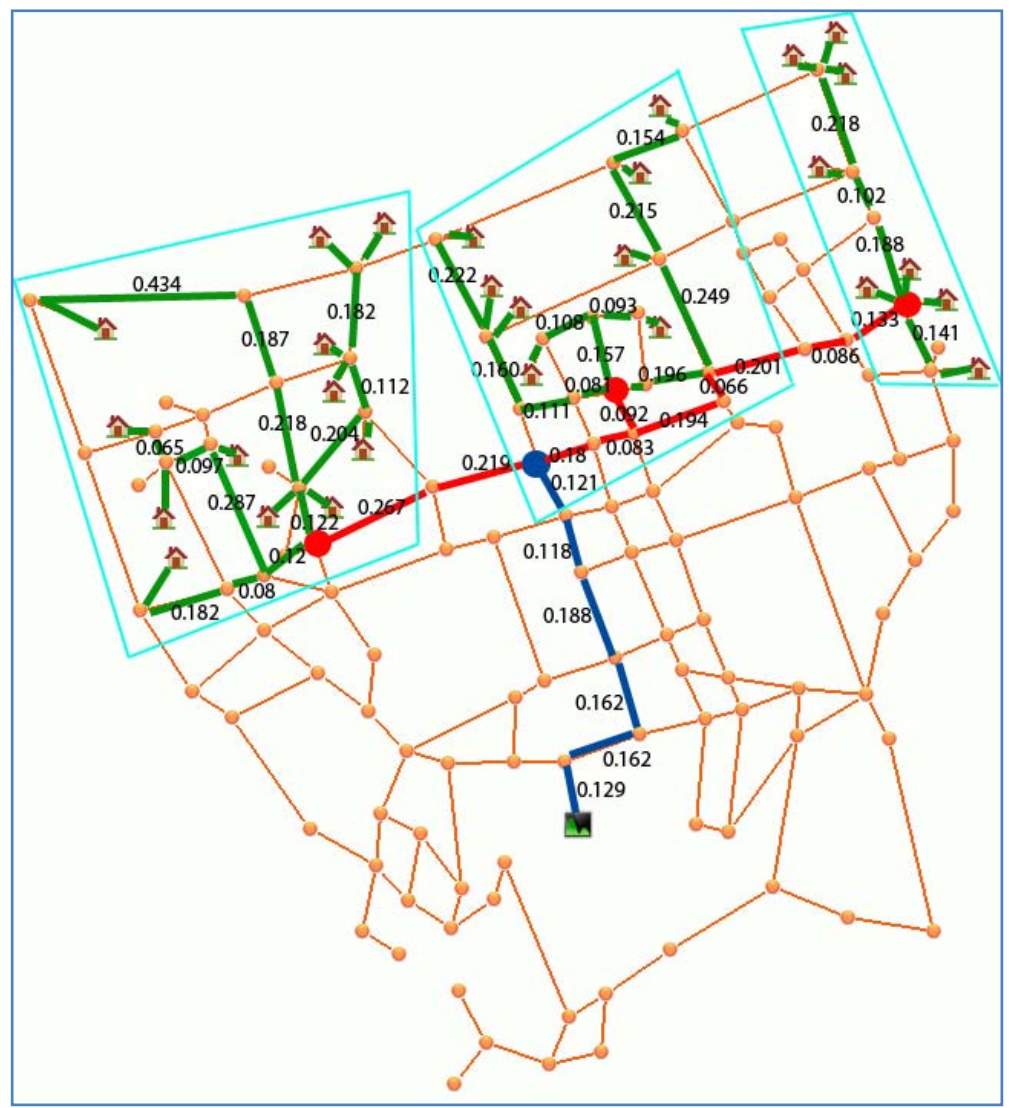

Figura 36. Distribuição manual para a topologia em árvore.

As distâncias entre os nós são apresentadas no grafo. Desta forma, é possível obter-se a distância desde a OLT até as ONUs. Estas distâncias são utilizadas para realizar a validação manual.

Para o desenho das topologias de rede (Figura 36, Figura 37 e Figura 38), foi utilizado o critério visual simples, tentando utilizar sempre o menor caminho. 


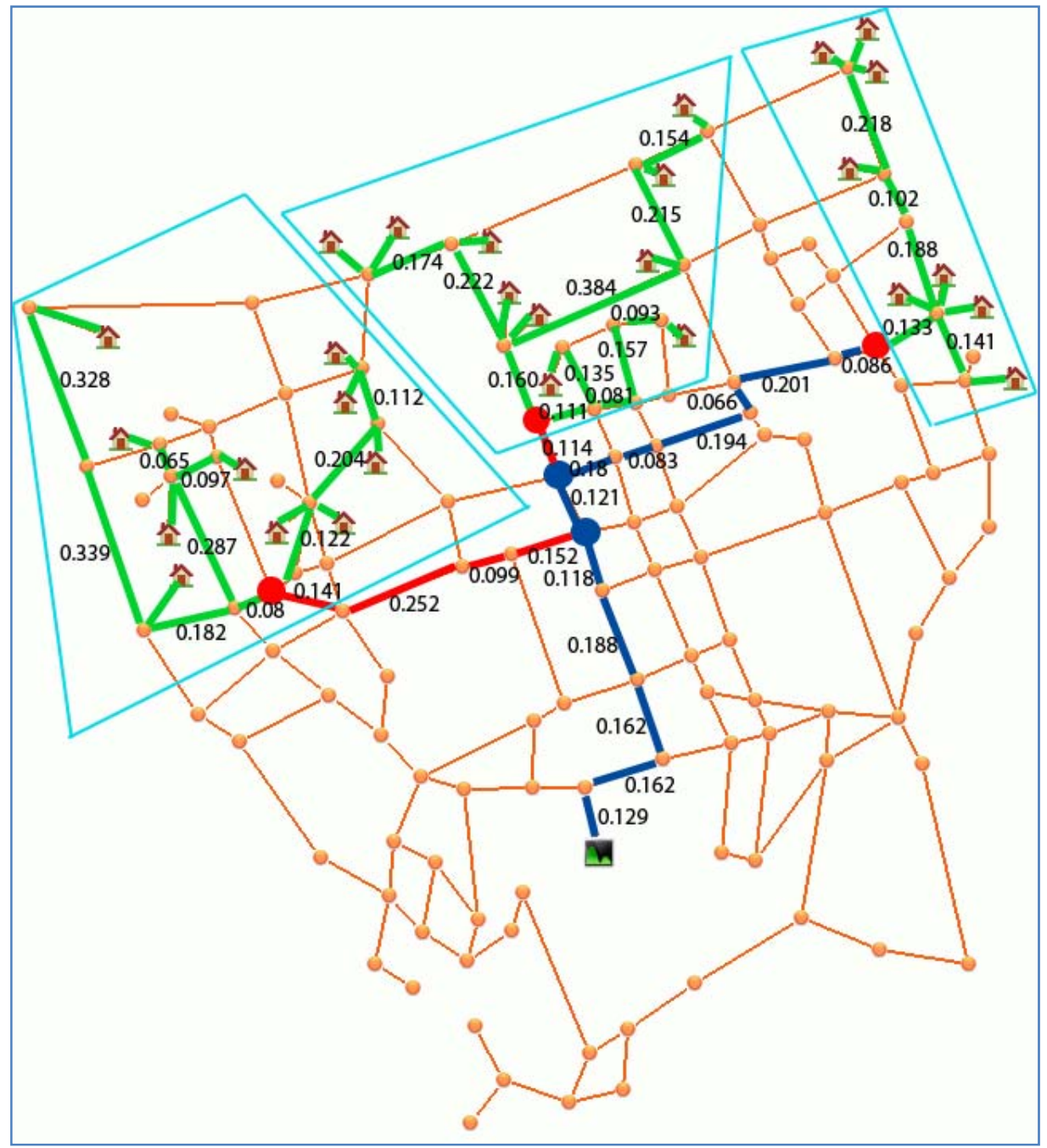

Figura 37. Distribuição manual para a topologia em barramento.

Similarmente se desenhou a topologia em anel, desta vez cuidando de ter o anel claramente definido, como se mostra na Figura 38, na linha de cor azul. 


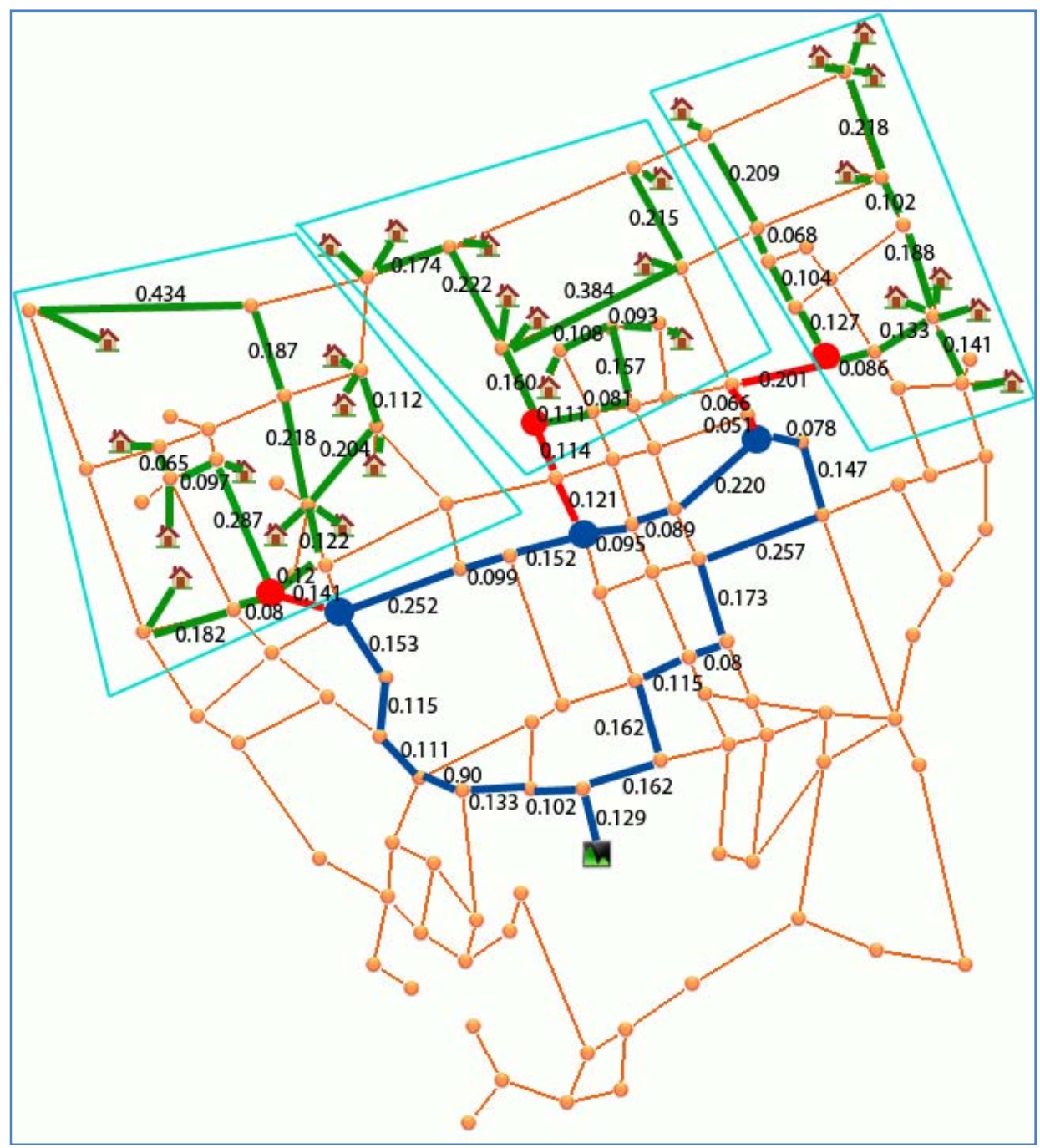

Figura 38. Distribuição manual para a topologia em anel.

Com os dados das distâncias podemos gerar uma figura muito similar (Figura 30) com os analisados pelo algoritmo genético, e desta forma, realizar uma comparação das curvas e validar os resultados obtidos pelo método utilizado neste trabalho.

A Figura 39 corresponde às distâncias encontradas pelo algoritmo genético para as 3 topologias. Assim, também adicionamos as curvas de distância das topologias desenhadas manualmente. Desta forma, observamos que as curvas estão próximas. No entanto, não é muito significante esta diferença. Utilizaremos o valor médio das distâncias para compará-los. 


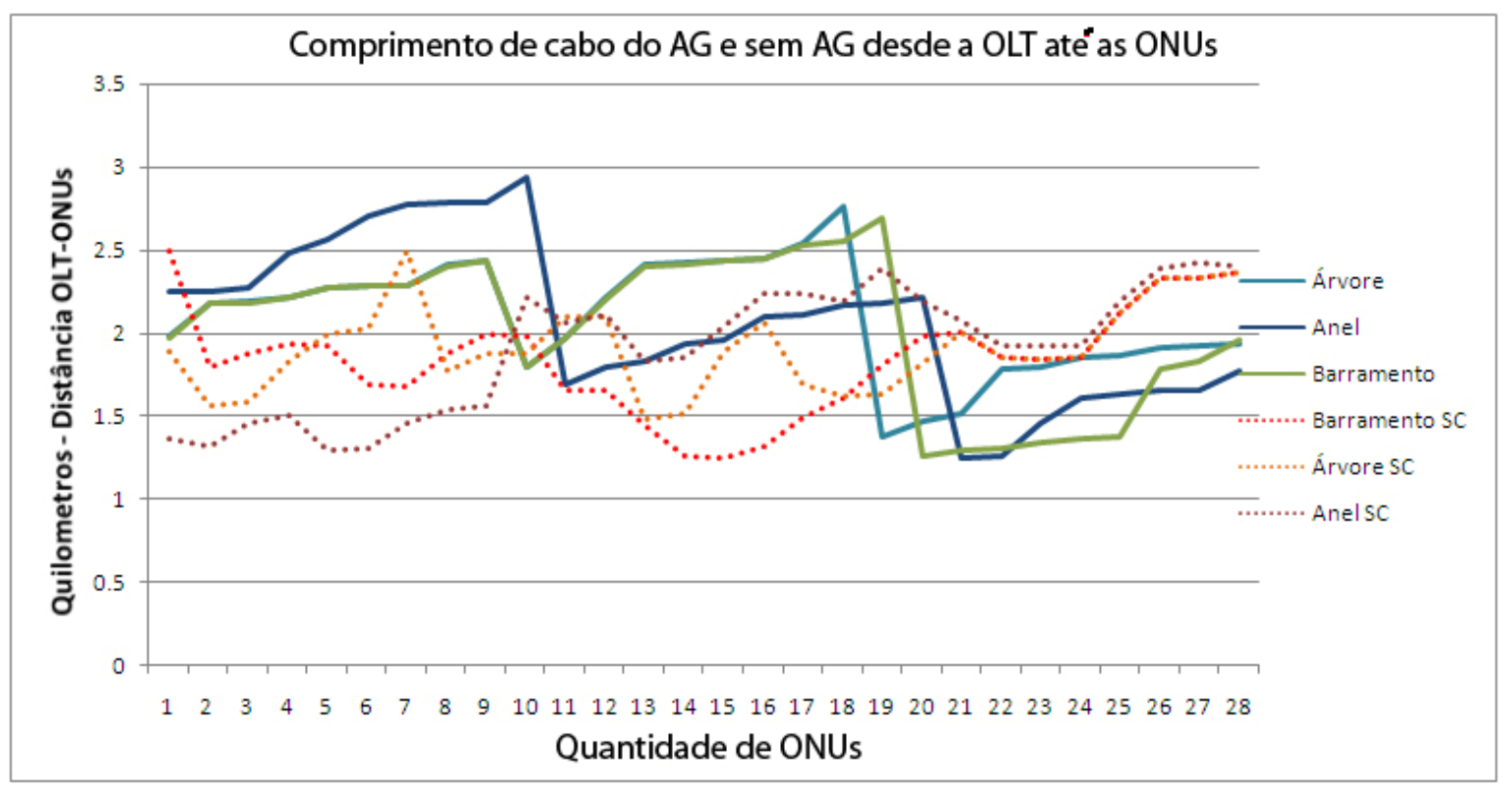

Figura 39. Comprimento de cabo utilizado desde a OLT até as ONUs utilizando AG e sem AG (i.e., manualmente).

Mostramos o valor médio na Tabela 18. Observamos que os valores são muito próximos o que nos permite validar os resultados obtidos pelo algoritmo genético.

Como foi mostrada na definição de algoritmos genéticos, a função deste é localizar um máximo global que nem sempre será a única solução ótima ao problema (convergência)

Tabela 18. Valor médio de distâncias.

\begin{tabular}{|c|c|c|c|c|c|c|c|c|c|}
\hline \multirow{2}{*}{ Topologia } & \multicolumn{3}{|c|}{ Árvore } & \multicolumn{3}{c|}{ Barramento } & \multicolumn{3}{c|}{ Anel } \\
\cline { 2 - 9 } & AG & Manual & & AG & Manual & & AG & Manual & \\
\hline $\begin{array}{c}\text { Média das } \\
\text { distâncias (km) }\end{array}$ & 2,0934 & 1,9089 & 0,1845 & 2,0431 & 1,8357 & 0,2074 & 2,0758 & 1,9093 & 0,1665 \\
\end{tabular}


O algoritmo foi validado neste primeiro teste simplificado, fazendo comparação com soluções obtidas manualmente, como apresentado. Para o segundo teste será utilizada uma área maior de distribuição composta pelos dados indicados na Tabela 19.

Tabela 19. Dados do segundo teste.

\begin{tabular}{|l|l|}
\hline \multicolumn{1}{|c|}{ Elementos } & \multicolumn{1}{c|}{ Valor } \\
\hline Número de Nós (incluído as ONUs e OLT) & 427 \\
\hline Número de ONUs & 128 \\
\hline Número de OLTs & 1 \\
\hline Área máxima (limitada pelo mapa) & $10 \mathrm{~km}$ por $10 \mathrm{~km}$ \\
\hline
\end{tabular}

\subsection{Outras simulações.}

A visualização da configuração para uma rede maior é um pouco mais complexa, em função da escala. Mostraremos os grupos isolados como o teste anterior para melhor entendimento.

A topologia em árvore gerada é ilustrada na figura 40. 
EESC - Escola de Engenharia de São Carlos

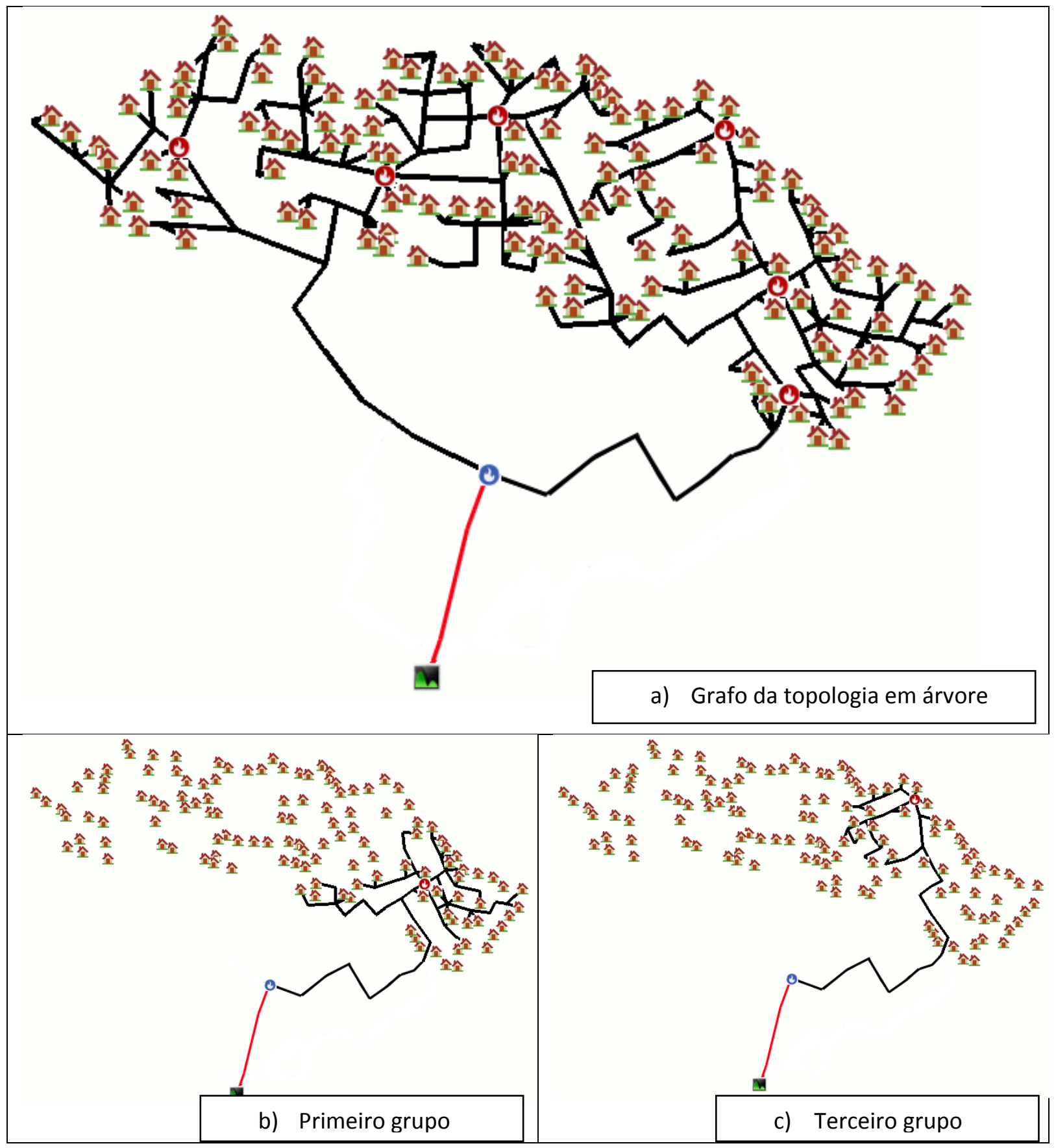




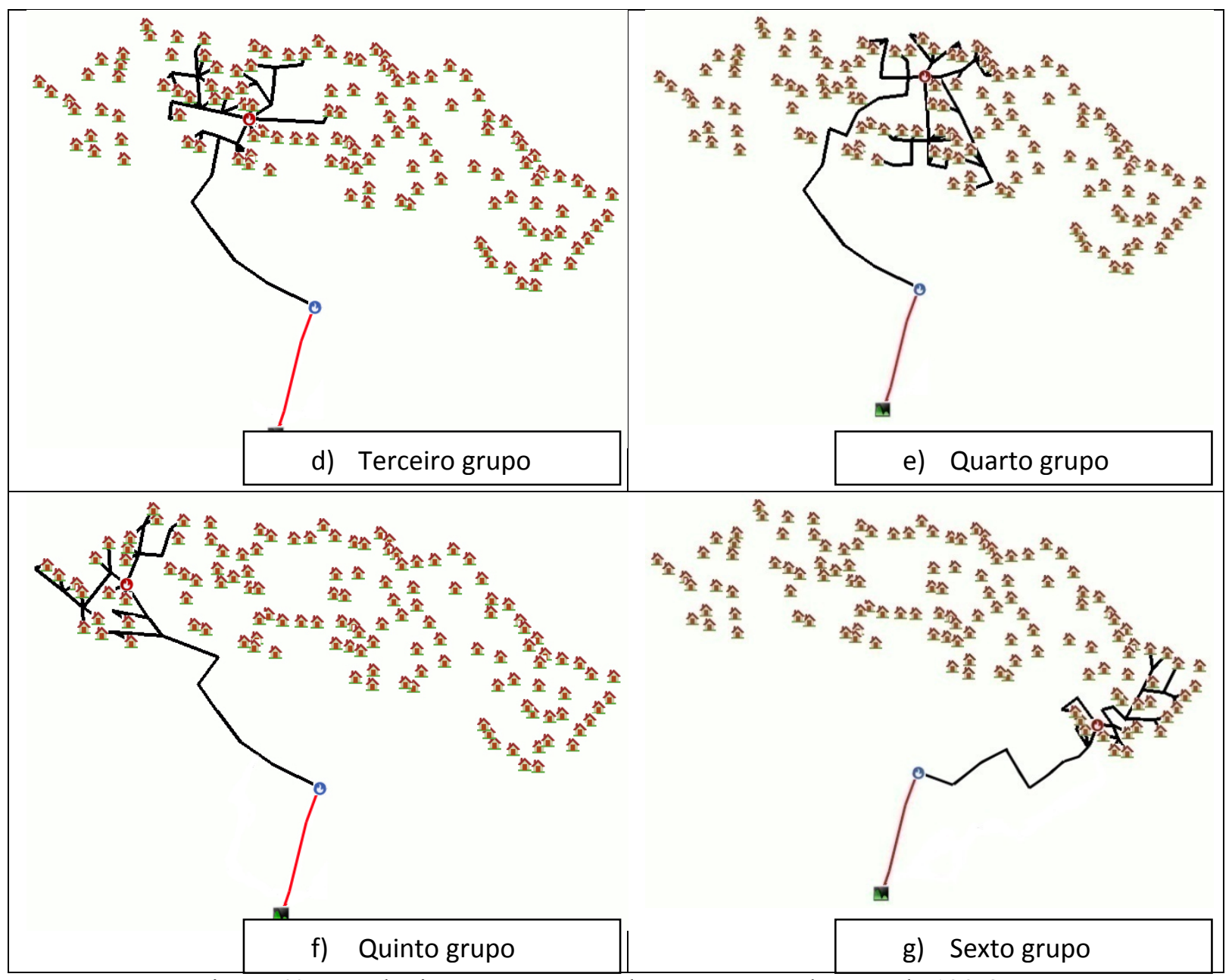

Figura 40. Topologia em árvore gerada para o segundo teste de 128 ONUs.

Na Figura 40, a linha vermelha representa o tronco principal, e as linhas em preto a ligação entre o divisor de primeiro nível e do segundo, além das ONUs ligadas a cada grupo. 
EESC - Escola de Engenharia de São Carlos

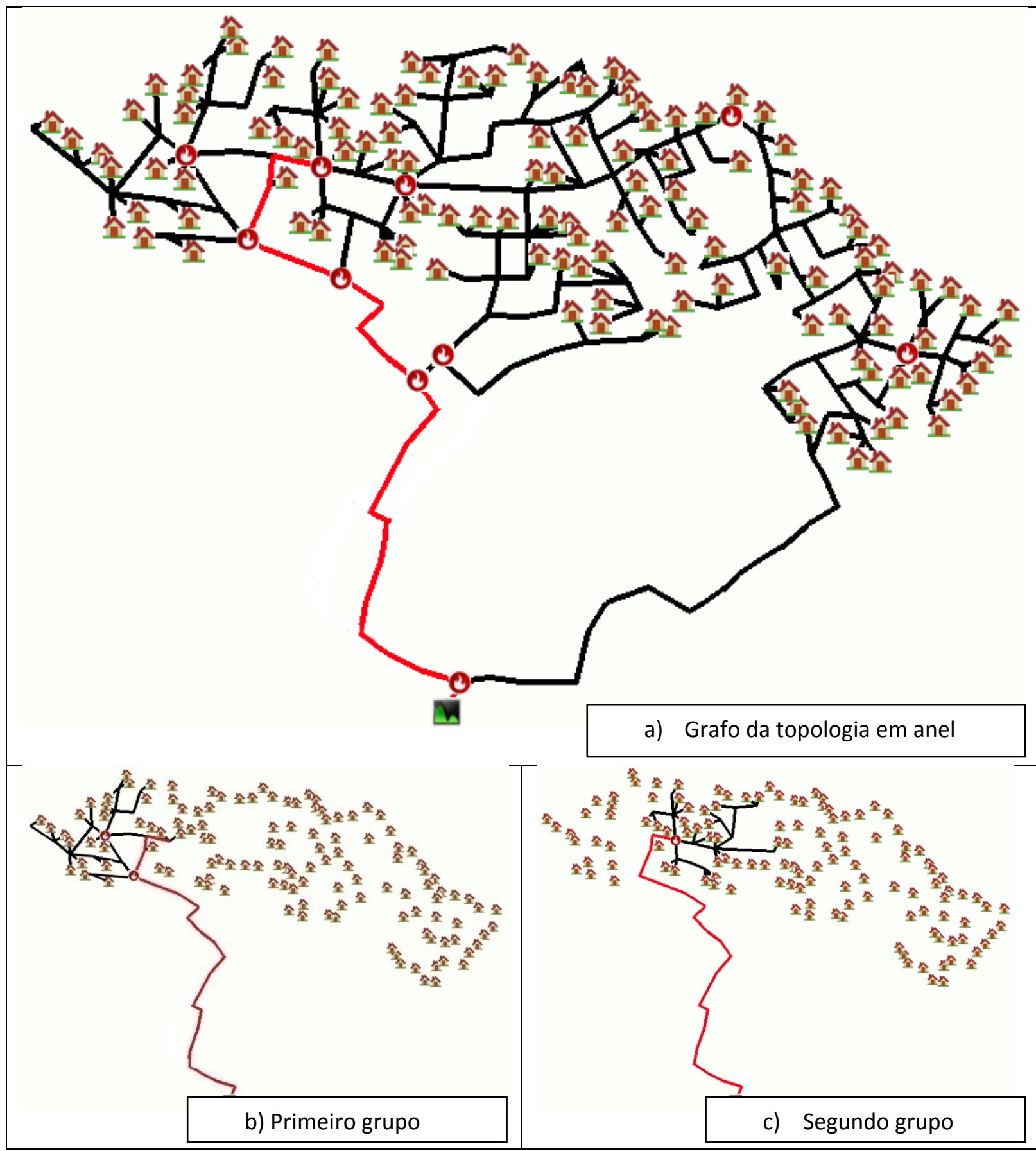




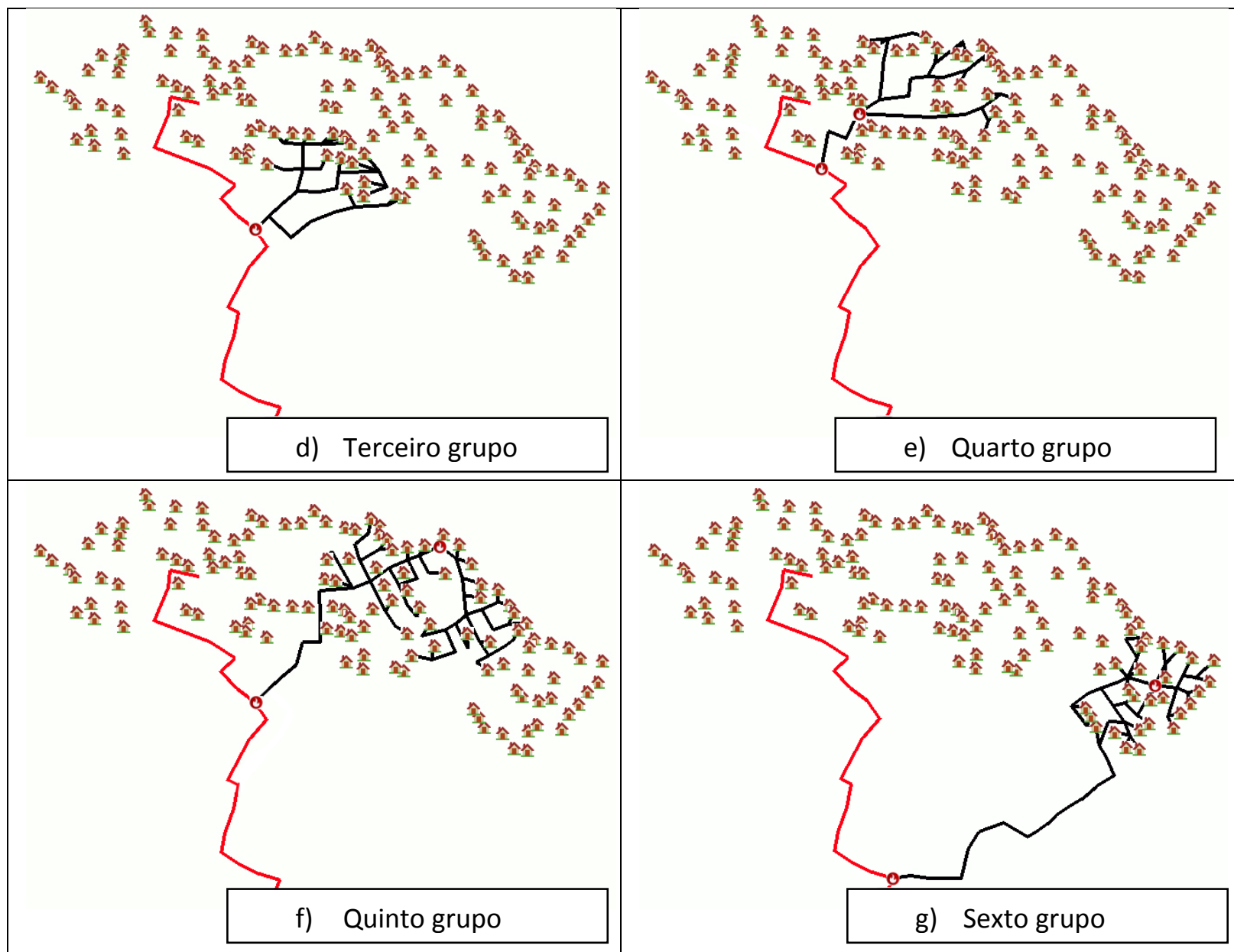

Figura 41. Topologia em anel gerada para o segundo teste de 128 ONUs.

A Figura 41, representa o grafo da topologia em anel, como mostrado no capitulo anterior, a tentativa de otimização para esta topologia, utilizando o menor caminho, faz com que o anel fique similar à topologia em barramento. No entanto, será comparada com as outras duas topologias. 
EESC - Escola de Engenharia de São Carlos

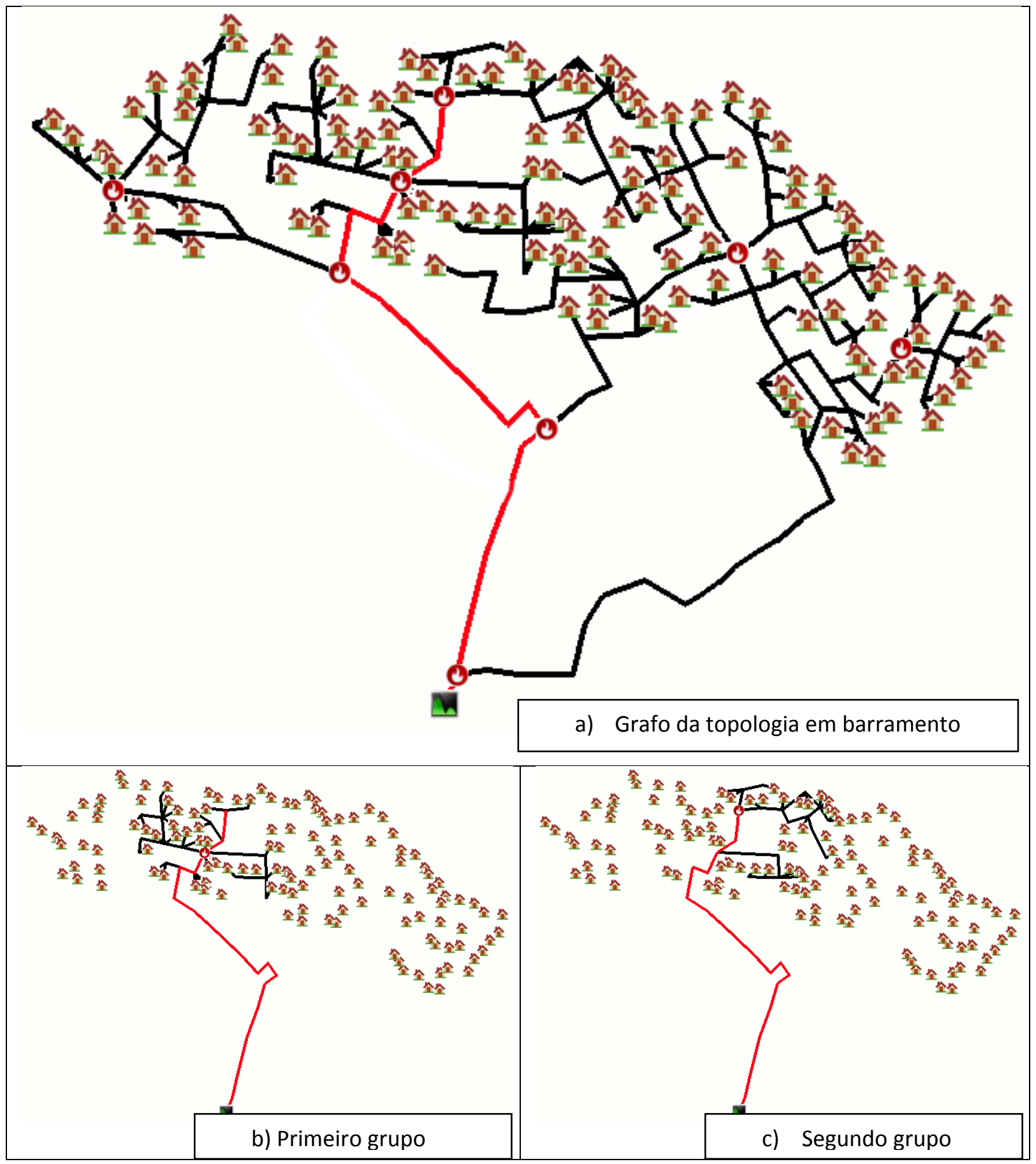




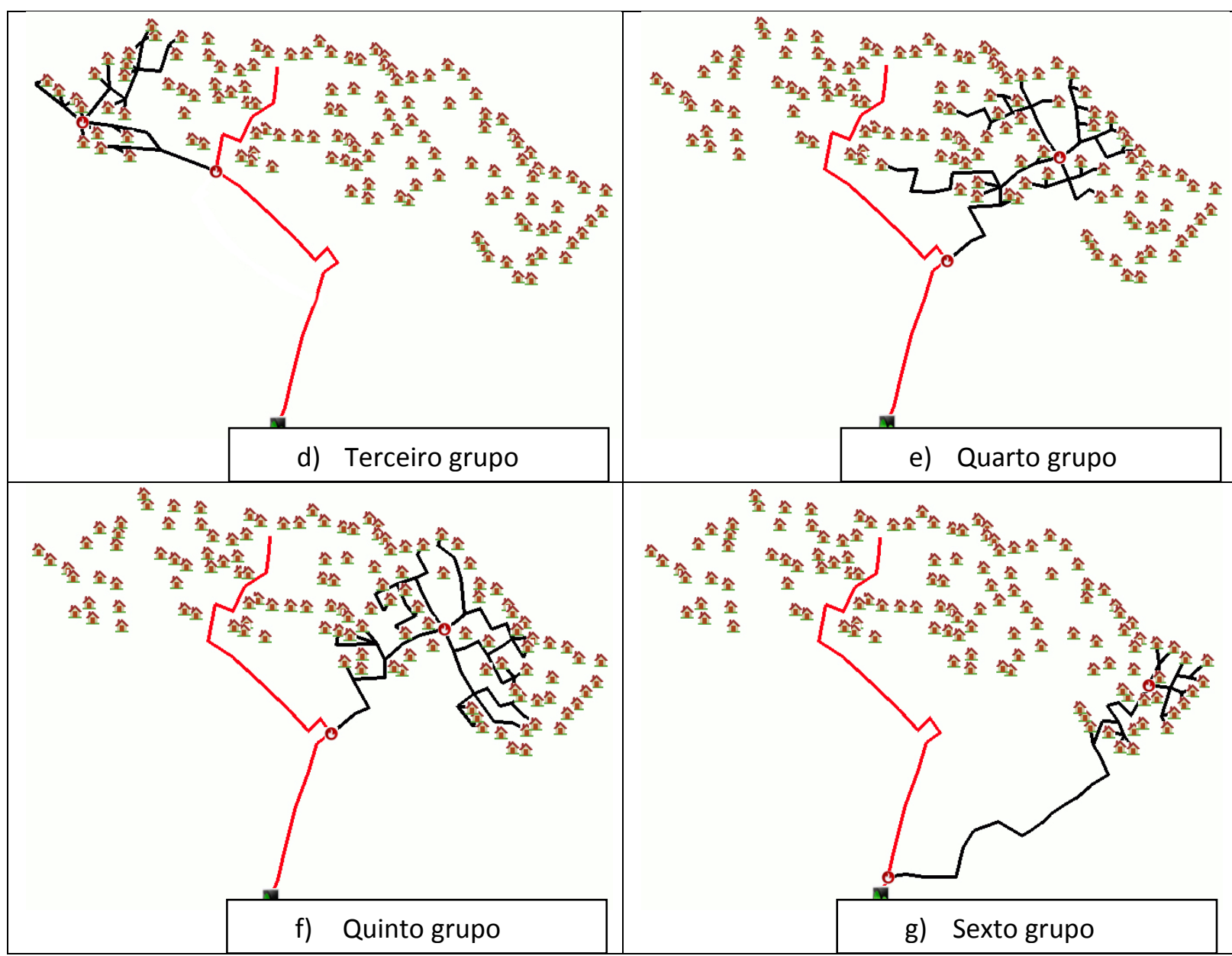

Figura 42. Topologia em barramento gerada para o segundo teste de 128 ONUs.

Como no caso anterior, se ilustra na Figura 42 o grafo correspondente à topologia em barramento: a linha de cor vermelha representa o barramento principal, que irá ligar os grupos de ONUs (grupos de árvores). Nas três topologias geradas, foi utilizado o critério hibrido conforme projetado neste trabalho.

Com os dados das três topologias geramos o gráfico de distâncias para realizar as primeiras comparações, mostradas na Figura 43. Pode-se observar que as curvas são próximas. Embora a topologia em barramento apresente as maiores distâncias esta tendência não ocorreu sempre para outros testes.

Os picos da Figura 43 representam as mudanças de grupo (ONUs agrupadas). As distâncias são ordenadas de forma ascendente pelo algoritmo genético, para eliminar os indivíduos com valor maior retornada pela função aptidão (seleção de indivíduos com menores comprimentos). 


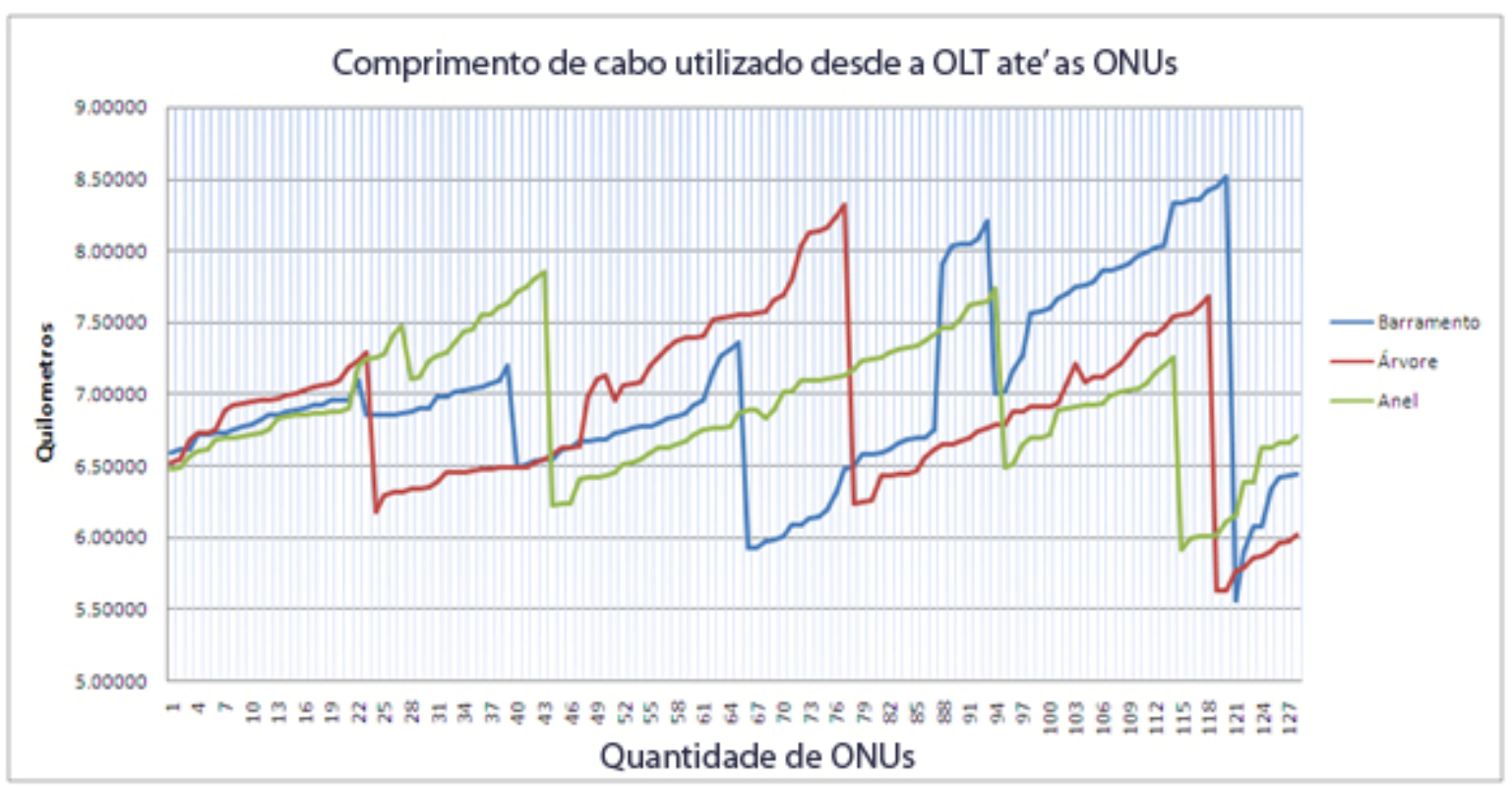

Figura 43. Comprimento de cabo utilizado desde a OLT até as ONUs, para o segundo teste de 128 ONUs.

A diferença entre topologias híbridas proposta neste trabalho, em termos de distância, são pequenas, mas considerando outro critério, vemos que uma topologia apresenta melhor desempenho, como se observa na Figura 44 para os orçamentos de potencia , onde as diferenças são evidentes. 


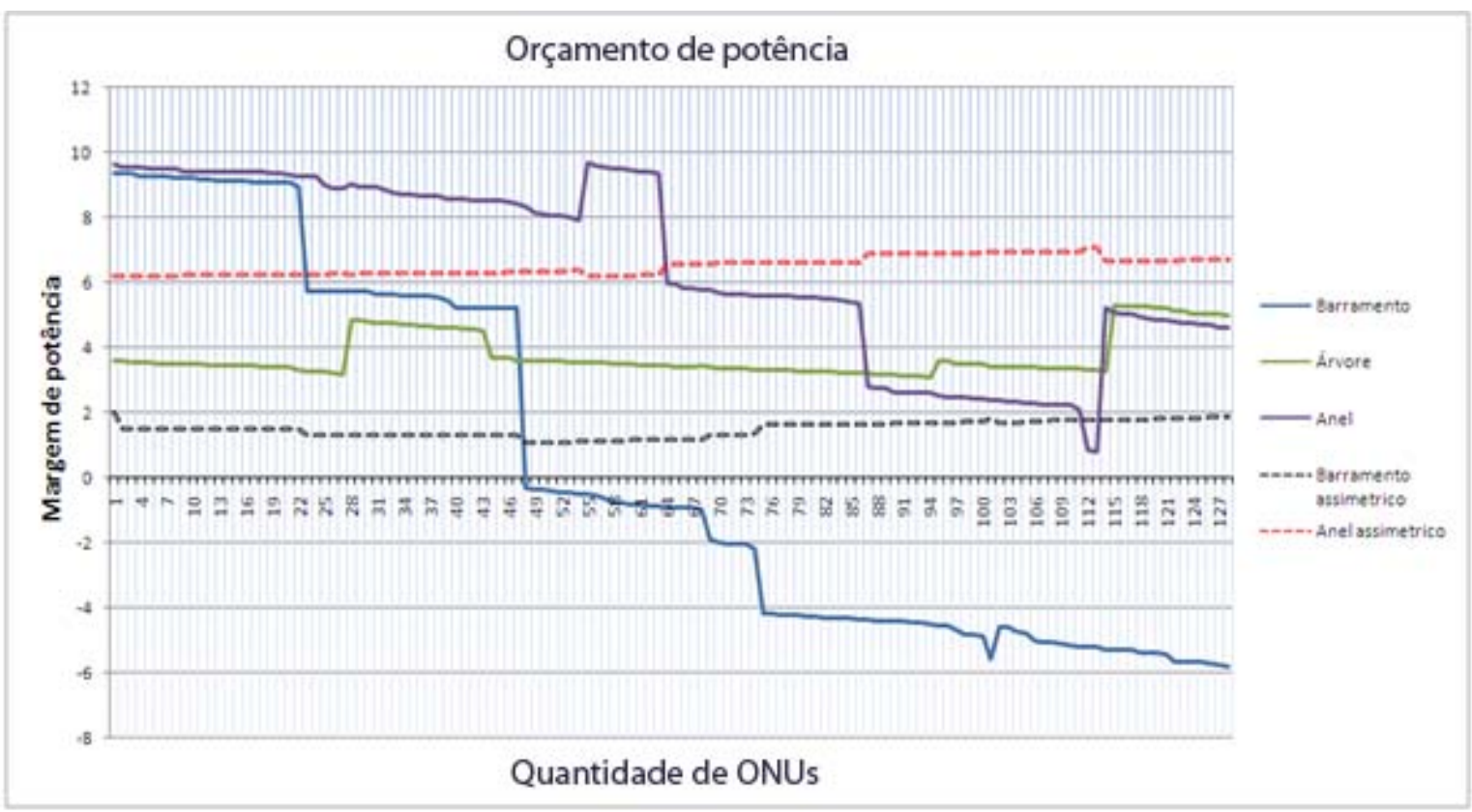

Figura 44. Orçamento de potência para o segundo teste de 128 ONUs.

Como ilustrado anteriormente no primeiro teste, apresentado no capitulo 3 , as topologias que utilizam divisores assimétricos apresentam uniformidade na margem de potência, porém maior sustentação da rede, no caso de crescimento (aumento de ONUs ligadas a qualquer divisor de segundo nível). A topologia em árvore também apresenta estabilidade, embora seja a menor (em termos de comprimento de fibras) das topologias que utilizam divisores assimétricos. No comportamento das topologias em barramento e anel, observa-se uma diminuição da potência à medida em que se aumenta o número de ONUs. A topologia em barramento apresento margem de potência negativa, o que significa que a implantação da rede não é viável devido ao fato de esgotar a potencia antes de atender a todas as ONUs.

A Tabela 20 mostra o número de divisores e o número de portas para cada grupo, o total de portas e o comprimento total de fibra em quilômetros. Na coluna de "divisores" o vetor corresponde à distribuição na ordem encontrada para a topologia, por exemplo na topologia em árvore o primeiro valor corresponde ao divisor de primeiro nível, o próximo valor corresponde ao divisor de segundo nível do primeiro grupo, e assim por diante. No caso para topologia em barramento e anel, o primeiro valor corresponde ao divisor do primeiro nível (2 portas), o segundo valor ao divisor de segundo nível do primeiro grupo, e o próximo valor volta para o divisor de primeiro nível que deriva a potencia para o segundo grupo, e assim para diante, como é ilustrado na Figura 45: 
Tabela 20. Componentes ópticos utilizados pelo segundo teste.

\begin{tabular}{|l|l|l|l|l|}
\hline Topologia & \multicolumn{1}{|c|}{ Divisores } & \multicolumn{1}{|c|}{$\begin{array}{c}\text { Total } \\
\text { Divisores }\end{array}$} & Total portas & \multicolumn{1}{|c|}{$\begin{array}{c}\text { Total Fibra } \\
\text { utilizada }\end{array}$} \\
\hline Árvore & {$[8,32,16,32,32,32,16]$} & 7 & 168 & $\begin{array}{l}189.03 \\
\text { quilômetros }\end{array}$ \\
\hline Barramento & $\begin{array}{l}{[2,32,2,32,2,32,2,16,2,} \\
32,32]\end{array}$ & 11 & 186 & $\begin{array}{l}168.29 \\
\text { quilômetros }\end{array}$ \\
\hline Anel & $\begin{array}{l}{[2,32,2,32,2,32,2,32,2,} \\
32,2,16]\end{array}$ & 12 & 188 & $\begin{array}{l}172.95 \\
\text { quilômetros }\end{array}$ \\
\hline
\end{tabular}

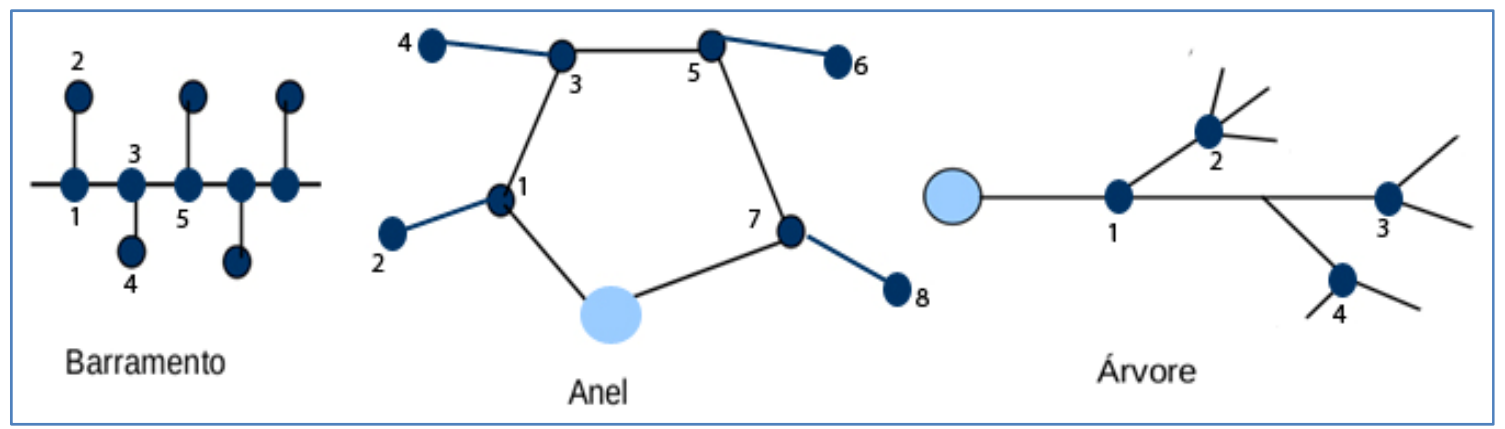

Figura 45. Ordem do vetor da coluna "Divisores" na Tabela 20.

Utilizaremos o total de número de portas em cada topologia e o total de comprimento de fibra para estimar um custo aproximado de implementação. Não consideramos o custo das ONUs e OLT, assumindo ser o mesmo para as três topologias. Nosso interesse é unicamente mostrar uma comparação de custo aproximado para este segundo teste. Na Tabela 21 se mostra o custo da fibra monomodo e o custo da porta para os divisores [22] . O custo será calculado, multiplicando o total de fibra utilizada pelo custo dos cabos utilizados, mais o total de número de portas encontradas vezes o custo unitário por porta.

Tabela 21. Custo de implementação do teste 2, considerando portas nos divisores e total fibra óptica. 


\begin{tabular}{|l|l|}
\hline \multicolumn{1}{|c|}{ Topologia } & \multicolumn{1}{c|}{ Custo } \\
\hline Árvore & 8204,53 dólares \\
\hline Barramento & 8442,87 dólares \\
\hline Anel & 8578.21 dólares \\
\hline
\end{tabular}

O fato de se precisar de menos divisores (menor número total de portas nos divisores) faz da topologia em árvore a mais econômica - estes valores não correspondem a uma proposta de instalação real, porém a comparação é apenas uma aproximação baseada na distribuição de divisores e seleção de grupos de ONUs pelo algoritmo genético.

Neste trabalho descrevemos toda a estrutura para implementação de uma ferramenta de geração de uma distribuição otimizada de divisores ópticos utilizando topologias híbridas com 2 níveis de derivação. A importância desta ferramenta é relativa à análise de redes com grande número de nós, ONUs e divisores. A norma ITU-T G.984 e alguns projetos já implementados, referenciados anteriormente, foram utilizados como os limites e condições de contorno para as implementações e testes dos exemplos. 
EESC - Escola de Engenharia de São Carlos 


\section{Capítulo 6. Conclusão}

Neste trabalho, foram analisadas diversas topologias físicas para redes GPON, otimizando o número e posicionamento dos divisores, os comprimentos de cabos de fibra, os custos de equipamentos e custos de cabeamento. Para isso foram utilizados algoritmos genéticos em grafos representando a rede de distribuição das ONUs e OLTs. A análise inicial feita mostra que a topologia em anel é a melhor para a distribuição de potência nos cenário analisados, em função da distribuição dos divisores. Entretanto, utiliza um número maior de divisores que as demais topologias.

A topologia em árvore é a mais empregada em redes xPON, por apresentar um orçamento de potência melhor usando um número menor de divisores simétricos, resultando em um custo de implementação menor que as outras topologias.

$\mathrm{O}$ uso de divisores de potência assimétricos tem melhorado muito o orçamento de potência em distribuição de potência em topologias em barramento e anel. Com isto, a topologia em anel apresentou os melhores resultados dentre todas as topologias estudadas.

O algoritmo foi validado em um exemplo simplificado, para comparação com soluções obtidas manualmente, e apresentado em um exemplo mais expandido, para ilustração de sua potencialidade como ferramenta de planejamento de redes por parte de operadoras de telecomunicação e/ou provedores de serviços. Para estes, escolher a topologia de rede mais adequada a certa região é importante, antes de sua implementação, para que se consiga uma redução de custos e otimização de QoS.

Interfaces gráficas amigáveis foram desenvolvidas para permitir a utilização do programa como ferramenta efetiva de planejamento e projeto de redes ópticas passivas Gigabit a partir de mapas e diagramas geográficos. 
EESC - Escola de Engenharia de São Carlos 


\section{Referências}

[1] ITU-T G.984.1, Gigabit-capable Passive Optical Networks (GPON): General characteristics, 2003

[2] C. -H. Lee, W. V. Sorin, "Fiber to the Home Using a PON Infrastructure", Journal of Lightwave Technology, V. 24, N. 12, pp. $4568-4583,2006$.

[3] IEEE 802.3ah EPON Framework

[4] Carmen Orencia Carrasco Arbieto, Dr Amilcar Careli Cesar, Alocação Dinamica de largura de banda em redes EPON. Dissertação de Mestrado, São Carlos 2007, Universidade de São Paulo.

[5] M.R. X. Barros, S.M. Rossi, A. E. Reggiani, C.A. Hortencio, J.G. D. Aguiar, D.C. Dini, P.C.L. Morais, M.L.C. Braga, M.R. Salvador, R. Bernardo, R.F. Silva, M.P. Mokarzel, R.A. Moreira, V. Corso, “Avaliação de Topologia para Redes GPON com Distribuição Assimétrica”, CPqD Cadernos de Tecnologia, V. 3, N. 2, artigo 5, 2007

[6] M. S. Nunes, "Redes de Acesso - Parte e - Redes de Acesso em Fibra Óptica”, Departamento de Engenharia Eletrotécnica e de Computadores, IST (Instituto Superior Técnico, Universidade Técnica de Lisboa ), Março 2005

[7] Marcos Portnoi, Priscilla Santos Moraes . Ethernet na primeira milha (ieee 802.3ah): estudo da topologia ponto a multiponto . Universidade Salvador - UNIFACS Núcleo de pesquisa interdepartamental em redes de computadores (NUPERC), 2006

[8] ITU-T G.984.2 Gigabit-capable Passive Optical Networks (GPON): Physical Media Dependent (PMD) layer specification, 2003.

[9] B. Perkins, "Reducing the Amount of Fiber in Fiber-to-the-Home Networks", Bechtel Telecommunications Technical Journal, V. 4, N. 1, pp. 1-8, 2006

[10] G. Kramer. Ethernet Passive Optical Networks, McGraw Hill, 2005

[11] ITU-T G.984.4 Gigabit-capable Passive Optical Networks (GPON): ONT management and control interface specification, 2004. 
[12] J. O. Pires. Lecture Notes, Departamento de Engenharia Electrotécnica e de Computadores Instituto Superior Técnico, Universidade Técnica de Lisboa, 2006.

[13] C. F. Lam. Passive Optical Networks: Principe and Practice, Academic Press, 2007.

[14] Mark Abrams, Philippe C. Becker, Y. Fujimoto, Vincent O'Byrne, e David Piehler, "FTTP Deployments in the United States and Japan-Equipment Choices and Service Provider Imperatives," J. Lightwave Technol. Vol. 23, n.1 pp. 236, 2005.

[15] Ericsson. "Ericsson to demonstrate world's first 10Gbps GPON for IPTV at NXTcomm08 in Las Vegas", http://www.ericsson.com/ericsson/press/releases/20080616-1228432.shtml (data de acesso, Junho de 2009).

[16] G. Keiser. Optical Fiber Communications. McGraw Hill, 3rd Edition, 2000.

[17] A. Webb, B. Turton, J. Brown. "A Genetic Algorithm for Designing Networks with Desirable Topological Properties", Evolutionary Image Analysis, Signal Processing and Telecommunications, Lecture Notes in Computer Science, Springer Berlin / Heidelberg, 1999

[18] B. Perkins. "Optimal Splitter Placement in PONs", Bechtel Telecommunications Technical Journal, V. 2, N. 2, pp. 49-52, 2004.

[19] C. Gazen and C. Ersoy. "Genetic algorithms for designing multihop lightwave network topologies”, Artificial Intelligence in Engineering, V. 13, N. 3, Pages 211-, 1999.

[20] C-H. Yeh and S. Chi. "Self-Healing Ring-Based Time-Sharing Passive Optical Networks", IEEE Photonics Technology Letters, V. 19, N. 15, pp. 1139-1141, 2007.

[21] J.H. Holland. "Adaptation in Natural and Artificial Systems: An Introductory Analysis with Applications to Biology, Control, and Artificial Intelligence”. Ann Arbor, MI: University of Michigan Press, 1975.

[22] FUJITSU NETWORK COMMUNICATIONS INC. Business Class Services over a GPON Network us.fujitsu.com/telecom, (data de acesso Junho, 2009) 